Key Words: Distribution coefficient, Cerium, Cesium, Europium, Nickel, Potassium, Rhenium, Strontium, Thorium, Zirconium, Cellulose degradation products, Organic matter, Performance Assessment

Retention: Permanent

\title{
INFLUENCE OF DISSOLVED ORGANIC CARBON AND pH ON CONTAMINANT SORPTION TO SEDIMENT
}

\author{
Daniel I. Kaplan and Steven M. Serkiz
}

September 30, 2004

Westinghouse Savannah River Company

Savannah River Site

Aiken, SC 29808

Prepared for the U.S. Department of Energy Under

Contract Number DE-AC09-96SR18500

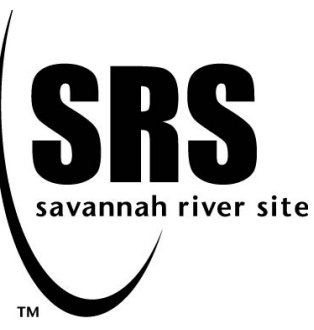


This document was prepared in conjunction with work accomplished under Contract No. DE-AC09-96SR18500 with the U. S. Department of Energy.

\section{DISCLAIMER}

This report was prepared as an account of work sponsored by an agency of the United States Government. Neither the United States Government nor any agency thereof, nor any of their employees, makes any warranty, express or implied, or assumes any legal liability or responsibility for the accuracy, completeness, or usefulness of any information, apparatus, product or process disclosed, or represents that its use would not infringe privately owned rights. Reference herein to any specific commercial product, process or service by trade name, trademark, manufacturer, or otherwise does not necessarily constitute or imply its endorsement, recommendation, or favoring by the United States Government or any agency thereof. The views and opinions of authors expressed herein do not necessarily state or reflect those of the United States Government or any agency thereof.

This report has been reproduced directly from the best available copy.

Available for sale to the public, in paper, from: U.S. Department of Commerce, National Technical Information Service, 5285 Port Royal Road, Springfield, VA 22161, phone: (800) 553-6847, fax: (703) 605-6900

email: orders@ntis.fedworld.gov

online ordering: http://www.ntis.gov/help/index.asp

Available electronically at http://www.osti.gov/bridge

Available for a processing fee to U.S. Department of Energy and its contractors, in paper, from: U.S. Department of Energy, Office of Scientific and Technical Information, P.O. Box 62, Oak Ridge, TN 37831-0062,

phone: (865)576-8401,

fax: (865)576-5728

email: $\underline{\text { reports@ adonis.osti.gov }}$ 
This page was intentionally left blank 
This page was purposely left blank. 


\section{TABLE OF CONTENTS}

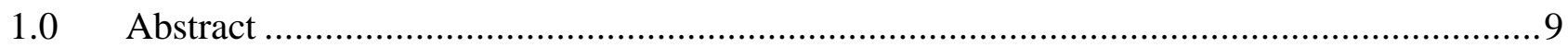

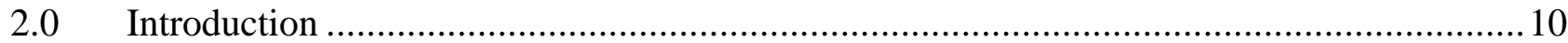

2.1 CDP and Their Potential Impact on Radionuclide Sorption ......................................... 10

2.2 Previous Research Related to the Impact of CDP on Radionuclide Sorption to SRS

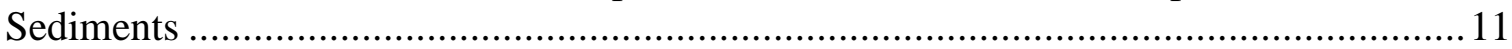

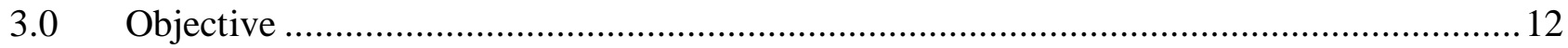

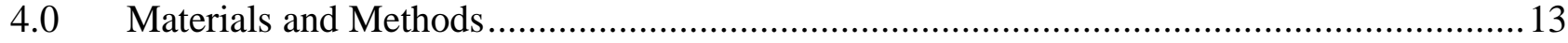

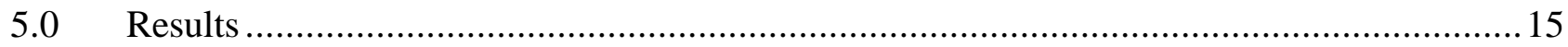

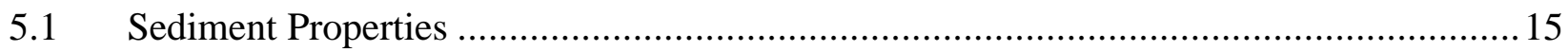

5.2 Organic Matter Interactions with the Sediments ........................................................... 17

5.3 Contaminant Sorption in the Presence of Varying $\mathrm{pH}$ and DOC Concentrations .............21

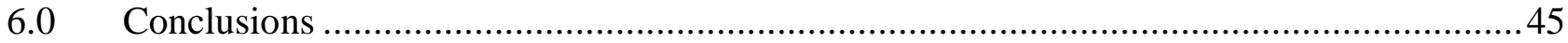

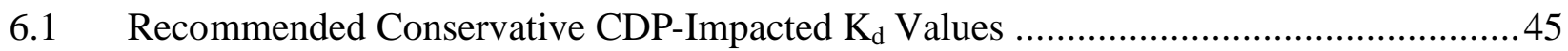

6.2 Utilization of Recommended CDP-Impacted $\mathrm{K}_{\mathrm{d}}$ Values in Future PA Modeling .............46

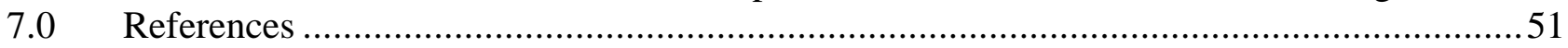

8.0 Appendix A: Detailed Description of Materials and Methods..........................................53

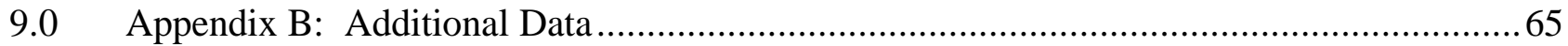




\section{LIST OF TABLES}

Table 1. Analogues of radionuclides of interest to the Low-Level Waste Performance Assessment.

Table 2. Sediment characterization.

Table 3. Dissolved organic carbon concentrations in the no-sediment control samples (all treatments were duplicated).

Table 4. Dissolved and sorbed organic carbon concentrations at end of experiment.

Table 5. Thermodynamic calculations of the saturation index of the no-sediment control solutions.

Table 6. Ni $\mathrm{K}_{\mathrm{d}}$ values $(\mathrm{mL} / \mathrm{g})$

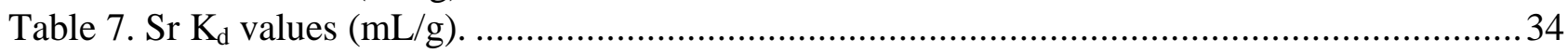

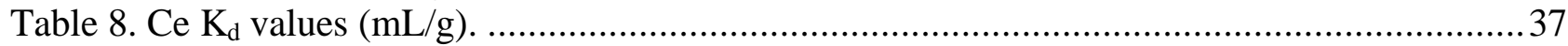

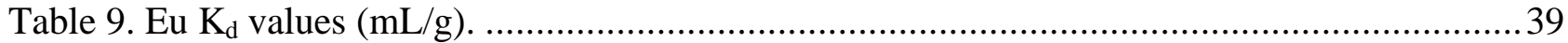

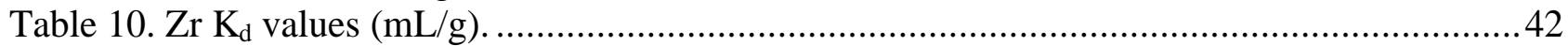

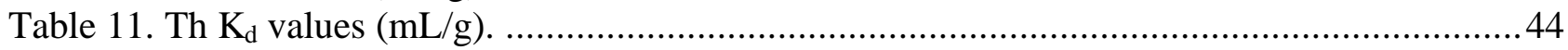

Table 12. CDP Correction Factors based on $\mathrm{K}_{\mathrm{d}}$ values measured in the $\mathrm{pH} 3.9$ or 5.3 sandy sediment

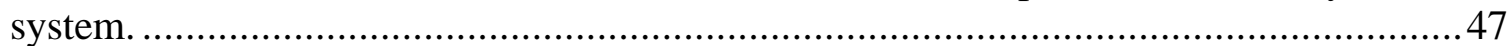

Table 13. Present soil Kd values for radionuclides of interest to the LLW-PA. .............................48

Table 14. CDP Correction Factors assuming no enhanced sorption due to presence of CDP and CDP-Corrected Kd values.

Table 15. Comparison of Recommended CDP-Corrected $\mathrm{K}_{\mathrm{d}}$ Values from this study and those proposed by Serkiz (2000); larger $K_{d}$ values based on comparison of both sets of data are shaded.......

Table A 1. Point of Zero Salt Effect for Sandy Sediment Raw Data............................................66

Table A 2. Point-of-Zero-Salt Effect of Clayey Sediment (Lysimeter Sediment)...........................67

Table A 3. ICP-MS results from solutions at the end of the equilibration period. ...........................69

Table A 4. Titration curve data for the sandy and red-clay sediments..........................................72 


\section{LIST OF FIGURES}

Figure 1. Point-of-Zero-Salt Effect (approximately the $\mathrm{pH}$ at which sediment has a net charge of zero) of the sandy sediment (the ZPSE is at $\mathrm{pH} 5.5$ to 6.5).....

Figure 2. Point-of-Zero-Salt Effect for the Red Clay Sediment (PZSE $=$ pH 5.6 to 6.2)..................16

Figure 3. Titration of the sand and clay sediments..................................................................... 17

Figure 4. Sorbed organic carbon vs. dissolved organic carbon added in the clayey sediment (top) and sandy sediment (bottom).................................................................................2 20

Figure 5. Final pH vs. targeted SR-NOM concentration of no-sediment control samples (2 observations for each mean and standard deviation).

Figure 6. Aqueous $\mathrm{Ni}, \mathrm{Sr}$, and $\mathrm{Cs}$ versus targeted $\mathrm{SR}-\mathrm{NOM}$ concentrations in the no-sediment

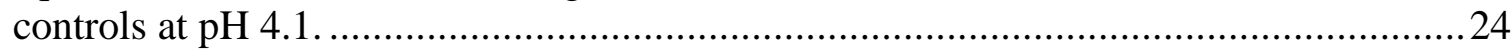

Figure 7. Aqueous $\mathrm{Ni}, \mathrm{Sr}$, and $\mathrm{Cs}$ versus targeted SR-NOM concentrations in no-sediment controls at $\mathrm{pH} 7.4$...

Figure 8. Aqueous $\mathrm{Ce}, \mathrm{Eu}, \mathrm{Th}$, and $\mathrm{Zr}$ versus targeted SR-NOM concentrations in no-sediment controls at $\mathrm{pH}$ 4.1.

Figure 9. Aqueous $\mathrm{Ce}, \mathrm{Eu}, \mathrm{Th}$, and $\mathrm{Zr}$ versus targeted $\mathrm{SR}-\mathrm{NOM}$ concentrations in the no-sediment

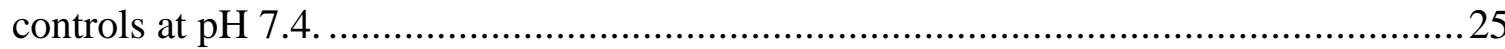

Figure 10. Cs $\mathrm{K}_{\mathrm{d}}$ values as a function of $\mathrm{pH}$ and SR-NOM concentrations in clayey (top) and sandy

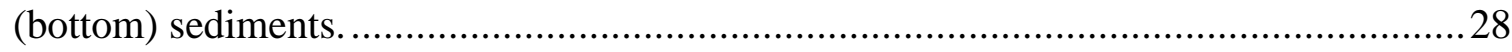

Figure 11. Ni $\mathrm{K}_{\mathrm{d}}$ values as a function of $\mathrm{pH}$ and SR-NOM concentrations in clayey (top) and sandy (bottom) sediments. 30

Figure 12. $\mathrm{Sr} \mathrm{K}_{\mathrm{d}}$ values as a function of $\mathrm{pH}$ and SR-NOM concentrations in clayey (top) and sandy (bottom) sediments.

Figure 13. Ce $\mathrm{K}_{\mathrm{d}}$ values as a function of $\mathrm{pH}$ and SR-NOM concentrations in clayey (top) and sandy (bottom) sediments (all $\mathrm{K}_{\mathrm{d}}$ values $>25,000 \mathrm{~mL} / \mathrm{g}$ are greater-than values).

Figure 14. Eu $\mathrm{K}_{\mathrm{d}}$ values as a function of $\mathrm{pH}$ and SR-NOM concentrations in clayey (top) and sandy (bottom) sediments (all $\mathrm{K}_{\mathrm{d}}$ values $>20,000 \mathrm{~mL} / \mathrm{g}$ are greater-than values).

Figure 15. $\mathrm{Zr} \mathrm{K} \mathrm{K}_{\mathrm{d}}$ values as a function of $\mathrm{pH}$ and SR-NOM concentrations in clayey (top) and sandy (bottom) sediments.

Figure 16. Th $\mathrm{K}_{\mathrm{d}}$ values as a function of $\mathrm{pH}$ and SR-NOM concentrations in clayey (top) and sandy (bottom) sediments. 


\section{ACRONYMS}

$\begin{aligned} \text { CDP } & \text { Cellulose Degradation Products } \\ \text { DOC } & \text { Dissolved Organic Carbon } \\ \text { ICP-MS } & \text { Inductively Coupled Plasma - Mass Spectrometry } \\ \text { ICP-AES } & \text { Inductively Coupled Plasma - Atomic Emission Spectrometry } \\ \text { K }_{\mathrm{d}} & \text { Distribution Coefficient } \\ \text { LLW } & \text { Low Level Waste } \\ \text { NOM } & \text { Natural Organic Matter } \\ \text { PA } & \text { Performance Assessment } \\ \text { SRS } & \text { Savannah River Site } \\ \text { SR-NOM } & \text { Suwannee River Natural Organic Matter } \\ \text { XRD } & \text { X-ray Diffraction }\end{aligned}$


WSRC-RP-2004-00593

\subsection{ABSTRACT}

Low-Level Waste buried on the SRS contains cellulosic materials, including wood, paper, and cardboard. Once buried, these materials are expected to degrade to form cellulose degradation products (CDP). Such materials are expected to influence radionuclide speciation in such a way that the radionuclides will sorb less to SRS subsurface sediments and therefore would migrate more rapidly from the disposal site. The objective of this study was to quantify through laboratory work the influence of $\mathrm{CDP}$ and $\mathrm{pH}$ on radionuclide sorption to SRS subsurface sediments.

The intent of this work was to create a $\mathrm{K}_{\mathrm{d}}$ look-up table as a function of radionuclide, $\mathrm{pH}$, and CDP concentration that could be used in future performance assessment calculations. Previous $\mathrm{CDP}$-impacted $\mathrm{K}_{\mathrm{d}}$ values were generated using two chemical analogues, $\mathrm{UO}_{2}{ }^{2+}$ and $\mathrm{Eu}^{3+}$. This study collected data from a wider range of analogues to validate and/or refine this approach. An incomplete-randomized-block-statistical design was used in a laboratory sorption study involving 2 soil types (sandy and clay textured), 5 dissolved organic carbon concentrations (a measure of CDP), and $3 \mathrm{pH}$ levels. Non-radioactive solutes were used as chemical analogues to the radionuclides of interest to the Low-Level Waste Performance Assessment: monovalent cations $\left(\mathrm{K}^{+}\right.$and $\left.\mathrm{Cs}^{+}\right)$, divalent cations $\left(\mathrm{Ni}^{2+}\right.$ and $\left.\mathrm{Sr}^{2+}\right)$, trivalent cations $\left(\mathrm{Ce}^{3+}\right.$ and $\left.\mathrm{Eu}^{3+}\right)$, tetravalent cations $\left(\mathrm{Th}^{4+}\right.$ and $\mathrm{Zr}^{4+}$ ), and an anion $\left(\mathrm{ReO}_{4}^{-}\right)$. Analogues were matched to $\sim 30$ radionuclides based on similarities in periodicity and chemical properties. All CDP-impacted $K_{d}$ values generated from this study were equal to or greater than those used in previous performance assessments. These larger $\mathrm{K}_{\mathrm{d}}$ values may result in a greater Waste Acceptance Criteria (WAC), which in turn may permit greater amounts of Low-Level Waste to be safely disposed on site, saving the site the expense of shipping the waste off-site for disposal. 
WSRC-RP-2004-00593

\subsection{INTRODUCTION}

\subsection{CDP and Their Potential Impact on Radionuclide Sorption}

Cellulosic materials (e.g., wood, paper, and cardboard products) readily degrade in the environment to form cellulose degradation products (CDP) in both the solid and dissolved (i.e., dissolved organic carbon; DOC) phases. Natural organic matter can greatly influence the speciation (i.e., chemical form) and mobility of nonradioactive elements (Perdue and Gjessing 1990, Thurman 1985, Stumm and Morgan 1981) and radioactive elements (Choppin 1988, Allard et al. 1989, Fairhurst et al. 1995; and Ledin et al. 1994). Co-disposal of radionuclides with cellulosic materials is, therefore, expected to influence nuclide fate and transport in the subsurface. The disposal and degradation of wood products in the E-Area slit trenches at the SRS are a source of organic matter that is expected to influence radionuclide fate and transport.

Insight into the fate of cellulosic material in SRS burial trenches can be drawn from the extensively studied behavior of natural organic matter in forested ecosystems. In both of these environments cellulosic materials are expected to decay to form a complex mixture of natural organic acids (e.g., humic and fulvic acids). These organic acids make up the majority of naturally occurring dissolved organic matter (Thurman, 1985). Even though organic matter will ultimately degrade to $\mathrm{CO}_{2}$ or methane, steady state DOC concentrations in soil porewater exists as a result of plant (and to a smaller extent animal) detritus decomposition. DOC concentrations in wetlands are typically between 17 and $33 \mathrm{mg} / \mathrm{L} \mathrm{C}$ (Thurman 1985). Subsurface groundwater typically contains about $0.7 \mathrm{mg} / \mathrm{L} \mathrm{C}$ (Thurman 1985; Figure 1.1).

Major processes influencing the impact of natural organic matter on radionuclide/metal geochemistry are: 1) natural organic matter partitions to the sediment, thereby increasing the sorption capacity of the sediment, (2) natural organic matter decreases the system $\mathrm{pH}$, generally decreasing cation sorption and increasing anion sorption, and (3) DOC complexes the radionuclide, thereby changing (generally decreasing) the tendency of the radionuclide to sorb to the sediment. These competing reactions can result in complex radionuclide sorption behavior. For example, Serkiz et al. (1998) reported that under low $\mathrm{pH}$ conditions, $\mathrm{UO}_{2}{ }^{2+}$ sorption to kaolinite in the presence of DOC increased when compared to when no DOC was present. They attributed this to the DOC sorbing to the kaolinite and increasing the solid phase sorption capacity. At higher $\mathrm{pH}$ levels, where little $\mathrm{C}$ sorbed to the sediment, less $\mathrm{UO}_{2}{ }^{2+}$ sorbed to the sediment in the presence of DOC than in its absence. They attributed this sorption behavior to the weaker tendency of DOC to sorb to kaolinite under higher $\mathrm{pH}$ conditions. The weaker tendency for DOC sorption resulted in greater DOC in solution to complex the $\mathrm{UO}_{2}{ }^{2+}$, thereby reducing the tendency for it to sorb.

Serkiz (2000) generated recommended $K_{d}$ values for use in the Low-Level Waste Performance Assessment (PA) for a wide range of elements based on $\mathrm{Cs}$, $\mathrm{Eu}$, and $\mathrm{U}$ laboratory sorption test results. These provisional values were conservative because of the underlying assumptions. Briefly, the $\mathrm{K}_{\mathrm{d}}$ values were assigned to a look-up table as a function of DOC or pH levels. $\mathrm{K}_{\mathrm{d}}$ values of multivalent radionuclides were based on trends observed from CDP laboratory sorption 
experiments with $\mathrm{U}$ and Eu. He assumed that monovalent cationic radionuclides were influenced indirectly by CDPs' influence on $\mathrm{pH}$, not by direct organic matter - cation interactions, i.e., the greater the CDP concentration, the lower the $\mathrm{pH}$ of the system. This assumption is based on the well established observation that monovalent cations form weak complexes to DOC. Specifically, monovalent cation $\mathrm{K}_{\mathrm{d}}$ values were assigned based on trends observed with $\mathrm{Cs}^{+}$sorption to SRS sediments as a function of $\mathrm{pH}$ (Johnson 1995). This indirect approach was adopted in the absence of more direct data.

\subsection{Previous Research Related to the Impact of CDP on Radionuclide Sorption to SRS Sediments}

Serkiz and Myers (1996) modeled radionuclide sorption in the presence of CDP using available literature and limited site-specific data. This initial modeling used published stability constants for reactions between low molecular weight acids (i.e., citric acid and EDTA) and radionuclides to approximate behavior of CDP. Notable differences in the allowable radionuclide inventory of the E-Area slit trench were determined when the presence of cellulose degradation products (CDP) was accounted for in this conceptual model.

A series of laboratory studies were initiated in April 1998 to validate and/or update the modeling assumptions and results utilizing uranium (VI) and europium (III) as representative of divalent and trivalent radionuclides in the disposal environment (Serkiz et al. 1998). Phase I of this work employed a surrogate organic matter collected from the Suwannee River (SR-NOM) to represent the influence of CDP on nuclide sorption. This natural organic matter has been extensively characterized and is believed to resemble more closely the products from the degradation of cellulosic material than any single organic compound. These modeling studies clearly demonstrated that both $\mathrm{pH}$ and organic matter have a significant influence on $\mathrm{Eu}^{3+}$ and $\mathrm{UO}_{2}{ }^{2+}$ mobility in SRS shallow waste burial environments.

Phase II of this work, investigated the major processes that influence nuclide transport in the presence of CDP (Serkiz et al. 1999). This work investigated: 1) the differences between laboratory-generated CDP and SR-NOM (used as a surrogate for CDP), especially as it related to Eu and U sorption 2) CDP sorption to SRS sediments, and, 3) radionuclide partitioning to sediments in the presence of CDP under a range of $\mathrm{pH}$ conditions. This work demonstrated that natural organic matter (SR-NOM) from the Suwannee River is an adequate surrogate for the radionuclide complexation chemistry of the mixture of organic compounds that comprise CDP under the conditions expected in SRS trenches. Furthermore, the concentration of CDP released from simulated cellulosic waste (paper, cardboard and wood) varied with time, decreasing as a function of increased leaching time. The amount of CDP sorbed to the sediments varied as a function of initial OM concentration, but was relatively independent of $\mathrm{pH}$. Conversely, $\mathrm{pH}$ greatly influenced $\mathrm{Eu}$ sorption to SRS sediments, irrespective of whether CDP was presence or absent.

In previous modeling for the performance assessment (McDowell et al. 2000), it was assumed that cellulose materials degrade to constantly produce dissolved organic carbon at $30 \mathrm{mg} / \mathrm{L} \mathrm{C}$. It is clear from this laboratory work that the production of CDP is a dynamic process, producing under 
the conditions of these experiments concentration $>1,000 \mathrm{mg} / \mathrm{L} \mathrm{C}$. Previous modeling also assumed a single $\mathrm{pH}$ value for the natural background to estimate contaminant sorption.

\subsection{OBJECTIVE}

The objective of this study was to measure sorption of $\mathrm{Ce}, \mathrm{Cs}, \mathrm{Eu}, \mathrm{Ni}, \mathrm{K} \mathrm{Rh}, \mathrm{Sr}$, Th, and $\mathrm{Zr}$ as a function of $\mathrm{pH}$ and DOC to E-Area sediments. The intent of this research was to create a geochemical model that can be used in performance assessment calculations. Because it would be prohibitively expensive to conduct these tests using all the radionuclides included in the performance assessment (>25 elements), non-radioactive elements that are easily detectable by inductively coupled plasma - mass spectrometry (ICP-MS) were selected as chemical analogues. The valances of the analogues used in this study are:

- two monovalent cations, $\mathrm{Cs}^{+}$and $\mathrm{K}^{+}$;

- two divalent cations, $\mathrm{Ni}^{2+}$ (transition metal) and $\mathrm{Sr}$ (alkaline earth);

- two trivalent cations, $\mathrm{Ce}^{3+}$ and $\mathrm{Eu}^{3+}$;

- two tetravalent cations, $\mathrm{Th}^{4+}$ (actinide) and $\mathrm{Zr}^{4+}$ (transition metal); and

- one anion, $\mathrm{RhO}_{4}{ }^{-}$(an analogue specifically for $\mathrm{TcO}_{4}{ }^{-}$).

Assignment of analogues to the radionuclides of interest to the Low-Level Waste Performance Assessment was based on similarities in periodicity (its location in the periodic chart) and chemical properties of the radionuclides (Table 1). 
WSRC-RP-2004-00593

Table 1. Analogues of radionuclides of interest to the Low-Level Waste Performance Assessment.

\begin{tabular}{ccc}
\hline Radionuclide & Assumed Valance & Analogue \\
\hline $\mathrm{Ac}$ & +3 & $\mathrm{Ce} \mathrm{\&} \mathrm{Eu}$ \\
$\mathrm{Am}$ & +3 & $\mathrm{Ce} \& \mathrm{Eu}$ \\
$\mathrm{C}^{(\mathrm{a})}$ & -2 & $\mathrm{None}$ \\
$\mathrm{Cf}$ & +3 & $\mathrm{Ce} \& \mathrm{Eu}$ \\
$\mathrm{Cm}$ & +3 & $\mathrm{Ce} \& \mathrm{Eu}$ \\
$\mathrm{Cs}$ & +1 & $\mathrm{Cs}$ \\
$\mathrm{H}^{(\mathrm{a})}$ & +1 & $\mathrm{None}$ \\
$\mathrm{I}$ & -1 & $\mathrm{Re}$ \\
$\mathrm{Nb}$ & +3 & $\mathrm{Ce} \mathrm{\&} \mathrm{Eu}$ \\
$\mathrm{Ni}$ & +2 & $\mathrm{Ni}$ \\
$\mathrm{Np}$ & +1 & $\mathrm{Cs}$ \\
$\mathrm{Pa}$ & +4 & $\mathrm{Th}$ \\
$\mathrm{Pb}$ & +2 & $\mathrm{Ni}$ \\
$\mathrm{Pd}$ & +2 & $\mathrm{Ni}$ \\
$\mathrm{Po}$ & +2 & $\mathrm{Ni}$ \\
$\mathrm{Pu}$ & +4 & $\mathrm{Th}$ \\
$\mathrm{Ra}$ & +2 & $\mathrm{Sr}$ \\
$\mathrm{Rb}$ & +1 & $\mathrm{Cs}$ \\
$\mathrm{Se}$ & -1 & $\mathrm{Re}$ \\
$\mathrm{Sn}$ & +2 & $\mathrm{Ni}$ \\
$\mathrm{Sr}$ & +2 & $\mathrm{Sr}$ \\
$\mathrm{Tc}$ & -1 & $\mathrm{Re}$ \\
$\mathrm{Th}$ & +4 & $\mathrm{Th}$ \\
$\mathrm{U}$ & +2 & $\mathrm{Sr}$ \\
$\mathrm{Zr}$ & +4 & $\mathrm{Zr}$ \\
\hline
\end{tabular}

(a) No attempt was made to use analogues to simulate carbon or hydrogen (tritium) because their chemistries are quite complicated and difficult to assess through the use of analogues.

\subsection{MATERIALS AND METHODS}

Details of the materials and methods are presented in section 8.0: Appendix A. A brief description of the experiment's materials and methods are described here. The experiment design was an incomplete factorial including two replicates, two sediments (sandy sediment and a clayey sediment from the E-Area subsurface environment), four $\mathrm{pH}$ levels, four DOC levels (Suwannee River Natural Organic Matter (reverse osmosis isolate) (SR-NOM); International Humic Substances Society, St. Paul, MN), and nine elements (Ce, $\mathrm{Cs}, \mathrm{Eu}, \mathrm{Ni}, \mathrm{K}, \mathrm{Rh}, \mathrm{Sr}, \mathrm{Th}$, and $\mathrm{Zr}$ atomic absorption standards; Fisher Scientific, Pittsburgh, PA). Batch contact experiments were conducted in 50-mL centrifuge tubes with 5-g sediment and 50-mL liquid. 
Complexity was added step-by-step to the system under study. Between each step, appropriate measurements were made to characterize the system. Initially, $\mathrm{NaOH}$ and $\mathrm{HCl}$ were added to a sediment $-0.02 \mathrm{M} \mathrm{NaCl}$ system to create the desired $\mathrm{pH}$ range of $\sim 3$ to 9 . After a one-week equilibration period, $\mathrm{pH}$ levels were measured. Then varying concentrations of DOC were added to the $\mathrm{pH}$ adjusted tubes; after a one-week equilibration period, $\mathrm{pH}$ levels were measured. Finally, a concentrated solution containing the tracers was added to the system; after a 2-week equilibration period, $\mathrm{pH}, \mathrm{DOC}$, and aqueous metal concentrations were measured.

A number of control samples were also included. For the $\mathrm{pH}$ adjusted sediment- $0.02 \mathrm{M} \mathrm{NaCl}$ system, no-sediment controls were included to permit calculating the zero-point-of-salt-effect (a measure of the $\mathrm{pH}$ level where the soil surface has a net zero charge). For the Sediment/0.02 M $\mathrm{NaCl} / \mathrm{DOC}$ system, no-sediment controls (samples that were identical to the treatment samples except they did not contain any sediment) were included for all four DOC levels at the two extreme $\mathrm{pH}$ levels. For the Sediment/0.02 M NaCl/DOC/metals system, no-sediment controls were included for all $4 \mathrm{DOC}$ levels at the two extreme $\mathrm{pH}$ levels.

DOC was measured using a standard $\mathrm{C}$ analyzer and metals were analyzed using an inductivelycoupled plasma - mass spectrometer (ICP-MS). The ICP-MS samples were preserved in $0.5 \%$ $\mathrm{HNO}_{3}$. The $\mathrm{pH}$ and DOC samples were not preserved in $0.5 \% \mathrm{HNO}_{3}$. 
WSRC-RP-2004-00593

\subsection{RESULTS}

\subsection{Sediment Properties}

Two sediments were used in this study: a red clayey sediment (Subsurface Red Clayey Burial Ground Sediment) and a sandy sediment (BG1 Sandy Sediment) collected from the E-Area subsurface. These two sediments represent end-members with respect to contaminant sorption properties expected in the E-Area subsurface. The clayey sediment, as the name implies, has a higher concentration of fine particles and greater surface area than the sandy sediment (Table 2). Both sediments had similar $\mathrm{pH}$ values and no detectable organic matter. They also had essentially identical points-of-zero-salt effect of $\mathrm{pH} 5.5$ to 6.5 (Figure 1 and Figure 2). The points-of-zero-salt effect provides an estimate of where the sediment has a net charge of zero, that is, the number of positive and negative surface charges are equal. The clayey sediment had XRD-detectable amounts of hematite and goethite, indicating they were present at concentrations $\bullet 5 \%$. The sandy sediment was yellow, indicative of the presence of goethite; no hematite was detected by XRD. The titration curves of the two sediments showed that the red clayey sediment had appreciably more buffering capacity than the sandy sediment (i.e., more acid or base must be added to the clayey sediment than to the sandy sediment to produce the same $\mathrm{pH}$ change; Figure 3 ). The implication of this observation is that the red clayey sediment is less likely to undergo $\mathrm{pH}$ changes in response to varying CDP concentrations leaching from the low-level waste.

Table 2. Sediment characterization.

\begin{tabular}{|c|c|c|c|}
\hline Parameter & Red Clay Sediment & $\begin{array}{c}\text { Sandy } \\
\text { Sediment }^{(\mathrm{a})}\end{array}$ & Comment \\
\hline $\mathrm{pH}$ & 4.6 & 4.2 & 1:1 Sediment:water; \\
\hline Sand / Silt / Clay (wt-\%) & $58 / 30 / 12$ & $96 / 0 / 4$ & Mini-pipette method \\
\hline Organic Matter (wt-\%) & $<0.01$ & $<0.02$ & Combustion \\
\hline Surface Area $\left(\mathrm{m}^{2} / \mathrm{g}\right)$ & 15.31 & $1.32^{(b)}$ & BET \\
\hline Mineralogy ${ }^{(c)}$ & $\begin{array}{l}\text { Kao > goeth > hem (no } \\
\text { qtz or } 1.4 \mathrm{~nm} \text { peak) }\end{array}$ & $\begin{array}{c}\text { kao }=\text { HIV >> } \\
\text { goeth }=\text { qtz }\end{array}$ & $\mathrm{XRD}, 25$ and $550^{\circ} \mathrm{C}$ \\
\hline Total Fe (wt-\%) & 5.97 & NA & $\begin{array}{l}\text { Total digestion, ICP- } \\
\text { AES }\end{array}$ \\
\hline Point-of-Zero-Salt-Effect ${ }^{(\mathrm{d})}$ & 5.6 to 6.2 & 5.5 to 6.5 & Figure $1 \&$ Figure 2 \\
\hline
\end{tabular}

\footnotetext{
(a) Kaplan 2003.

(b) Surface area was not measured on this sample. Provided is the average surface area of two sediments with similar particle size distributions and were also from the E-Area subsurface.

${ }^{(c)} \mathrm{kao}=$ kaolinite, goeth = goethite, hem = hematite, $\mathrm{qtz}=$ quartz, HIV = hydroxyl-interlayered vermiculite.

(d) PZSE, provides an estimate of the $\mathrm{pH}$ at which the sediment surface has no net charge.
} 
WSRC-RP-2004-00593

Point of Zero Salt Effect - SRS Sandy Sediment

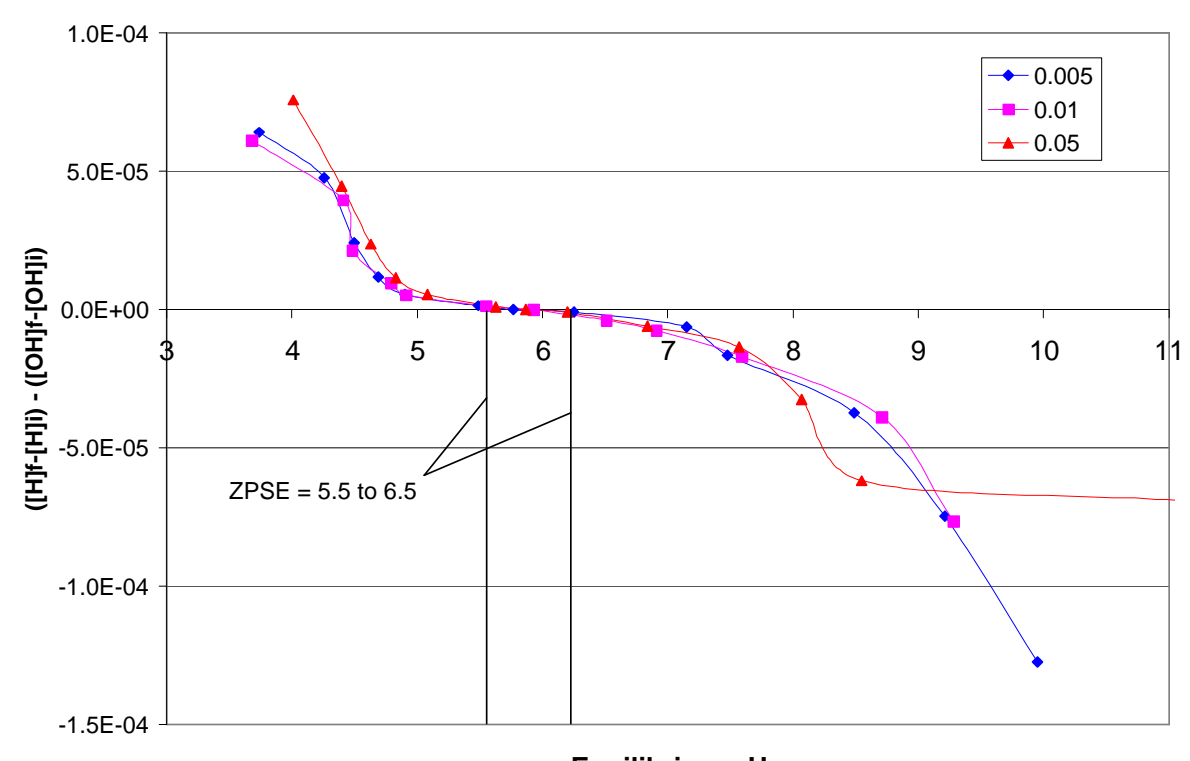

Equilibrium pH

Figure 1. Point-of-Zero-Salt Effect (approximately the $\mathrm{pH}$ at which sediment has a net charge of zero) of the sandy sediment Conducted at 3 Ionic Strengths (the ZPSE is at pH 5.5 to 6.5).

Point-of-Zero-Salt Effect of Red Clayey Sediment

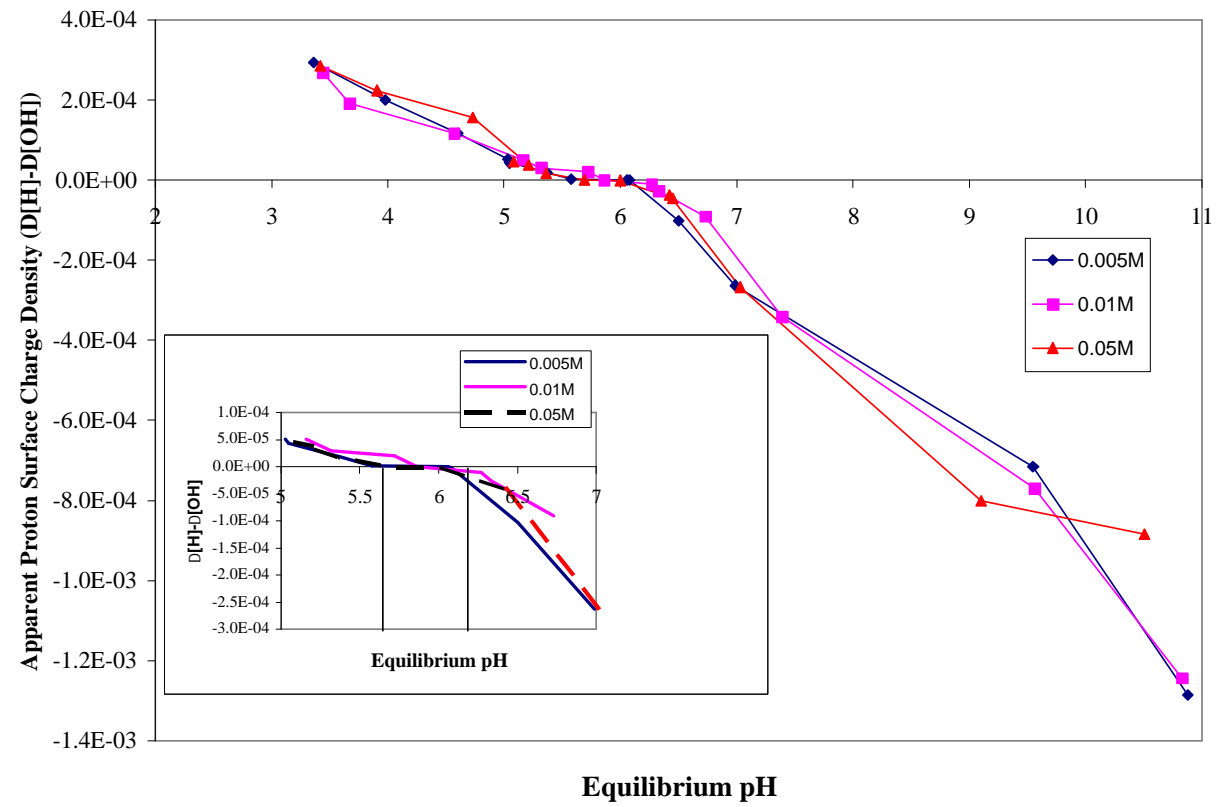

Figure 2. Point-of-Zero-Salt Effect for the Red Clay Sediment Conducted at 3 Ionic Strengths $(\mathrm{PZSE}=\mathrm{pH} 5.6$ to 6.2). 
WSRC-RP-2004-00593

Titration Curves of the Sand and Red Clay Sediments

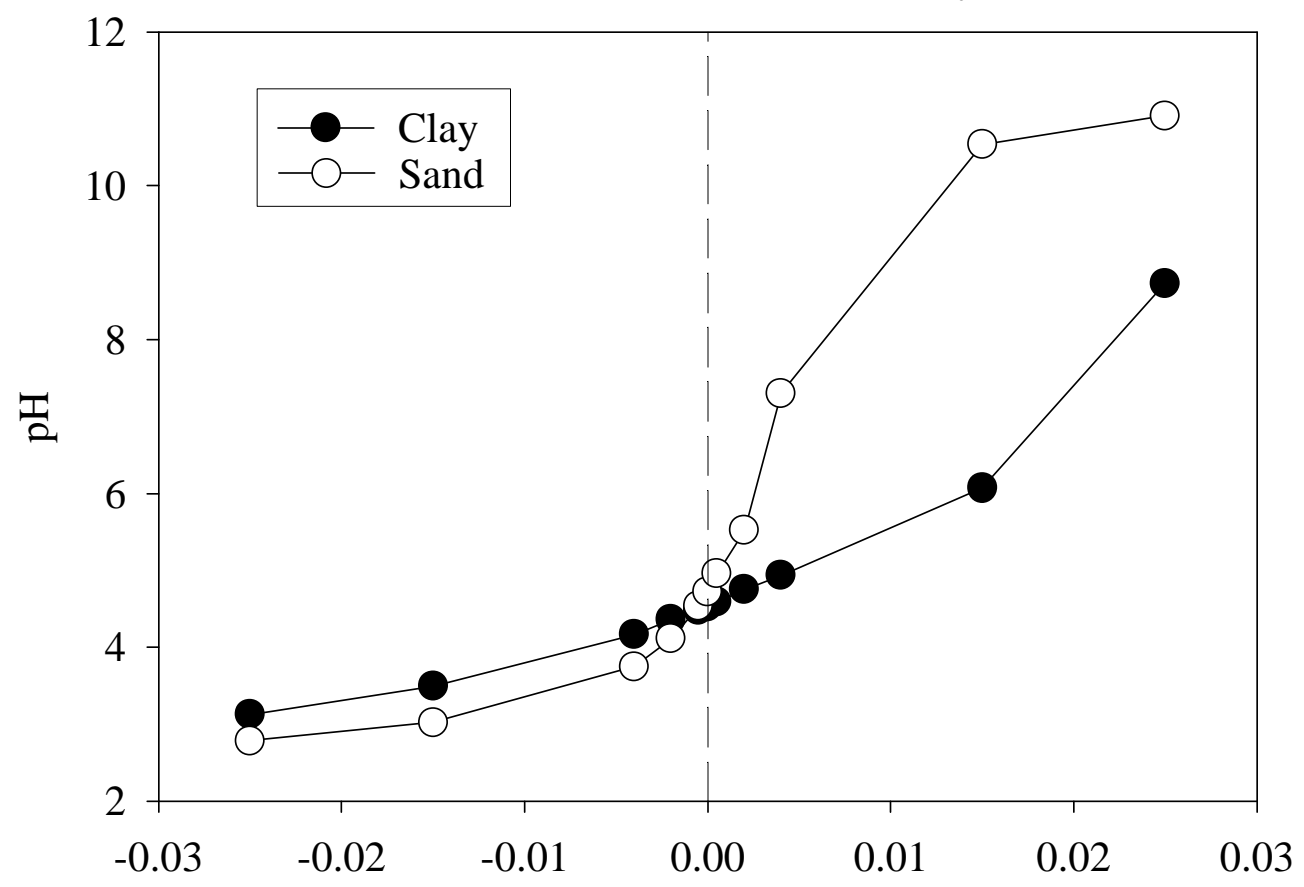

Acid (Negative Values) or Base Added (meq/g sediment)

Figure 3. Titration of the sand and clay sediments.

\subsection{Organic Matter Interactions with the Sediments}

After the sediment suspensions were $\mathrm{pH}$ adjusted, varying amounts of SR-NOM were added to the tubes. The $\mathrm{pH}$ levels of the tubes were readjusted two more times within a one-week period. After this $\mathrm{pH}$ and SR-NOM equilibration period, the contaminants were introduced into the suspensions. The suspensions were $\mathrm{pH}$ adjusted for a forth time. The contaminants were then permitted to come to equilibration for another week. The DOC concentrations in the no-sediment controls are presented in Table 3. Except for the $0 \mathrm{mg} / \mathrm{L} \mathrm{C}$ samples, the measured DOC concentrations were close to the targeted concentrations. This was unexpected considering that the amount of $\mathrm{C}$ in the SR-NOM had to be estimated and then there were a number of dilutions resulting from the various $\mathrm{pH}$ adjustments. The cause for the unexpected high DOC concentrations for the samples that did not receive any SR-NOM $(0 \mathrm{mg} / \mathrm{L} \mathrm{C}$ treatments $)$ is not known, but needs to be further evaluated. There is no $\mathrm{pH}$ effect on DOC concentrations over the range of conditions in this experiment. This conclusion was anticipated but had to be confirmed prior to calculating the amount of organic carbon sorbed. 
Table 3. Dissolved organic carbon concentrations in the no-sediment control samples (all treatments were duplicated).

\begin{tabular}{ccc}
\hline $\mathrm{pH}$ & $\begin{array}{c}\text { Targeted DOC } \\
\text { Addition }(\mathrm{mg} / \mathrm{L} \mathrm{C})\end{array}$ & $\begin{array}{c}\text { Measured DOC } \\
(\mathrm{mg} / \mathrm{L} \mathrm{C})\end{array}$ \\
\hline 4.1 & 0 & $11 \pm 1$ \\
& 10 & $10 \pm 1$ \\
& 30 & $29 \pm 4$ \\
7.4 & 100 & $83 \pm 4$ \\
& 300 & $215 \pm 16$ \\
& 0 & $5 \pm 1$ \\
& 10 & $11 \pm 0$ \\
Average $^{(\text {a) }}$ & 30 & $28 \pm 0$ \\
& 100 & $107 \pm 0$ \\
& 300 & $230 \pm 8$ \\
& 0 & $8 \pm 1$ \\
& 10 & $10 \pm 1$ \\
& 30 & $29 \pm 2$ \\
& 100 & $95 \pm 2$ \\
& 300 & $222 \pm 12$ \\
\hline
\end{tabular}

(a) Averages are across both $\mathrm{pH}$ values $(n=4)$.

The average measured DOC values reported in Table 3 were used to calculate the amount of organic carbon, OC, sorbed on to the sediment by difference between the added DOC and the final solution DOC (Table 4 and Figure 4). Generally, there was more OC sorbed to the clayey than to the sandy sediment. Again, this was expected because of the greater surface area of the former sediment. There was also a tendency for more OC to be sorbed at lower $\mathrm{pH}$ levels, especially at lower DOC loadings. This trend may be attributed to anionic nature of various SR-NOM functional groups. This organic matter sorption data will be modeled in a subsequent study to be conducted in FY05. 
Table 4. Dissolved and sorbed organic carbon concentrations at end of experiment.

\begin{tabular}{|c|c|c|c|c|c|c|}
\hline \multirow[b]{2}{*}{$\mathrm{pH}$} & \multirow[b]{2}{*}{$\begin{array}{c}\text { Targeted DOC } \\
\text { Addition } \\
(\mathrm{mg} / \mathrm{L} \mathrm{C})\end{array}$} & \multirow[b]{2}{*}{$\begin{array}{c}\text { Actual DOC } \\
\text { Addition } \\
(\mathrm{mg} / \mathrm{L} \mathrm{C})\end{array}$} & \multicolumn{2}{|c|}{ Clayey Sediment } & \multicolumn{2}{|c|}{ Sandy Sediment } \\
\hline & & & $\begin{array}{c}\text { Final } \\
\text { Measured } \\
\text { DOC } \\
(\mathrm{mg} / \mathrm{L} \mathrm{C})\end{array}$ & $\begin{array}{l}\text { OC Sorbed } \\
\text { (mg C/g } \\
\text { sediment) }\end{array}$ & $\begin{array}{c}\text { Final } \\
\text { Measured } \\
\text { DOC } \\
(\mathrm{mg} / \mathrm{L} \mathrm{C})\end{array}$ & $\begin{array}{l}\text { OC Sorbed } \\
(\mathrm{mg} \mathrm{C} / \mathrm{g} \\
\text { sediment) }\end{array}$ \\
\hline \multirow[t]{5}{*}{3.9} & 0 & 8 & $11 \pm 0$ & $0^{(\mathrm{b})}$ & $3 \pm 1$ & $0^{(\mathrm{b})}$ \\
\hline & 10 & 10 & $9 \pm 5$ & 0.015 & $3 \pm 0$ & 0.079 \\
\hline & 30 & 20 & $11 \pm 2$ & 0.201 & $7 \pm 1$ & 0.240 \\
\hline & 100 & 95 & $28 \pm 21$ & 0.752 & $37 \pm 3$ & 0.644 \\
\hline & 300 & 222 & $79 \pm 4$ & 1.600 & $160 \pm 10$ & 0.700 \\
\hline \multirow[t]{5}{*}{5.3} & 0 & 8 & $18 \pm 2$ & $0^{(\mathrm{b})}$ & $8 \pm 0$ & $0^{(\mathrm{b})}$ \\
\hline & 10 & 10 & $5 \pm 0$ & 0.062 & $4 \pm 0$ & 0.075 \\
\hline & 30 & 20 & $6 \pm 0$ & 0.260 & $9 \pm 1$ & 0.224 \\
\hline & 100 & 95 & $14 \pm 3$ & 0.906 & $42 \pm 8$ & 0.597 \\
\hline & 300 & 222 & $74 \pm 4$ & 1.662 & $177 \pm 16$ & 0.505 \\
\hline \multirow[t]{5}{*}{6.7} & 0 & 8 & $11 \pm 1$ & $0^{(b)}$ & $2 \pm 1$ & $0^{(\mathrm{b})}$ \\
\hline & 10 & 10 & $7 \pm 2$ & 0.035 & $6 \pm 1$ & 0.054 \\
\hline & 30 & 20 & $6 \pm 1$ & 0.259 & $14 \pm 0$ & 0.165 \\
\hline & 100 & 95 & $14 \pm 1$ & 0.910 & $59 \pm 4$ & 0.405 \\
\hline & 300 & 222 & $111 \pm 20$ & 1.248 & $180 \pm 10$ & 0.470 \\
\hline
\end{tabular}

(a) OC Sorbed is based on "Actual DOC Addition." It reflects an average value based on an average aqueous volume of $55.9 \mathrm{~mL} /$ tube and suspension load of $5.000 \mathrm{~g} / \mathrm{tube}$.

(b) Due to analytical uncertainty associated with the Actual DOC Addition when no DOC was added, OC Sorbed was assumed equal to zero $\mathrm{mg} \mathrm{C} / \mathrm{g}$ sediment. 


\section{Sorbed OC vs. Added DOC: Clayey Sediment}

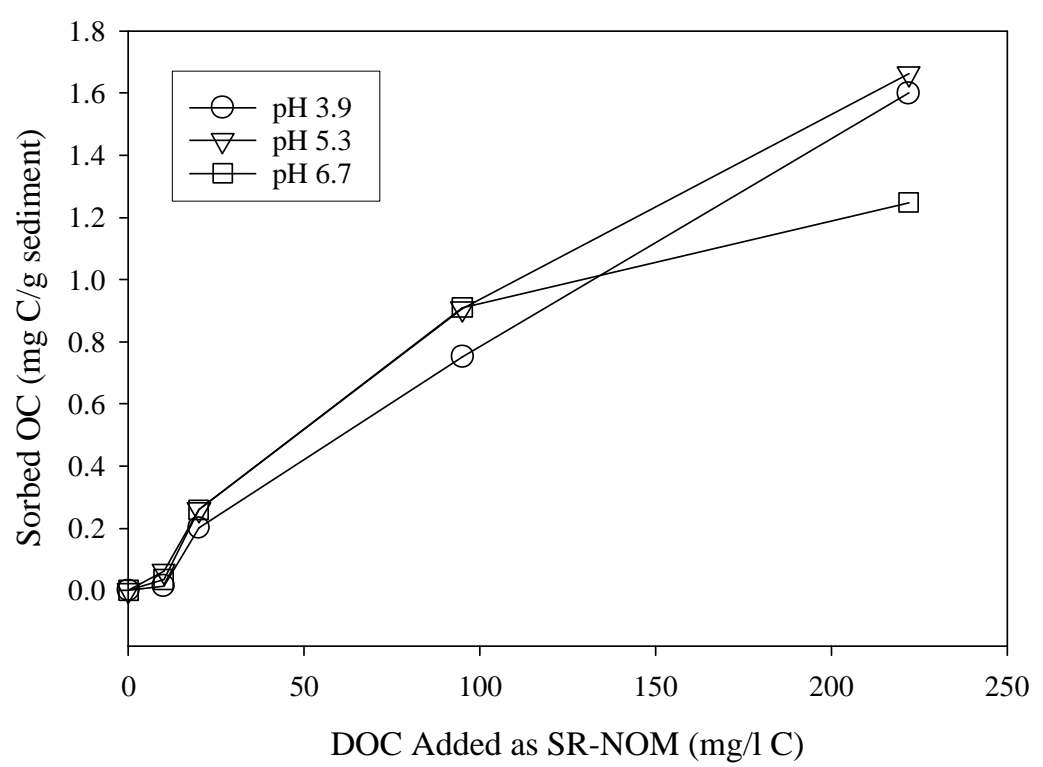

Sorbed OC vs. Added DOC: Sandy Sediment

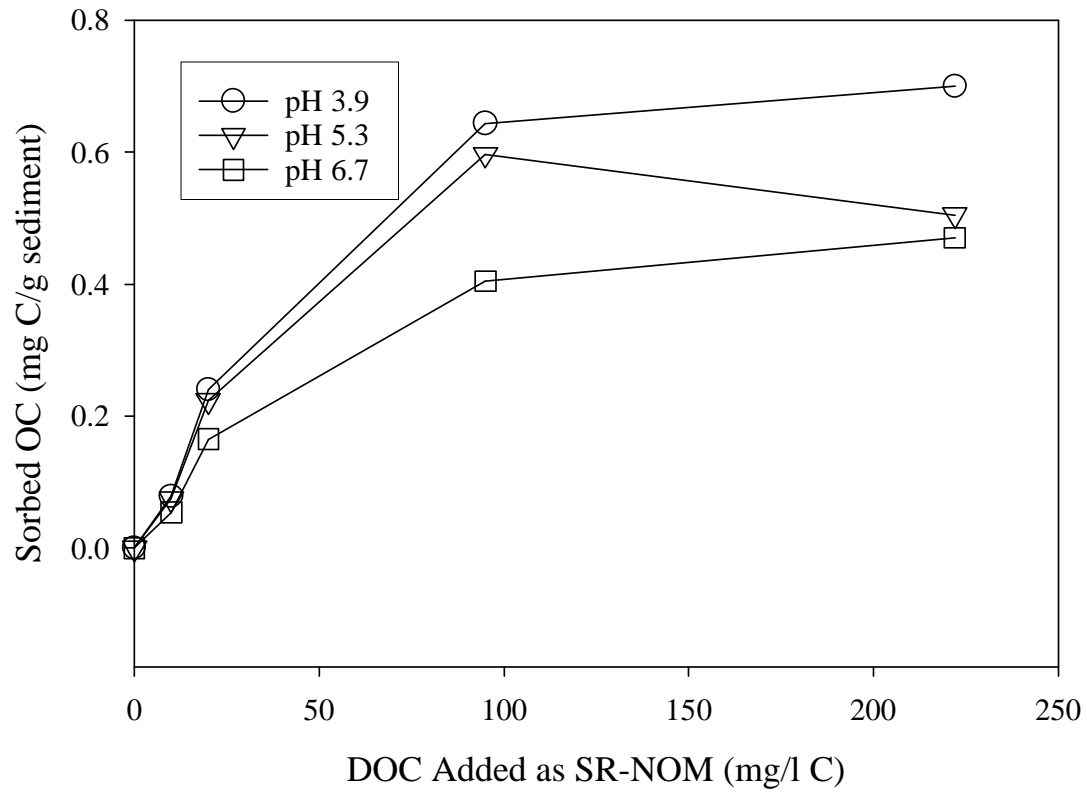

Figure 4. Sorbed organic carbon vs. dissolved organic carbon added in the clayey sediment (top) and sandy sediment (bottom). 
WSRC-RP-2004-00593

\subsection{Contaminant Sorption in the Presence of Varying pH and DOC Concentrations}

\subsection{1 pH and SR-NOM Controls}

A number of controls were included in this study, approximately 1 control for every 3 samples. One set of controls ran along side the samples were the no-sediment controls. These controls were treated identically as the other samples except that they did not include any sediment. They were adjusted to two $\mathrm{pH}$ values, $\mathrm{pH} 4.1$ and 7.4. By not including the sediment, it is possible to separate chemical reactions involving sediments from those that do not involve sediments.

The $\mathrm{pH}$ values were adjusted by adding either $\mathrm{NaOH}$ or $\mathrm{HCl}$ to solutions containing varying concentrations of SR-NOM. The $\mathrm{pH}$ was adjusted and permitted to come to a steady state for one week prior to introducing the contaminants. Upon adding the contaminants, the $\mathrm{pH}$ was again adjusted. The final $\mathrm{pH}$ values of these controls as a function of SR-NOM concentrations are reported in Figure 5. This shows that the $\mathrm{pH}$ values remained essentially constant as a function of targeted SR-NOM concentration. The importance of this is that the natural tendencies of $\mathrm{pH}$ values decreasing as SR-NOM concentrations increase were overcome by acid and base additions. Thus, SR-NOM and $\mathrm{pH}$ were in fact independent variables in this set of controls, consistent with the experimental design.

Final pH vs. Targeted SR-NOM Concentration of No-Sediment Control Samples

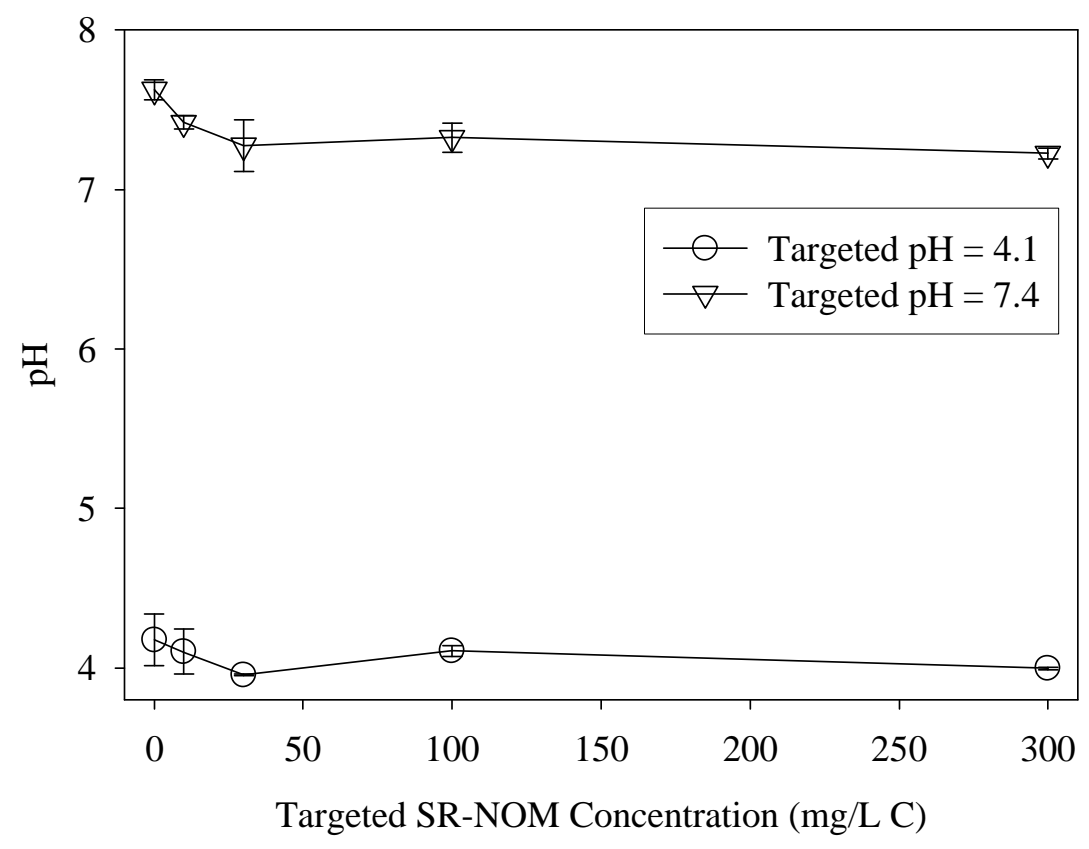

Figure 5. Final pH vs. targeted SR-NOM concentration of no-sediment control samples (2 observations for each mean and standard deviation). 
WSRC-RP-2004-00593

\subsubsection{Contaminant Spike Controls}

Another concern regarding the contaminant spikes, was to determine how soluble they remained as a function of $\mathrm{pH}$ and SR-NOM. Conclusions regarding these controls are listed below.

- The ICP-MS did not detect any rhenium in the controls (or sediment samples) (data presented in section 9.0, Appendix B). Rhenium was somehow lost from the sample during the experiment or, more likely, an analytical issue existed whereby Re could not be detected. Rhenium data will therefore not be discussed further.

- The $\mathrm{K}$ control data indicated that some $\mathrm{K}$ was introduced into the system though sources other than the spike (data presented in section 9.0, Appendix B). The sediment and SR-NOM contained $\mathrm{K}$, and it was anticipated that they may desorb some $\mathrm{K}$ into the aqueous phase. Unfortunately, this occurred in an apparently non-systematic manner, thus precluding further evaluation of these data.

- $\mathrm{Cs}, \mathrm{Ni}$, and $\mathrm{Sr}$ aqueous concentrations at $\mathrm{pH} 4.1$ remained fairly constant as a function of SRNOM concentrations. Considering the means and standard deviation bars, there was not a systematic change in solute concentrations as a function of SR-NOM concentrations (Figure 6).

- $\mathrm{Cs}, \mathrm{Ni}$, and $\mathrm{Sr}$ aqueous concentrations at $\mathrm{pH} 7.4$ also did not show any systematic change with SR-NOM concentrations (Figure 7). However, the standard errors were quite large in one case ( $\mathrm{Ni}$ in the $100 \mathrm{mg} / \mathrm{L} \mathrm{C}$ treatment). There may have been some $\mathrm{Ni}$ that precipitated from solution in the $0 \mathrm{mg} / \mathrm{L} \mathrm{C}$ treatment, but not in any of the other SR-NOM treatments.

- $\mathrm{Ce}, \mathrm{Eu}, \mathrm{Th}$, and $\mathrm{Zr}$ aqueous concentrations at $\mathrm{pH} 4.1$ remained constant as a function of SRNOM concentration (Figure 8). Contaminant concentration variability in these samples was quite low.

- $\mathrm{Ce}, \mathrm{Eu}, \mathrm{Th}$, and $\mathrm{Zr}$ aqueous concentrations at $\mathrm{pH} 7.4$, varied greatly as a function of SRNOM concentrations (Figure 9). At $0 \mathrm{mg} / \mathrm{L} \mathrm{C}$ treatments, aqueous concentrations were significantly lower that the other SR-NOM treatments. This may be the result of the contaminants precipitating out these elements. When SR-NOM concentrations were sufficiently high, these elements were presumably solubilized by solution complexation with the SR-NOM. Presumably, the SR-NOM complexation reaction was able to out-compete the hydrolysis precipitation reaction, thereby permitting the contaminant to remain in solution as a SR-NOM complex.

To evaluate which phases may have precipitated out of solution in the $\mathrm{pH} 7.4$, no SR-NOM solutions, thermodynamic calculations were conducted using the software Visual MINTEQA2 (Gustaffsson 2003) to calculate the saturation index (Eq. 1):

$$
\text { Saturation Index }=\log \left(\frac{\text { IAP }}{K_{s}}\right)
$$

where IAP is the ion activity product (the product of the reactants raised to their stoichiometric power) and $K_{s}$ is the solubility constant of the solid. When the saturation index $=0$, the system is at equilibrium with respect to that solid. When the saturation index is $>0$, the solid phase is supersaturated with respect to that solid and is inclined to precipitate. When the saturation index is $<0$, the solid phase is undersaturated with respect to the solid. All solids with a saturation index 
near or greater than 0 are presented in Table 5. Given the uncertainty of the analytical results and the thermodynamic constants that go into making this calculation, any of these solids may have precipitated from solution. Conclusions regarding these thermodynamic calculations for the experimental conditions employed in this study are listed below.

- $\mathrm{Cs}, \mathrm{Sr}$, or Ni solid phases were not expected to form.

- Trivalent $\left(\mathrm{Ce}^{3+}\right.$ and $\left.\mathrm{Eu}^{3+}\right)$ and tetravalent $\left(\mathrm{Th}^{4+}\right.$ and $\left.\mathrm{Zr}^{4+}\right)$ cations were the most likely to precipitate at $\mathrm{pH} 7.4$,

- With the exception of $\mathrm{ThO}_{2}$, no solids were supersaturated at $\mathrm{pH} 4.1$. 
WSRC-RP-2004-00593

Aqueous Ni, Sr, and Cs vs. Targeted Fulvic Acid Concentrations in No-Sediment Controls at pH 4.1

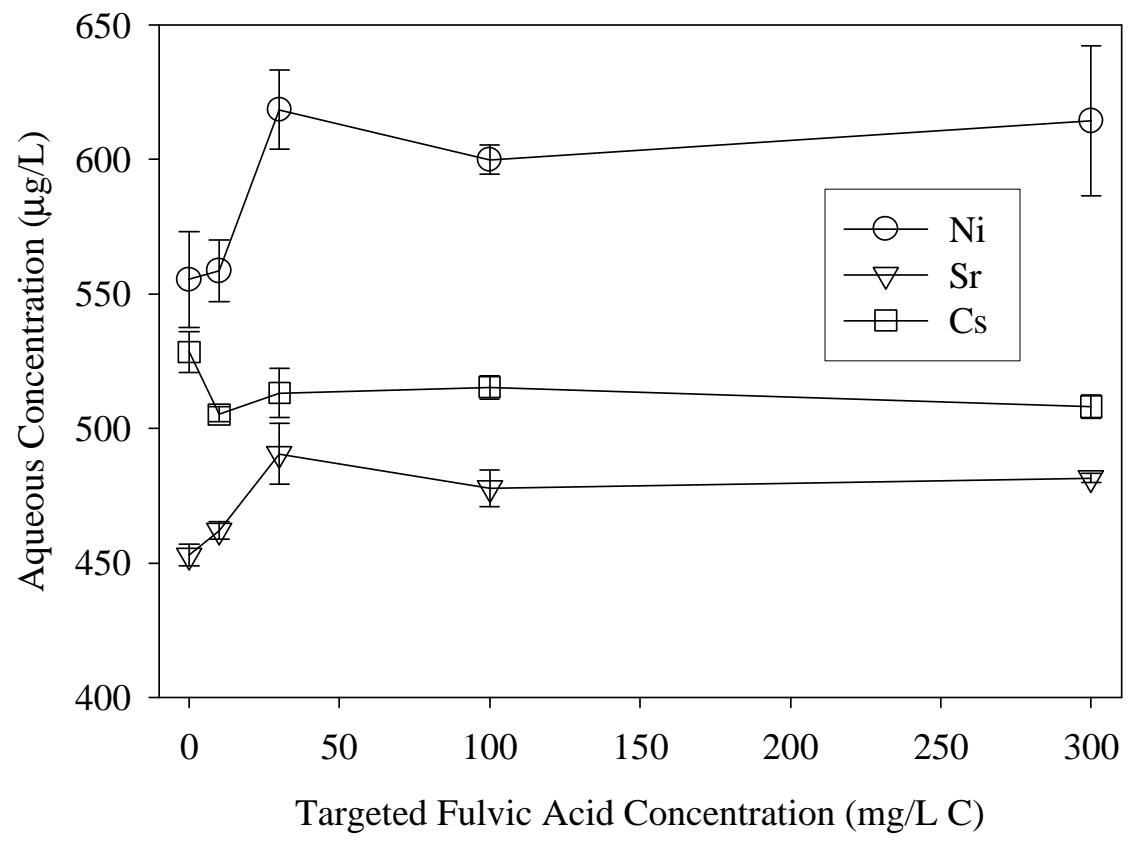

Figure 6. Aqueous $\mathrm{Ni}, \mathrm{Sr}$, and $\mathrm{Cs}$ versus targeted $\mathrm{SR}-\mathrm{NOM}$ concentrations in the no-sediment controls at $\mathrm{pH} 4.1$.

Aqueous Ni, Sr, and Cs vs. Targeted Fulvic Acid Concentrations in No-Sediment Controls at pH 7.4

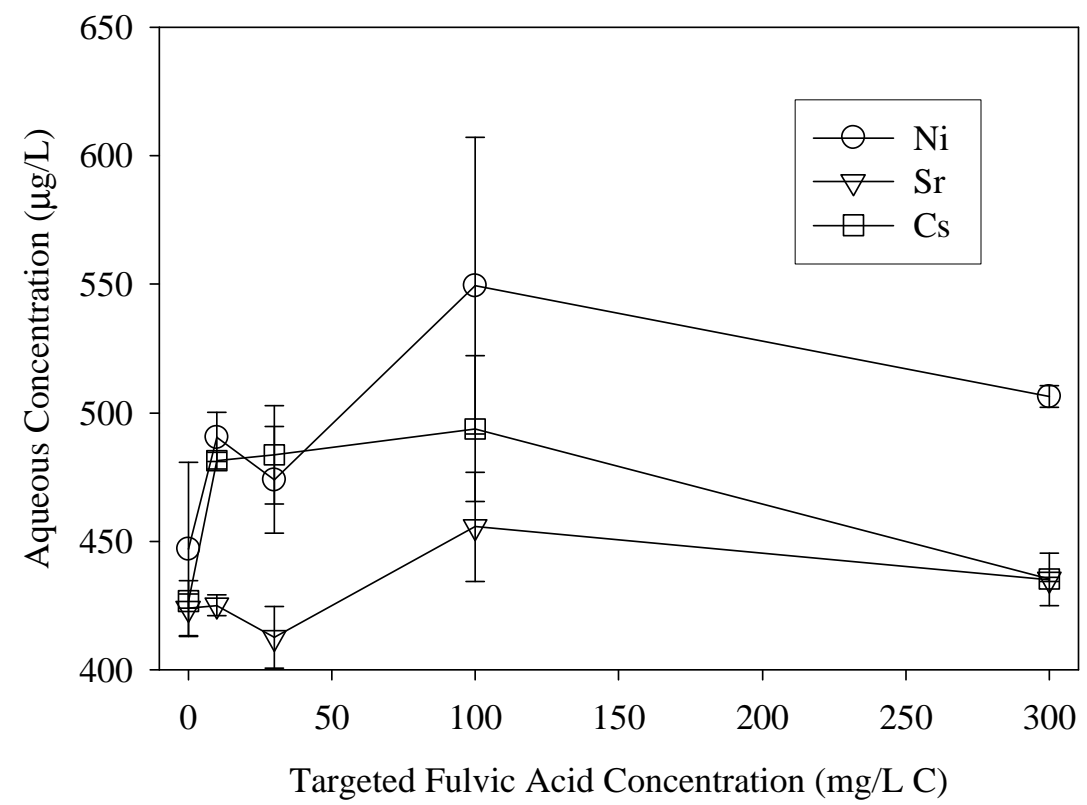

Figure 7. Aqueous Ni, Sr, and Cs versus targeted SR-NOM concentrations in no-sediment controls at $\mathrm{pH}$ 7.4. 
Aqueous Ce, Eu, Th, and Zr vs. Targeted Fulvic Acid Concentrations in No-Sediment Controls at pH 4.1

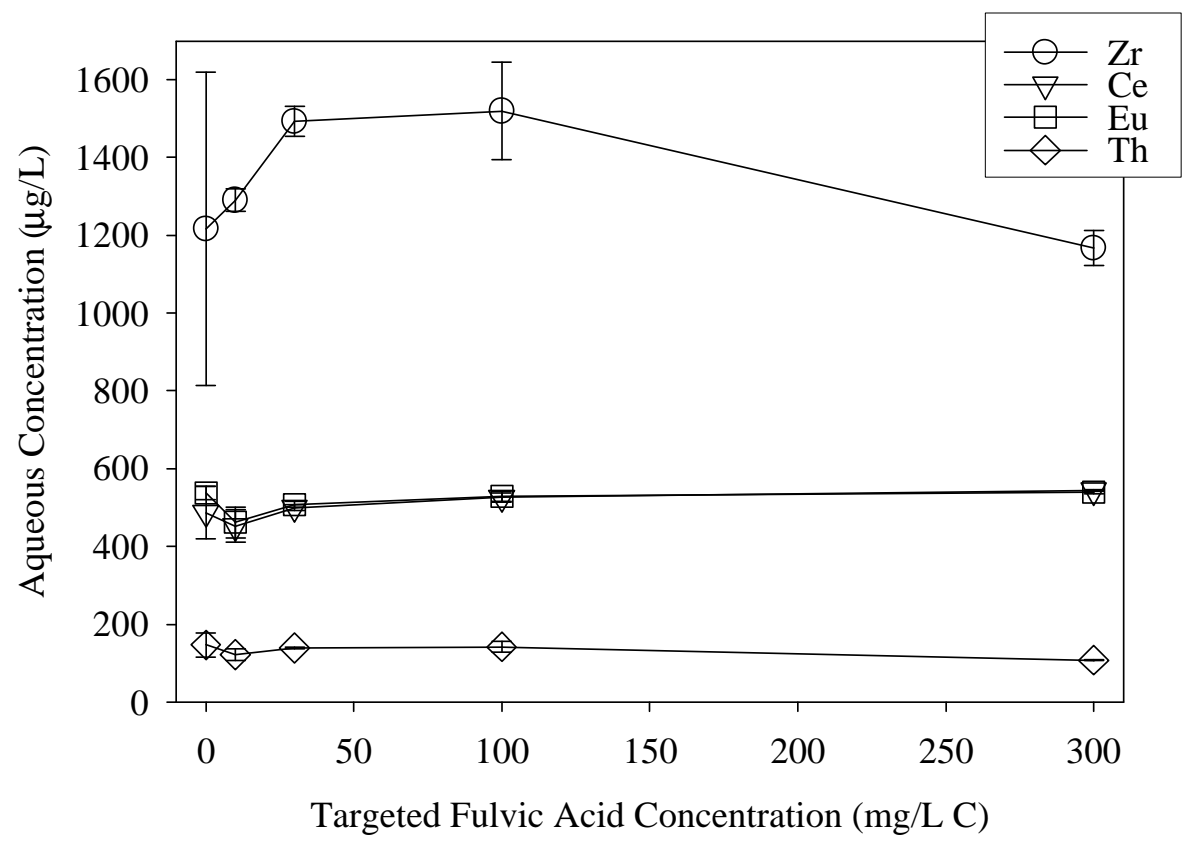

Figure 8. Aqueous $\mathrm{Ce}, \mathrm{Eu}, \mathrm{Th}$, and $\mathrm{Zr}$ versus targeted SR-NOM concentrations in no-sediment controls at $\mathrm{pH} 4.1$.

Aqueous Ce, Eu, Th, and $\mathrm{Zr}$ vs. Targeted Fulvic Acid Concentrations in No-Sediment Controls at pH 7.4

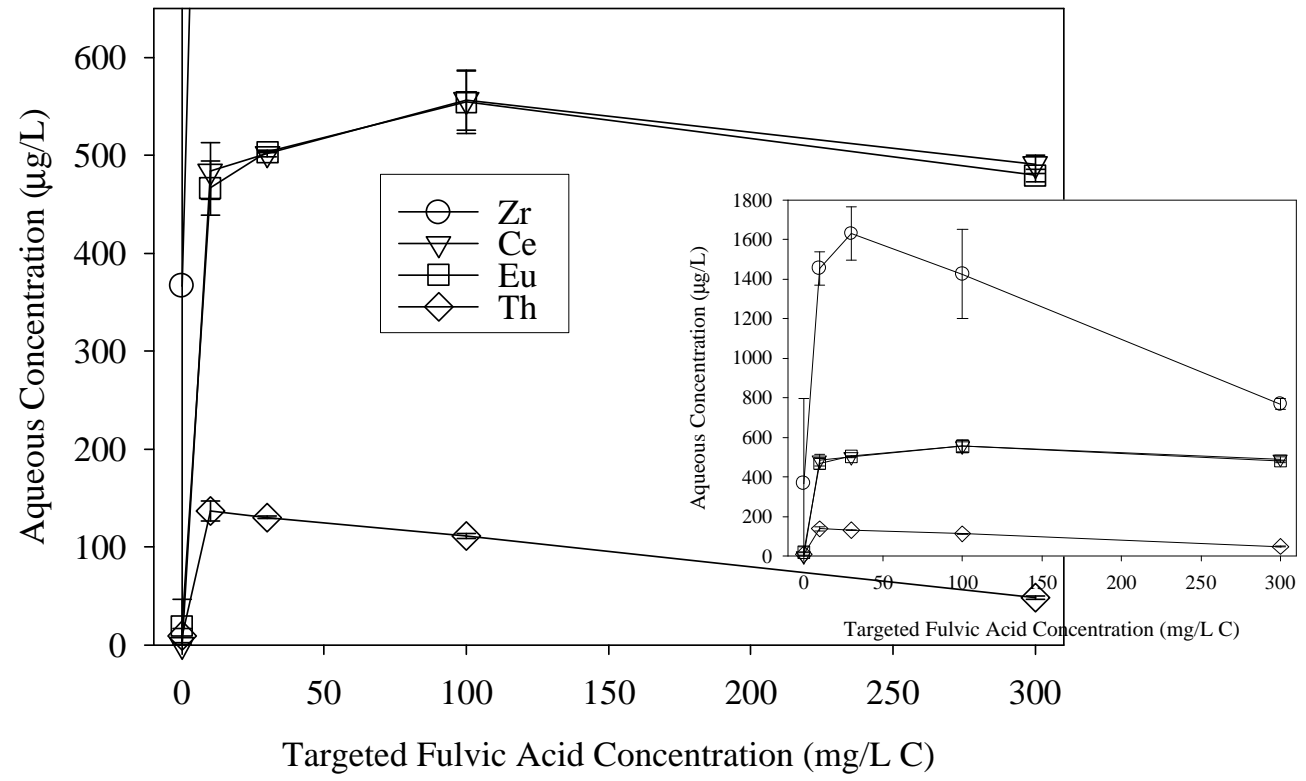

Figure 9. Aqueous $\mathrm{Ce}, \mathrm{Eu}, \mathrm{Th}$, and $\mathrm{Zr}$ versus targeted $\mathrm{SR}-\mathrm{NOM}$ concentrations in the no-sediment controls at $\mathrm{pH}$ 7.4. 
WSRC-RP-2004-00593

Table 5. Thermodynamic calculations of the saturation index of the no-sediment control solutions.

\begin{tabular}{llcc}
\hline $\mathrm{pH}$ & Solid phase & $\log ($ Ion Activity Product) & Saturation Index: $\log \left(\mathrm{IAP} / \mathrm{K}_{\mathrm{s}}\right)^{(\mathrm{a})}$ \\
\hline \multirow{4}{*}{4.1} & $\mathrm{ThO}_{2}$ & 8.3 & 2.0 \\
& & & -0.3 \\
7.4 & $\mathrm{Eu}(\mathrm{OH})_{3}$ & 16.1 & 1.0 \\
& $\mathrm{Ce}(\mathrm{OH})_{3}$ & 16.7 & 3.9 \\
& $\mathrm{Th}(\mathrm{OH})_{4}$ & 15.2 & 8.9 \\
& $\mathrm{ThO}_{2}$ & 15.2 & -0.2 \\
& $\mathrm{ZrO}_{2}$ & 1.7 & \\
\end{tabular}

(a) When the saturation index $=0$, the system is at equilibrium with respect to that solid. When the saturation index is $>0$, the solid phase is supersaturated and is inclined to precipitate. When the saturation index is $<0$, the solid phase is undersaturated.

\subsubsection{Monovalent Cation Sorption}

Monovalent cation radionuclides of interest to the LLW-PA are $\mathrm{Cs}^{+}, \mathrm{NpO}_{2}^{+}$, and $\mathrm{Rb}^{+}$(Table 1). There were two monovalent cations included in this study as analogues for these radionuclides, $\mathrm{Cs}^{+}$ and $\mathrm{K}^{+}$. Unfortunately, the $\mathrm{K}^{+}$data are unreliable because $\mathrm{K}^{+}$was introduced into the system during the course of the study, likely from the sediment, SR-NOM, and to a lesser extent, as impurities in chemicals. This does not compromise the results greatly because stable Cs is a perfect analogue for radioactive $\mathrm{Cs}$, and a close chemical analogue for $\mathrm{Rb}$, which exists just above it on the periodic chart. Cesium is not an especially good analogue for $\mathrm{NpO}_{2}{ }^{+}$due to the disparity between their sizes, ionization energies, and nuclear charges.

Cesium $\mathrm{K}_{\mathrm{d}}$ values changed in a rather systematic way with $\mathrm{pH}$, sediment type, and SR-NOM concentrations (Figure 10):

- Cs $K_{d}$ values were 2 to 3 times greater in the clayey than in the sandy sediment,

- $\mathrm{Cs}_{\mathrm{d}}$ values increased with $\mathrm{pH}$, and

- Cs $K_{d}$ values increased with SR-NOM concentrations.

Of these findings, the latter one is of greatest importance because the performance assessment presently assumes the opposite trend, namely that $\mathrm{Cs}_{\mathrm{d}}$ decreases as SR-NOM concentrations increase. The cause for this disparity is not known but may be attributed to the fact that Cs has a weak tendency to complex with SR-NOM, and as such, as the SR-NOM concentrations in solution increase we do not observe a concomitant increase in solution Cs concentrations. The weak tendency for $\mathrm{Cs}$ to form complexes to humic materials is shown by the following ranking of cations by their propensity to form complexes with humic materials (Bovard et al. 1970):

$$
\mathrm{Cd}^{3+}>\mathrm{Fe}^{3+}>\mathrm{Co}^{2+} \cdot \mathrm{Ru}^{2+} \cdot \mathrm{Sr}^{2+}>\mathrm{Cs}^{+} .
$$


Furthermore, complexation of Cs by common industrial chelates (e.g., EDTA) is believed to be poor due to their low stabilities and the presence of competing cations (e.g., $\mathrm{Ca}^{2+}$ ) at appreciably higher concentrations than that of Cs. The data may suggest that Cs bonds stronger to SR-NOM coated soils than the original soil surface itself. Stated differently, Cs may complex better with sorbed SR-NOM than to dissolved SR-NOM. 


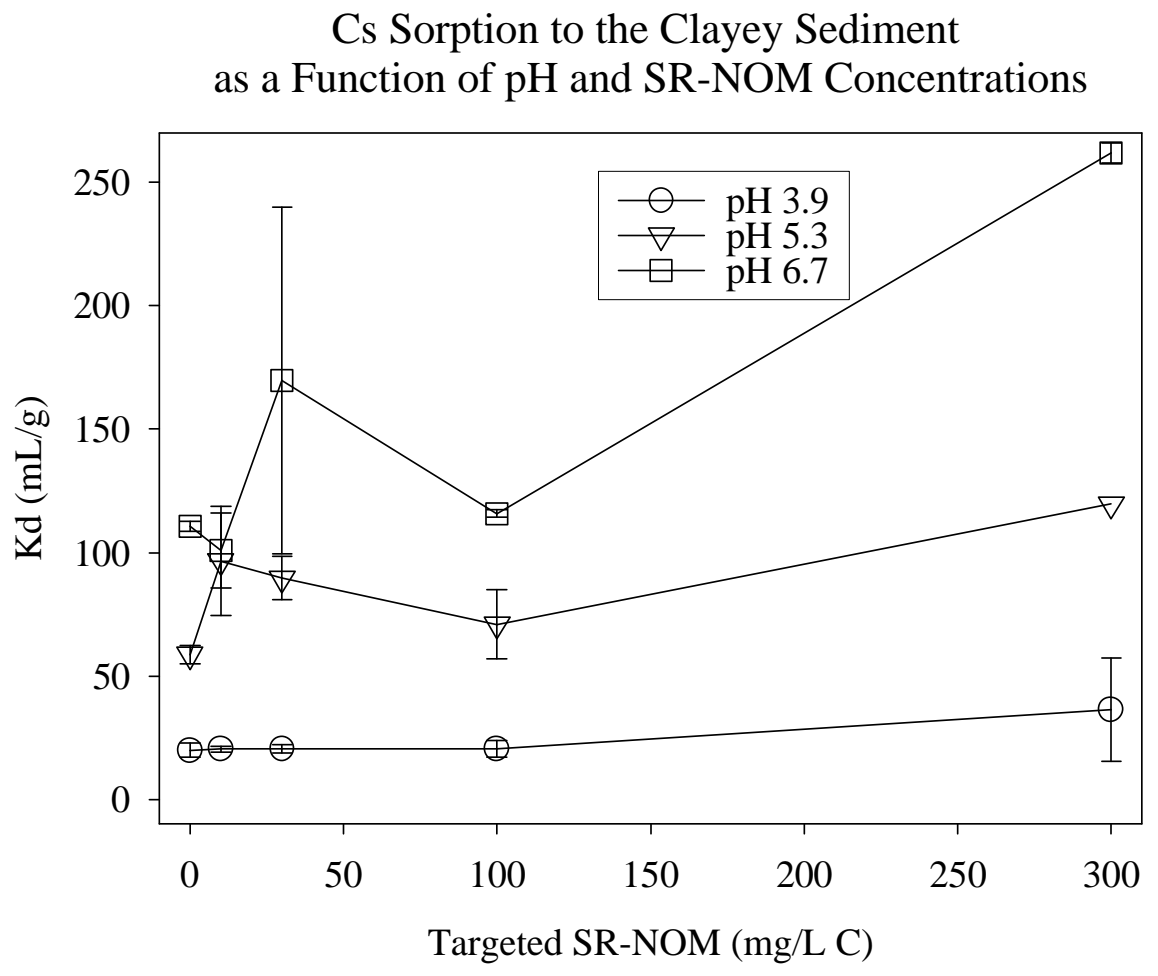

Cs Sorption to the Sandy Sediment as a Function of $\mathrm{pH}$ and SR-NOM Concentrations

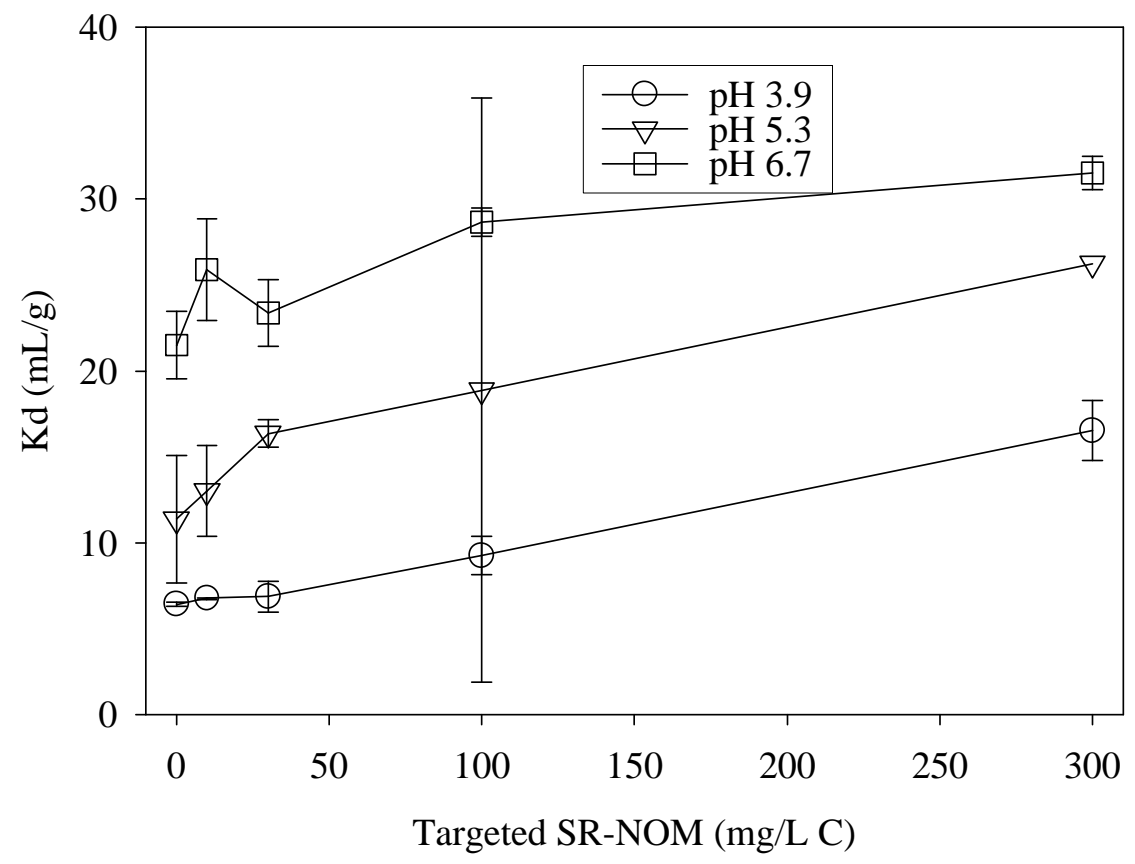

Figure 10. Cs $\mathrm{K}_{\mathrm{d}}$ values as a function of $\mathrm{pH}$ and SR-NOM concentrations in clayey (top) and sandy (bottom) sediments. 
WSRC-RP-2004-00593

\subsubsection{Divalent Cation Sorption}

Divalent cation radionuclides of interest to the LLW-PA are $\mathrm{Ni}^{2+}, \mathrm{Pb}^{2+}, \mathrm{Pd}^{2+}, \mathrm{Po}^{2+}, \mathrm{Ra}^{2+}, \mathrm{Sn}^{2+}$, $\mathrm{Sr}^{2+}$, and $\mathrm{UO}_{2}{ }^{2+}$ (Table 1). There were two divalent cations included in this study as analogues for these radionuclides, $\mathrm{Ni}^{2+}$ and $\mathrm{Sr}^{2+}$. Stable $\mathrm{Ni}^{2+}$ was used directly to provide $\mathrm{K}_{\mathrm{d}}$ values for radioactive $\mathrm{Ni}$, and as an analogue for $\mathrm{Pb}, \mathrm{Pd}, \mathrm{Po}$ and $\mathrm{Sn}$. Similarly, stable $\mathrm{Sr}^{2+}$ will be used directly to provide $\mathrm{K}_{\mathrm{d}}$ values for radioactive $\mathrm{Sr}$, and as an analogue for $\mathrm{Ra}^{2+}$ and $\mathrm{UO}_{2}{ }^{2+}$. Previously, data on the influence of CDP on $\mathrm{UO}_{2}{ }^{2+}$ sorption to kaolinite were reported in Serkiz (2000). The assignment of the analogues to the radionuclides was based upon periodicity (its location in the periodic chart) and chemical properties of the radionuclides, as compared to those of the analogue.

Nickel $\mathrm{K}_{\mathrm{d}}$ values (Figure 11, Table 6) followed similar trends with $\mathrm{pH}$ and sediment type as described for Cs (Figure 10; Section 5.3.3):

- $\mathrm{Ni} \mathrm{K}_{\mathrm{d}}$ values increased with $\mathrm{pH}$,

- $\mathrm{Ni} \mathrm{K}_{\mathrm{d}}$ values were 2 to 3 times greater in the clayey than in the sandy sediment (except at $\mathrm{pH}$ 3.9).

Nickel $\mathrm{K}_{\mathrm{d}}$ values had a more complicated trend with SR-NOM concentrations than was observed with $\mathrm{Cs}_{\mathrm{d}}$ values. First, there was an interactive effect between $\mathrm{pH}$ and SR-NOM on Ni $\mathrm{K}_{\mathrm{d}}$ values. As the $\mathrm{pH}$ increased, there was a greater impact of SR-NOM concentrations on $\mathrm{Ni} \mathrm{K}_{\mathrm{d}}$ values. At $\mathrm{pH} 3.9$, there was essentially no Ni sorption occurring in either sediment and there was no significant $(\mathrm{P} \leq 0.05, \mathrm{df}=4)$ correlation between $\mathrm{Ni} \mathrm{K}_{\mathrm{d}}$ values and targeted SR-NOM concentrations. The average $\mathrm{Ni}_{\mathrm{d}}$ value across all SR-NOM concentrations in the sandy sediment was $2.5 \pm 2.0 \mathrm{~mL} / \mathrm{g}$ and in the clayey sediment was $2.4 \pm 1.6 \mathrm{~mL} / \mathrm{g}$ (Table 6). At pH 5.3, there were measurable amounts of $\mathrm{Ni}$ sorbed to the sediments, but there was no significant $(\mathrm{P} \leq 0.05, \mathrm{df}=4)$ correlation between targeted SR-NOM concentrations and $\mathrm{K}_{\mathrm{d}}$ values. At $\mathrm{pH}$ 5.3, the average $\mathrm{Ni}_{\mathrm{d}}$ value across all SR-NOM concentrations in the sandy sediment was $9.6 \pm 2.4 \mathrm{~mL} / \mathrm{g}$ and in the clayey sediment was $59.4 \pm 26.1 \mathrm{~mL} / \mathrm{g}$ (Table 6).

At $\mathrm{pH}$ 6.7, the $\mathrm{Ni} \mathrm{K}_{\mathrm{d}}$ values were generally greater than at the lower $\mathrm{pH}$ levels. In the sandy sediment, the overall $\mathrm{Ni} \mathrm{K}_{\mathrm{d}}$ was $128 \pm 110 \mathrm{~mL} / \mathrm{g}$, whereas in the clayey sediment it was $423 \pm 312$ $\mathrm{mL} / \mathrm{g}$. The large standard deviation can be attributed to the large fluctuations with SR-NOM additions. The trend between $\mathrm{Ni} \mathrm{K}_{\mathrm{d}}$ values and SR-NOM concentrations (Figure 11) is one that was observed with several of the other analytes. When no SR-NOM was added, a relatively low $\mathrm{K}_{\mathrm{d}}$ value was observed. Upon adding a little SR-NOM, between 10 or $30 \mathrm{mg} / \mathrm{L} \mathrm{C}$, an increase in sorption was observed. SR-NOM additions $>\sim 30 \mathrm{mg} / \mathrm{L} \mathrm{C}$, result in a steady decline in $\mathrm{K}_{\mathrm{d}}$ values, to values lower than those for the $0 \mathrm{mg} / \mathrm{L} \mathrm{C}$ treatment. One possible explanation for this trend is that at low SR-NOM additions, a greater fraction of the SR-NOM sorbs to the sediment thereby increasing the relative number of organic sorption sites on the solid phase over that in solution. SRNOM sorption was shown in section 5.2 to be very $\mathrm{pH}$ dependent, consistent with the apparent trends in Figure 11. At higher organic matter loadings, the concentration of SR-NOM may have increased in the aqueous phase, promoting SR-NOM-Ni solution complexation. Consistent with this explanation is that the maximum $\mathrm{K}_{\mathrm{d}}$ in the sandy sediment is at $10 \mathrm{mg} / \mathrm{L} \mathrm{C}$, whereas in the clayey sediment, which contains a greater number of $\mathrm{Ni}$ and SR-NOM sorption sites, the maximum $\mathrm{K}_{\mathrm{d}}$ is much greater and occurs at $20 \mathrm{mg} / \mathrm{L} \mathrm{C} \mathrm{(Figure} \mathrm{11).} \mathrm{Importantly,} \mathrm{not} \mathrm{all} \mathrm{SR-NOM} \mathrm{additions}$ 
decreased $\mathrm{K}_{\mathrm{d}}$ values. Such decreases in $\mathrm{K}_{\mathrm{d}}$ values were observed only at higher SR-NOM concentrations. Also, these decreases were observed only in the high $\mathrm{pH}$ system. The low $\mathrm{pH}$ systems showed no apparent correlation between $\mathrm{K}_{\mathrm{d}}$ and SR-NOM concentrations.

Ni Sorption to the Clayey Sediment as a Function of $\mathrm{pH}$ and SR-NOM Concentrations

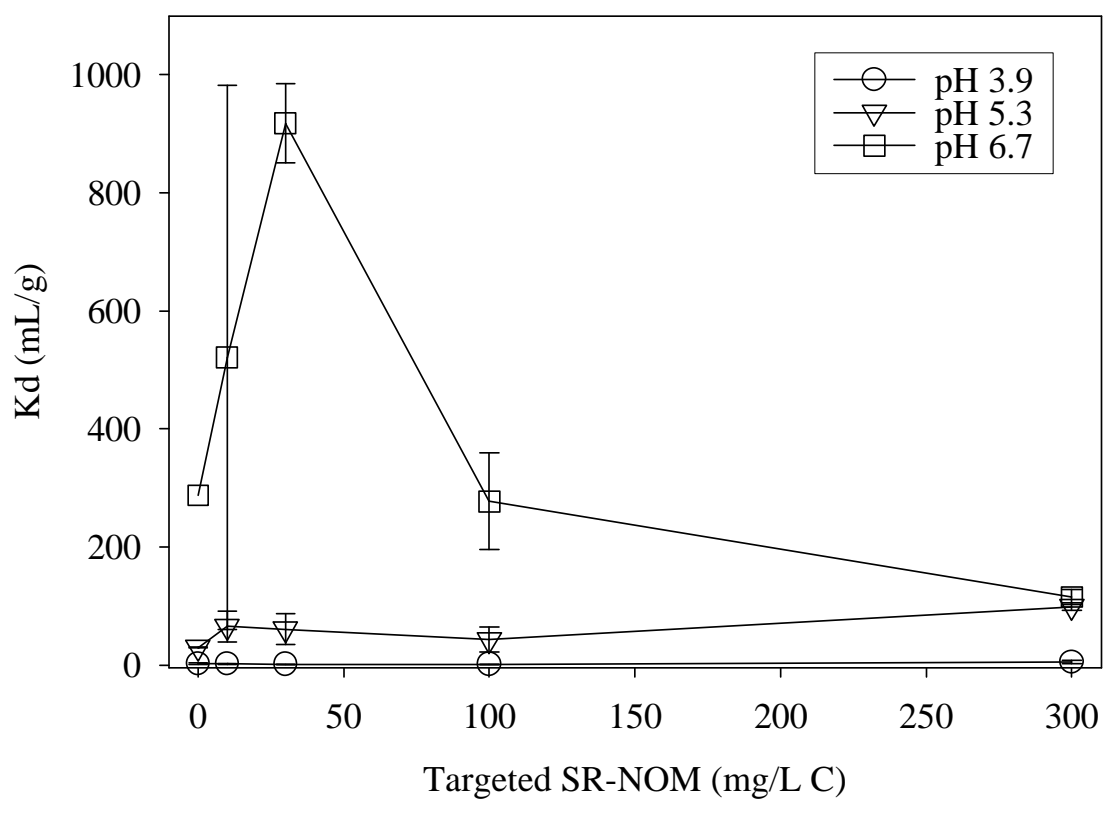

Ni Sorption to the Sandy Sediment as a Function of $\mathrm{pH}$ and SR-NOM Concentrations

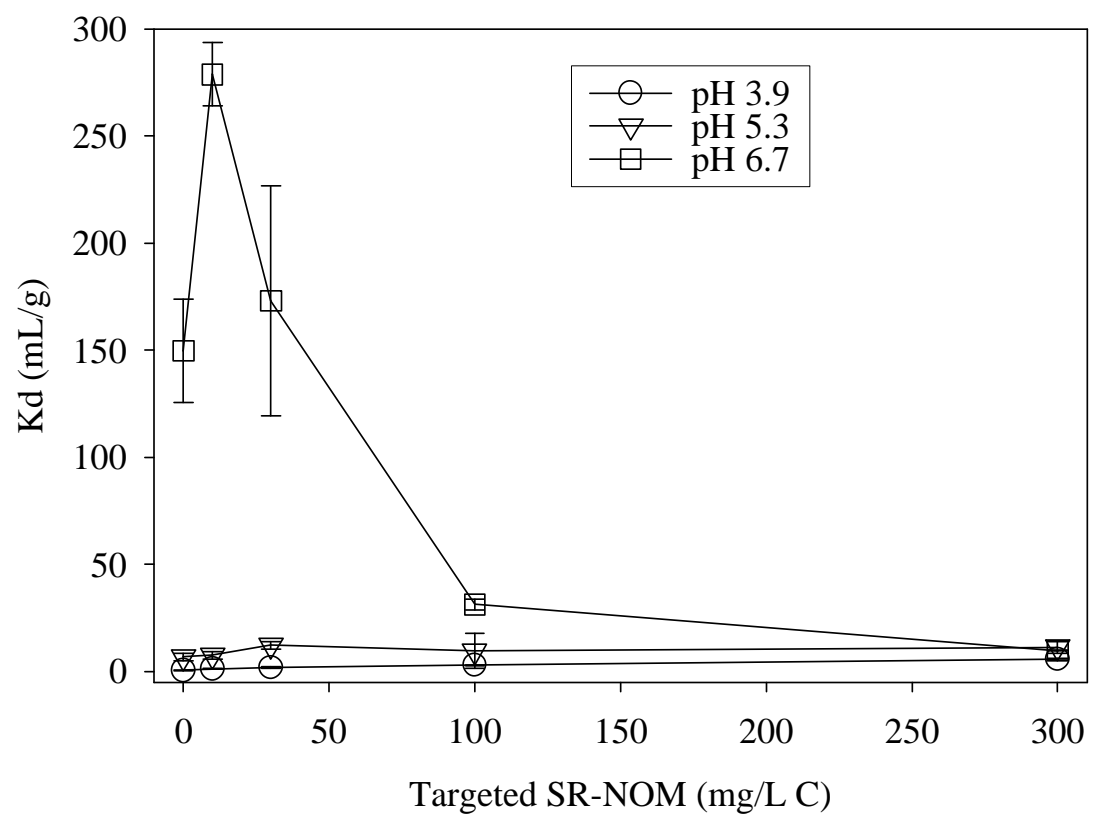

Figure 11. $\mathrm{Ni} \mathrm{K}_{\mathrm{d}}$ values as a function of $\mathrm{pH}$ and SR-NOM concentrations in clayey (top) and sandy (bottom) sediments. 
WSRC-RP-2004-00593

Table 6. $\mathrm{Ni} \mathrm{K}_{\mathrm{d}}$ values $(\mathrm{mL} / \mathrm{g})$.

\begin{tabular}{|c|c|c|c|c|c|c|c|c|c|c|c|c|}
\hline \multirow{3}{*}{$\begin{array}{c}\text { Target } \\
\text { SR-NOM } \\
(\mathrm{mg} / \mathrm{L} \mathrm{C})\end{array}$} & \multicolumn{6}{|c|}{ Clayey Sediment } & \multicolumn{6}{|c|}{ Sandy Sediment } \\
\hline & \multicolumn{2}{|c|}{ pH 3.9} & \multicolumn{2}{|c|}{$\mathrm{pH} 5.3$} & \multicolumn{2}{|c|}{ pH 6.7} & \multicolumn{2}{|c|}{ pH 3.9} & \multicolumn{2}{|c|}{ pH 5.3} & \multicolumn{2}{|c|}{$\mathrm{pH} 6.7$} \\
\hline & Avg. & Stdev. & Avg. & Stdev. & Avg. & Stdev. & Avg. & Stdev. & Avg. & Stdev. & Avg. & Stdev. \\
\hline 0 & 2.3 & 0.8 & 29.5 & 0.8 & 287.3 & 0.0 & 0.6 & 0.3 & 6.8 & 1.6 & 149.8 & 24.2 \\
\hline 10 & 1.8 & 0.5 & 65.3 & 25.9 & 521.0 & 460.3 & 1.3 & 0.3 & 7.7 & 1.8 & 278.8 & 14.8 \\
\hline 30 & 1.1 & 0.0 & 60.8 & 25.9 & 917.7 & 66.5 & 1.8 & 0.4 & 12.4 & 1.7 & 173.1 & 53.6 \\
\hline 100 & 1.6 & 0.0 & 43.0 & 21.0 & 277.0 & 81.9 & 2.9 & 0.1 & 9.6 & 8.1 & 31.4 & 2.5 \\
\hline 300 & 5.1 & 2.9 & 98.7 & 5.9 & 115.3 & 12.2 & 5.8 & 0.3 & 11.4 & 2.8 & 9.8 & 0.2 \\
\hline Avg. & 2.4 & & 59.4 & & 423.7 & & 2.5 & & 9.6 & & 128.6 & \\
\hline Stdev. & 1.6 & & 26.2 & & 311.8 & & 2.0 & & 2.4 & & 110.2 & \\
\hline
\end{tabular}


Strontium $\mathrm{K}_{\mathrm{d}}$ values in the clayey sediment exhibited no discernable trends with respect to SRNOM concentrations (Figure 12 and Table 7), i.e., there were no significant differences in the means of $\mathrm{Sr} \mathrm{K}_{\mathrm{d}}$ values based on Dunnett's test for comparing means to a control $(p \leq 0.05, \mathrm{n}=8)$. However, two conclusions can be made from this data.

- As $\mathrm{pH}$ increased, $\mathrm{Sr} \mathrm{K}_{\mathrm{d}}$ values increased.

- The clayey sediment sorbed more $\mathrm{Sr}$ than the sandy sediment.

Sr $\mathrm{K}_{\mathrm{d}}$ values in the sandy sediment (Figure 12 and Table 7) followed similar trends as those observed for $\mathrm{Ni}_{\mathrm{d}}$ values in the sandy sediment (Figure 11 and Table 6). These trends in the sandy sediment are listed below.

- $\mathrm{Sr} \mathrm{K}_{\mathrm{d}}$ values increased as $\mathrm{pH}$ of the system increased.

- There was an interactive effect of $\mathrm{pH}$ and SR-NOM concentration on $\mathrm{Sr} \mathrm{K}_{\mathrm{d}}$ values.

- At pH 3.9, little Sr was sorbed, irrespective of SR-NOM concentrations.

- At $\mathrm{pH}$ 5.3, $\mathrm{Sr} \mathrm{K}_{\mathrm{d}}$ values increased with SR-NOM concentrations.

- At pH 6.7, there was a maximum $\mathrm{Sr} \mathrm{K}_{\mathrm{d}}$ value obtained at $10 \mathrm{mg} / \mathrm{L}$ C SR-NOM, followed by a systematic decrease in $\mathrm{Sr} \mathrm{K}_{\mathrm{d}}$ values as the SR-NOM concentrations increased. The $\mathrm{Sr} \mathrm{K}_{\mathrm{d}}$ value for the highest SR-NOM concentration, $300 \mathrm{mg} / \mathrm{L} \mathrm{C}$, were less than that measured in the 0 $\mathrm{mg} / \mathrm{L}$ C SR-NOM treatment. 
Sr Sorption to the Clayey Sediment as a Function of $\mathrm{pH}$ and SR-NOM Concentrations

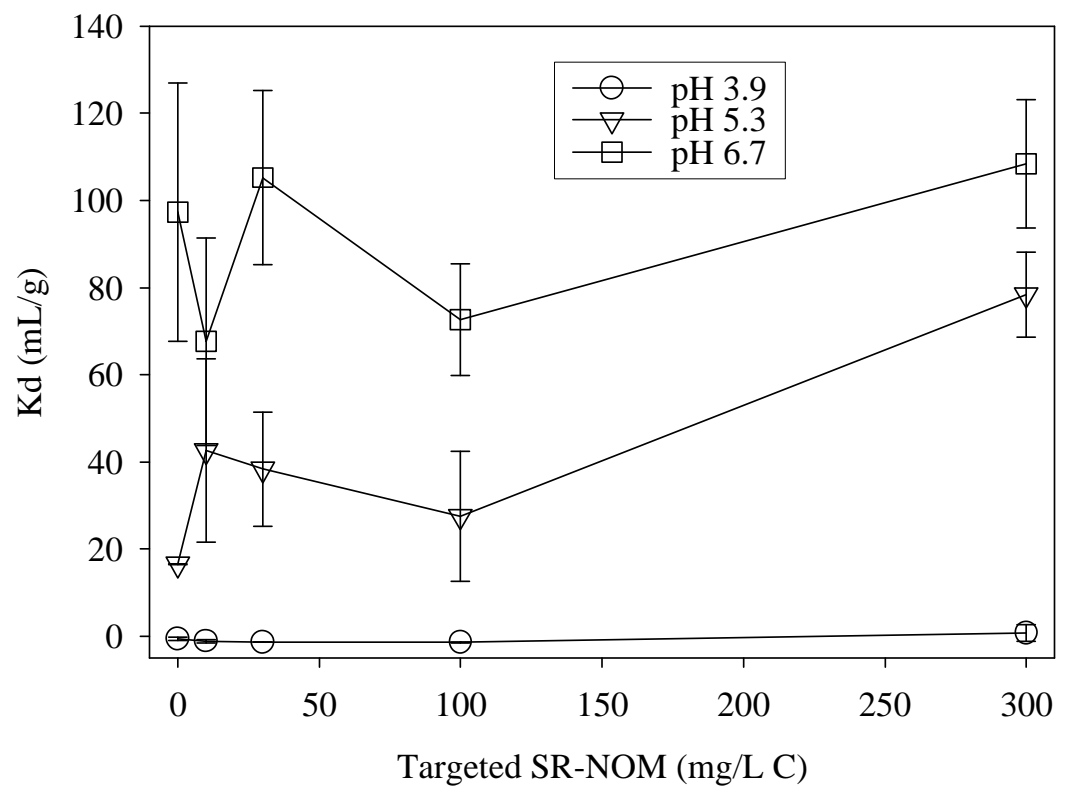

Sr Sorption to the Sandy Sediment as a Function of $\mathrm{pH}$ and SR-NOM Concentrations

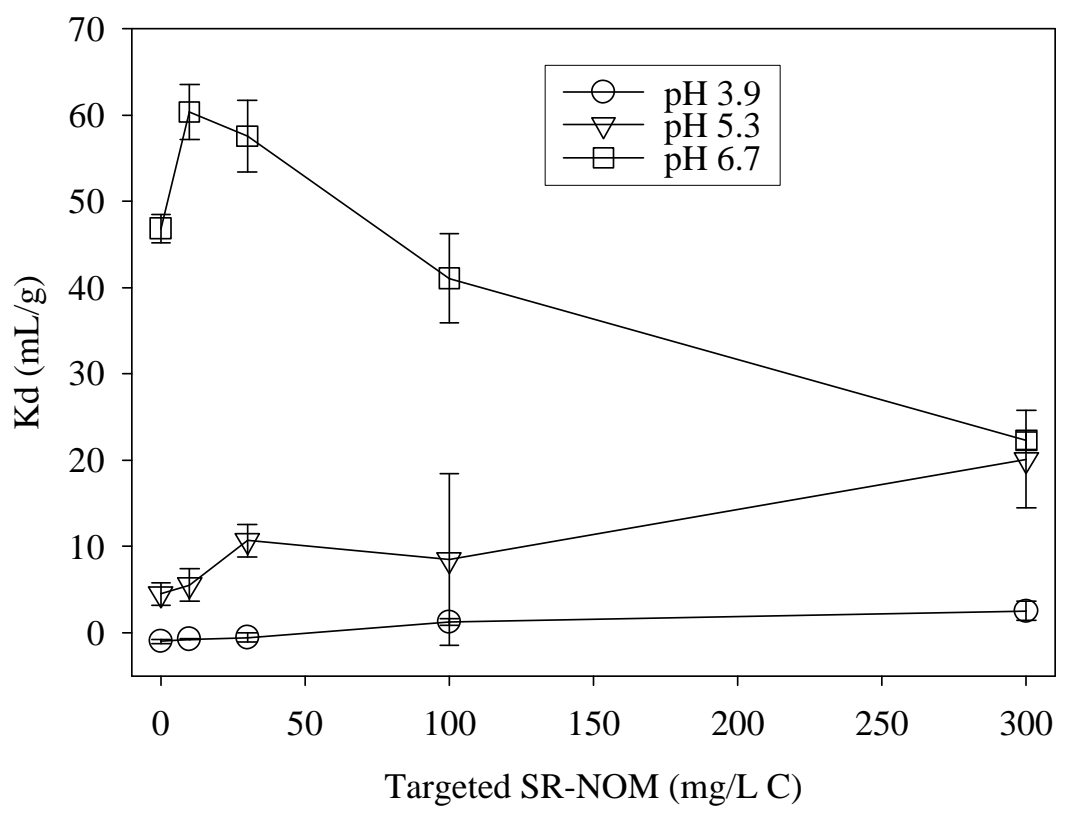

Figure 12. $\mathrm{Sr} \mathrm{K}_{\mathrm{d}}$ values as a function of $\mathrm{pH}$ and $\mathrm{SR}-\mathrm{NOM}$ concentrations in clayey (top) and sandy (bottom) sediments. 
Table 7. $\mathrm{Sr} \mathrm{K}$ d values (mL/g).

\begin{tabular}{|c|c|c|c|c|c|c|c|c|c|c|c|c|}
\hline \multirow{3}{*}{$\begin{array}{c}\text { Target SR- } \\
\text { NOM } \\
(\mathrm{mg} / \mathrm{L} \mathrm{C})\end{array}$} & \multicolumn{6}{|c|}{ Clayey Sediment } & \multicolumn{6}{|c|}{ Sandy Sediment } \\
\hline & \multicolumn{2}{|c|}{$\mathrm{pH} 3.9$} & \multicolumn{2}{|c|}{ pH 5.3} & \multicolumn{2}{|c|}{$\mathrm{pH} 6.7$} & \multicolumn{2}{|c|}{ pH 3.9} & \multicolumn{2}{|c|}{$\mathrm{pH} 5.3$} & \multicolumn{2}{|c|}{$\mathrm{pH} 6.7$} \\
\hline & Avg. & Stdev. & Avg. & Stdev. & Avg. & Stdev. & Avg. & Stdev. & Avg. & Stdev. & Avg. & Stdev. \\
\hline 0 & $-0.6^{(a)}$ & 0.4 & 16.6 & 0.0 & 97.4 & 29.6 & -1.0 & 0.3 & 4.5 & 1.3 & 46.9 & 1.7 \\
\hline 10 & -1.1 & 0.4 & 42.6 & 21.1 & 67.7 & 23.8 & -0.8 & 0.0 & 5.5 & 1.9 & 60.4 & 3.2 \\
\hline 30 & -1.3 & 0.0 & 38.3 & 13.1 & 105.3 & 20.0 & -0.6 & 0.5 & 10.7 & 1.9 & 57.6 & 4.2 \\
\hline 100 & -1.4 & 0.1 & 27.5 & 14.9 & 72.7 & 12.8 & 1.2 & 0.4 & 8.5 & 10.0 & 41.1 & 5.2 \\
\hline 300 & 0.7 & 1.9 & 78.4 & 9.7 & 108.4 & 14.8 & 2.5 & 1.1 & 20.1 & 5.7 & 22.3 & 1.0 \\
\hline Avg & -0.7 & & 40.7 & & 90.3 & & 0.3 & & 9.8 & & 45.6 & \\
\hline Stdev & 0.9 & & 23.4 & & 18.9 & & 1.5 & & 6.2 & & 15.2 & \\
\hline
\end{tabular}

${ }^{\text {(a) }}$ Negative $K_{d}$ values can be attributed to analytical error. 
WSRC-RP-2004-00593

\subsubsection{Trivalent Cation Sorption}

Trivalent cation radionuclides of interest to the LLW-PA are $\mathrm{Ac}^{3+}, \mathrm{Am}^{3+}, \mathrm{Cf}^{3+}, \mathrm{Cm}^{3+}$, and $\mathrm{Nb}^{3+}$ (Table 1). Two trivalent cations were included in this study as analogues for these radionuclides, $\mathrm{Ce}^{3+}$ and $\mathrm{Eu}^{3+}$. Cerium and Eu are both lanthanides, and as such would be expected to interact with ligands and sediment in a similar manner to each other. So they do not represent a wide range of geochemical behaviors of trivalent cations.

Cerium (Figure 13 and Table 8) and europium (Figure 14 and Table 9) $\mathrm{K}_{\mathrm{d}}$ values followed nearly identical trends with $\mathrm{pH}$, sediment type, and SR-NOM concentrations. Furthermore these trends were similar to those of Ni (Figure 11) and Sr (Figure 12; sandy sediment only).

- $\mathrm{Ce}$ and $\mathrm{Eu} \mathrm{K} \mathrm{K}_{\mathrm{d}}$ values were higher in the clayey sediment than in the sandy sediment.

- $\mathrm{Ce}$ and $\mathrm{Eu} \mathrm{K}_{\mathrm{d}}$ values increased with increasing $\mathrm{pH}$.

- There was a pH and SR-NOM concentration interactive effect on Ce and Eu $\mathrm{K}_{\mathrm{d}}$ values. As $\mathrm{pH}$ increased, there was a greater SR-NOM effect on Ce and Eu $\mathrm{K}_{\mathrm{d}}$ values, especially true in the sandy sediment. At $\mathrm{pH} 3.9$, SR-NOM concentration did not have an effect on Ce $\mathrm{K}_{\mathrm{d}}$ values.

- $\mathrm{Ce}$ and $\mathrm{Eu} \mathrm{K}_{\mathrm{d}}$ values had a strong dependence on SR-NOM concentrations. Small additions of SR-NOM to the system, $10 \mathrm{mg} / \mathrm{L} \mathrm{C}$, caused the $\mathrm{K}_{\mathrm{d}}$ values to increase sharply compared to when no SR-NOM was in the system. Additions of greater concentrations of SR-NOM caused incrementally larger decreases in $\mathrm{K}_{\mathrm{d}}$ values. At SR-NOM additions $\bullet 100 \mathrm{mg} / \mathrm{L} \mathrm{C}$, the $\mathrm{K}_{\mathrm{d}}$ values decreased below those for when no SR-NOM was in the system. Very similar trends were reported for Eu $\mathrm{K}_{\mathrm{d}}$ by Serkiz (2000).

Not surprisingly, Ce and Eu $\mathrm{K}_{\mathrm{d}}$ values were very large. What was surprising was just how sensitive the values were to $\mathrm{pH}$ and SR-NOM concentrations. For example, at $0 \mathrm{mg} / \mathrm{L}$ SR-NOM, the Ce $\mathrm{K}_{\mathrm{d}}$ values in the clayey sediment increased from 36 to $19,000 \mathrm{~mL} / \mathrm{g}$ as the $\mathrm{pH}$ increased from 3.9 to 6.7. Similarly, at pH 6.7, Ce $\mathrm{K}_{\mathrm{d}}$ values in the clayey sediment varied from 105 to $>29963 \mathrm{~mL} / \mathrm{g}$ with change in SR-NOM concentrations. 
Ce Sorption to the Sandy Sediment as a Function of $\mathrm{pH}$ and SR-NOM Concentrations

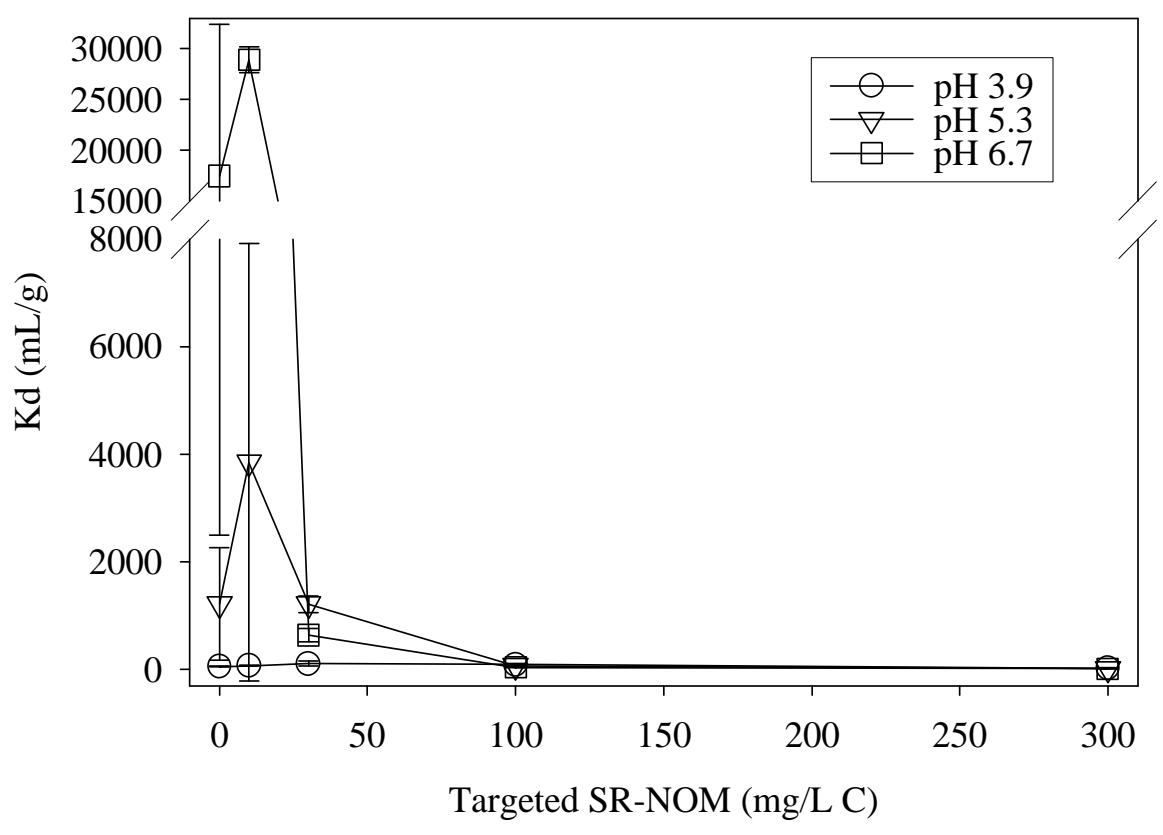

Ce Sorption to the Sandy Sediment as a Function of $\mathrm{pH}$ and SR-NOM Concentrations

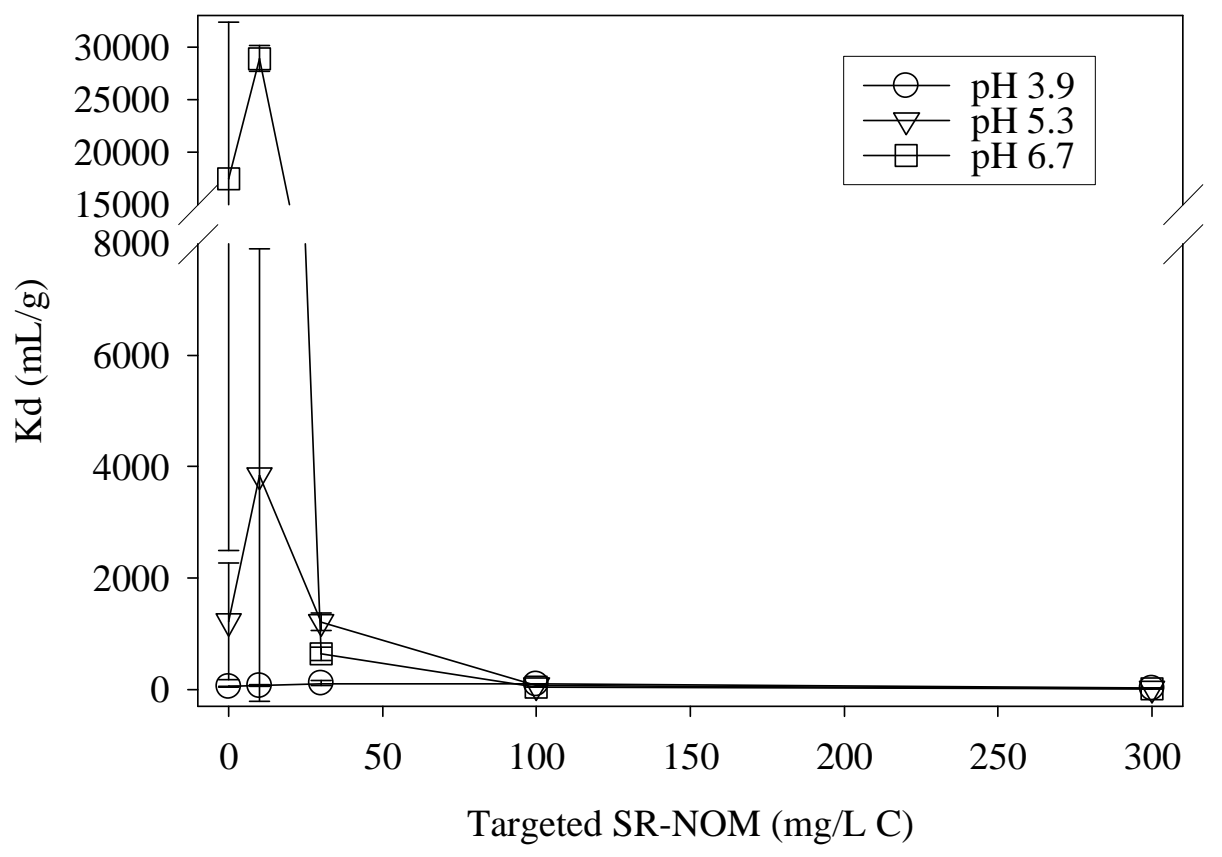

Figure 13. Ce $\mathrm{K}_{\mathrm{d}}$ values as a function of $\mathrm{pH}$ and SR-NOM concentrations in clayey (top) and sandy (bottom) sediments (all $\mathrm{K}_{\mathrm{d}}$ values $>25,000 \mathrm{~mL} / \mathrm{g}$ are greater-than values). 
Table 8. Ce $\mathrm{K}_{\mathrm{d}}$ values $(\mathrm{mL} / \mathrm{g})$.

\begin{tabular}{|c|c|c|c|c|c|c|c|c|c|c|c|c|}
\hline \multirow{3}{*}{$\begin{array}{c}\text { Target } \\
\text { SR-NOM } \\
(\mathrm{mg} / \mathrm{L} \mathrm{C})\end{array}$} & \multicolumn{6}{|c|}{ Clayey Sediment } & \multicolumn{6}{|c|}{ Sandy Sediment } \\
\hline & \multicolumn{2}{|c|}{$\mathrm{pH} 3.9$} & \multicolumn{2}{|c|}{$\mathrm{pH} 5.3$} & \multicolumn{2}{|c|}{ pH 6.7} & \multicolumn{2}{|c|}{$\mathrm{pH} 3.9$} & \multicolumn{2}{|c|}{$\mathrm{pH} 5.3$} & \multicolumn{2}{|c|}{ pH 6.7} \\
\hline & Avg. & Stdev. & Avg. & Stdev. & Avg. & Stdev. & Avg. & Stdev. & Avg. & Stdev. & Avg. & Stdev. \\
\hline 0 & 36 & 8 & 8687 & 4980 & 19343 & 9316 & 49 & 7 & 1220 & 1042 & 17450 & 14961 \\
\hline 10 & 26 & 1 & $>28020$ & 12 & $>29963$ & 1934 & 68 & 12 & 3845 & 4067 & $>28918$ & 1257 \\
\hline 30 & 33 & 4 & $>22913$ & 7242 & $>27481$ & 1985 & 107 & 45 & 1210 & 157 & 638 & 122 \\
\hline 100 & 40 & 4 & 4960 & 1690 & 7822 & 1694 & 92 & 9 & 69 & 22 & 37 & 3 \\
\hline 300 & 71 & 27 & 361 & 180 & 105 & 14 & 21 & 4 & 14 & 3 & 10 & 0 \\
\hline Avg & 41 & & 12988 & & 16943 & & 67 & & 1272 & & 9411 & \\
\hline Stdev & 18 & & 11904 & & 12777 & & 34 & & 1554 & & 13213 & \\
\hline
\end{tabular}


Eu Sorption to the Clayey Sediment as a Function of $\mathrm{pH}$ and SR-NOM Concentrations

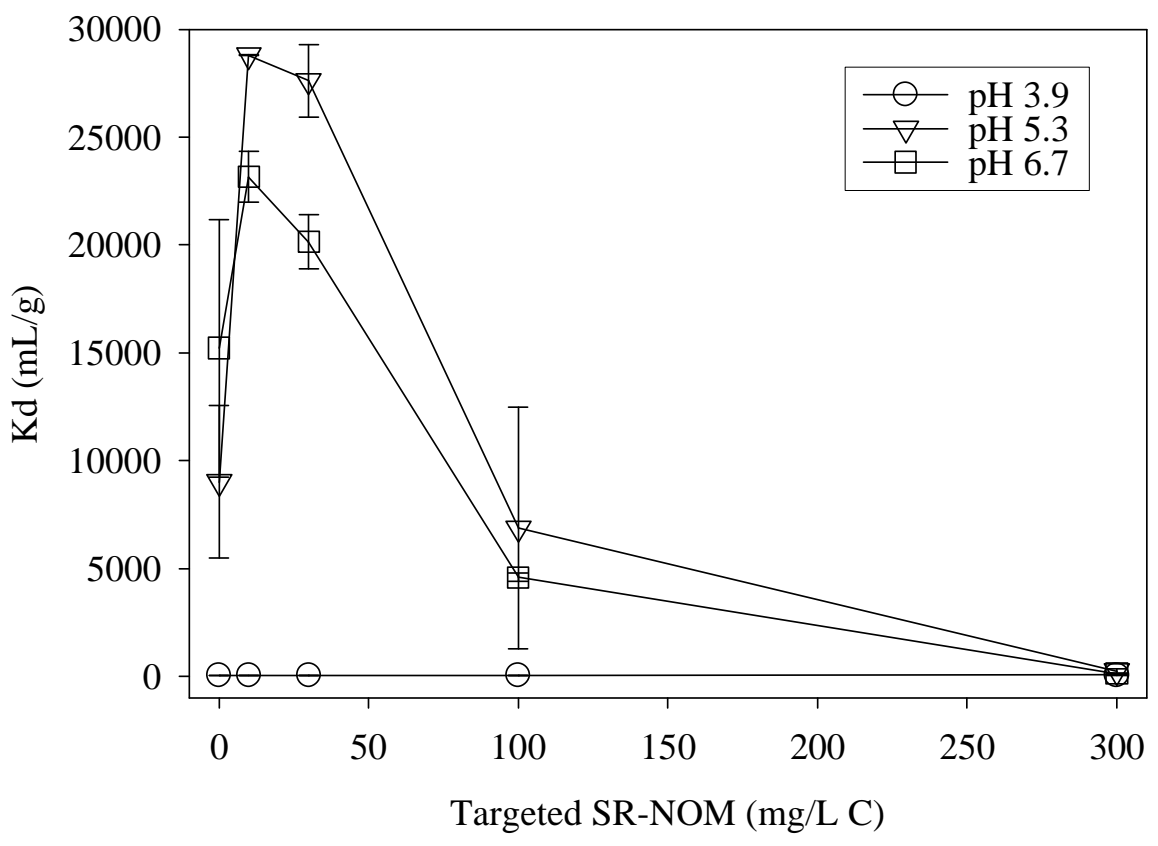

Eu Sorption to the Sandy Sediment as a Function of $\mathrm{pH}$ and SR-NOM Concentrations

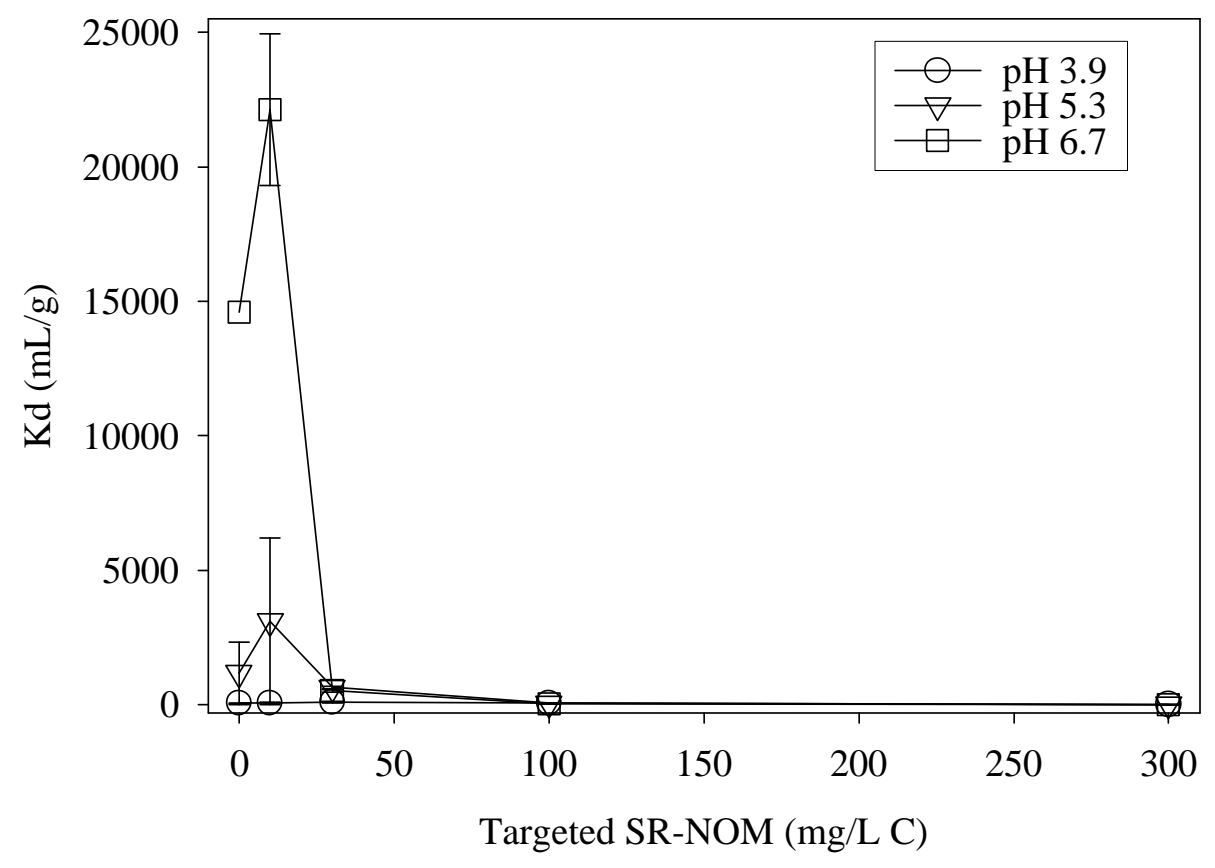

Figure 14. Eu $\mathrm{K}_{\mathrm{d}}$ values as a function of $\mathrm{pH}$ and SR-NOM concentrations in clayey (top) and sandy (bottom) sediments (all $\mathrm{K}_{\mathrm{d}}$ values $>20,000 \mathrm{~mL} / \mathrm{g}$ are greater-than values). 
Table 9. Eu $\mathrm{K}_{\mathrm{d}}$ values $(\mathrm{mL} / \mathrm{g})$.

\begin{tabular}{|c|c|c|c|c|c|c|c|c|c|c|c|c|}
\hline \multirow{3}{*}{$\begin{array}{c}\text { Target } \\
\text { SR-NOM } \\
(\mathrm{mg} / \mathrm{L} \mathrm{C})\end{array}$} & \multicolumn{6}{|c|}{ Clayey Sediment } & \multicolumn{6}{|c|}{ Sandy Sediment } \\
\hline & \multicolumn{2}{|c|}{$\mathrm{pH} 3.9$} & \multicolumn{2}{|c|}{$\mathrm{pH} 5.3$} & \multicolumn{2}{|c|}{ pH 6.7} & \multicolumn{2}{|c|}{ pH 3.9} & \multicolumn{2}{|c|}{$\mathrm{pH} 5.3$} & \multicolumn{2}{|c|}{ pH 6.7} \\
\hline & Avg. & Stdev. & Avg. & Stdev. & Avg. & Stdev. & Avg. & Stdev. & Avg. & Stdev. & Avg. & Stdev. \\
\hline 0 & 45 & 8 & 9020 & 3526 & 15218 & 5967 & 47 & 7 & 1168 & 1159 & 14602 & 20072 \\
\hline 10 & 37 & 0 & 28787 & 12 & 23159 & 1194 & 65 & 11 & 3096 & 3094 & 22121 & 2812 \\
\hline 30 & 40 & 4 & 27609 & 1686 & 20135 & 1252 & 97 & 38 & 641 & 52 & 516 & 53 \\
\hline 100 & 47 & 4 & 6882 & 5606 & 4583 & 192 & 59 & 4 & 49 & 5 & 33 & 3 \\
\hline 300 & 67 & 22 & 252 & 92 & 127 & 2 & 15 & 0 & 11 & 2 & 10 & 0 \\
\hline Avg & 47.1 & & 14510.0 & & 12644.4 & & 56.5 & & 993.4 & & 7456.5 & \\
\hline Stdev & 11.6 & & 12913.3 & & 9936.8 & & 29.6 & & 1268.1 & & 10305.9 & \\
\hline
\end{tabular}




\subsubsection{Tetravalent Cation Sorption}

Tetravalent cation radionuclides of interest to the LLW-PA are $\mathrm{Pa}^{4+}, \mathrm{Pu}^{4+}, \mathrm{Th}^{4+}$, and $\mathrm{Zr}^{4+}($ Table 1). There were two tetravalent cations included in this study, $\mathrm{Th}^{4+}$, and $\mathrm{Zr}^{4+}$. Thorium is expected to be a good chemical analogue for $\mathrm{Pa}^{4+}$ and $\mathrm{Pu}^{4+}$, because all three elements are actinides. Plutonium exists in four oxidation states, $+3,+4,+5$, and +6 , of which +4 and +5 are the most common in the SRS environment (Kaplan and Wilhite 2001). It is important to note that $\mathrm{Th}^{4+}$ is expected to be a reasonable analogue for only $\mathrm{Pu}^{4+}$ and not for $\mathrm{Pu}$ when it exists in the other oxidation states.

With the type of sorption tests conducted for this study, it is impossible to discern the sorption mechanism, i.e., it is impossible to differentiate between chemosorption, adsorption, and precipitation. However, it is readily apparent based on the no-sediment control data presented in section 5.3.2 that precipitation of the tetravalent cations occurred during this study, especially of Th. Consequently, much of the reported sorption can be attributed to the homogeneous (aqueous phase only system) precipitation. Zirconium $\mathrm{K}_{\mathrm{d}}$ values followed similar trends as discussed for $\mathrm{Ni}, \mathrm{Sr}$ (sandy sediment only), Ce, and Eu $\mathrm{K}_{\mathrm{d}}$ values (Figure 15 and Table 10). These trends are discussed in Section 5.3.5. However, there are two $\mathrm{K}_{\mathrm{d}}$ values with extremely large error bars, perhaps outliers, in the sandy sediment data set, that do not follow the expected trends.

Thorium $\mathrm{K}_{\mathrm{d}}$ values followed expected trends (Table 11 and Figure 16). Two slight differences in these trends are:

- Th $\mathrm{K}_{\mathrm{d}}$ values in the clayey sediment and in the presence of SR-NOM never decreased below those values measured in system that did not receive any SR-NOM.

- $\mathrm{pH}$ did not have a strong impact on $\mathrm{Th}_{\mathrm{d}}$ values, especially in the sandy sediment. 
Zr Sorption to the Clayey Sediment as a Function of $\mathrm{pH}$ and SR-NOM Concentrations

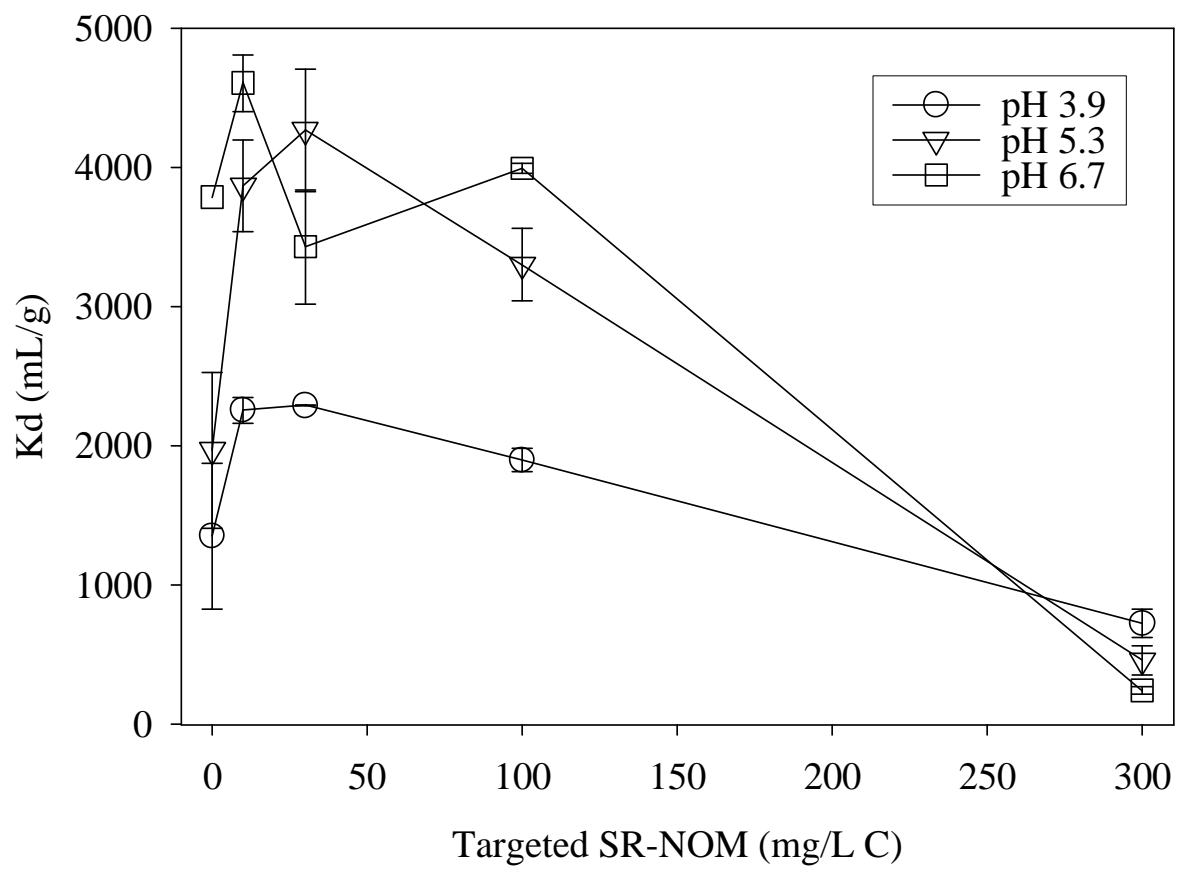

Zr Sorption to the Sandy Sediment as a Function of $\mathrm{pH}$ and SR-NOM Concentrations

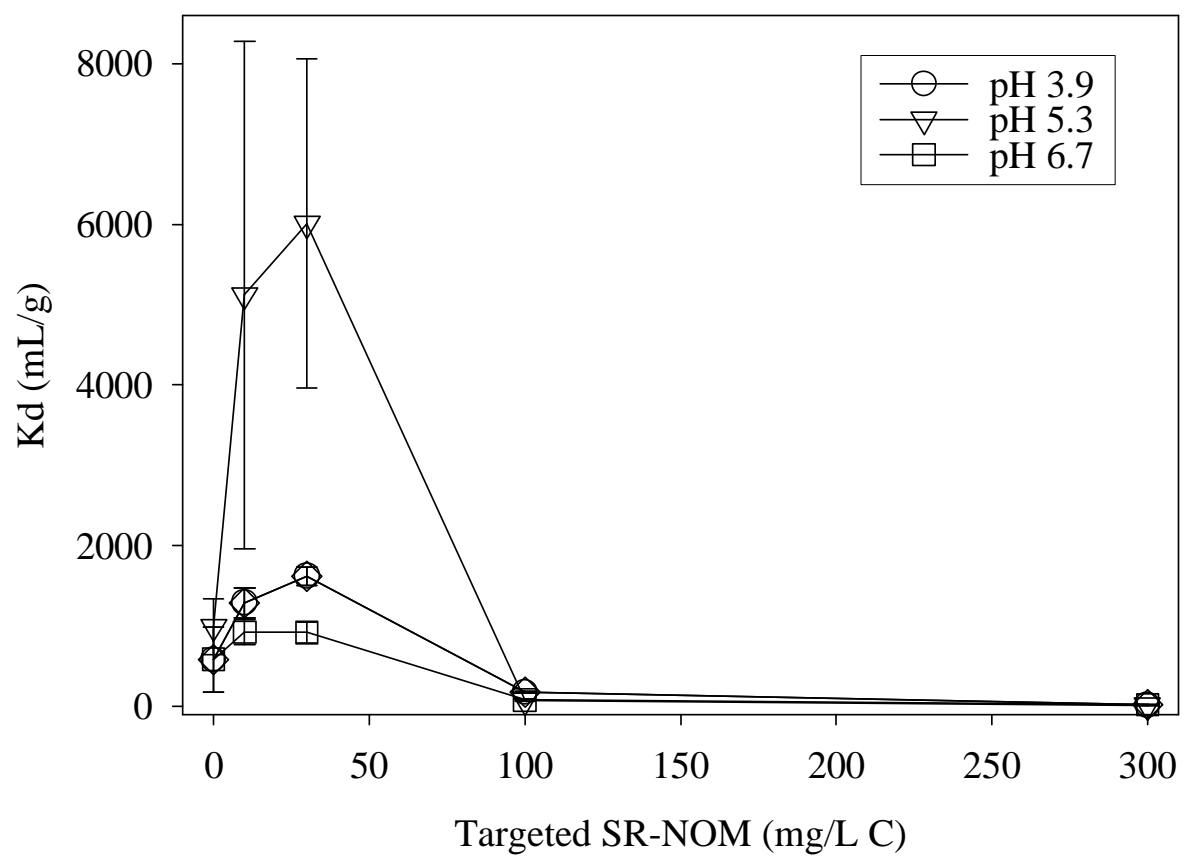

Figure 15. $\mathrm{Zr} \mathrm{K} \mathrm{K}_{\mathrm{d}}$ values as a function of $\mathrm{pH}$ and SR-NOM concentrations in clayey (top) and sandy (bottom) sediments. 
Table 10. $\mathrm{Zr} \mathrm{K} \mathrm{K}_{\mathrm{d}}$ values $(\mathrm{mL} / \mathrm{g})$.

\begin{tabular}{|c|c|c|c|c|c|c|c|c|c|c|c|c|}
\hline \multirow{3}{*}{$\begin{array}{c}\text { Target } \\
\text { SR-NOM } \\
(\mathrm{mg} / \mathrm{L} \mathrm{C})\end{array}$} & \multicolumn{6}{|c|}{ Clayey Sediment } & \multicolumn{6}{|c|}{ Sandy Sediment } \\
\hline & \multicolumn{2}{|c|}{ pH 3.9} & \multicolumn{2}{|c|}{$\mathrm{pH} 5.3$} & \multicolumn{2}{|c|}{$\mathrm{pH} 6.7$} & \multicolumn{2}{|c|}{$\mathrm{pH} 3.9$} & \multicolumn{2}{|c|}{$\mathrm{pH} 5.3$} & \multicolumn{2}{|c|}{$\mathrm{pH} 6.7$} \\
\hline & Avg. & Stdev. & Avg. & Stdev. & Avg. & Stdev. & Avg. & Stdev. & Avg. & Stdev. & Avg. & Stdev. \\
\hline 0 & 1351 & 526 & 1969 & 561 & 3787 & 0 & 580 & 406 & 991 & 352 & 585 & 0 \\
\hline 10 & 2256 & 92 & 3867 & 329 & 4607 & 2040 & 1290 & 187 & 5122 & 3161 & 922 & 155 \\
\hline 30 & 2290 & 5 & 4267 & 439 & 3429 & 409 & 1620 & 113 & 6011 & 2051 & 919 & 133 \\
\hline 100 & 1899 & 83 & 3302 & 262 & 3993 & 36 & 174 & 10 & 75 & 18 & 79 & 8 \\
\hline 300 & 724 & 101 & 459 & 106 & 243 & 26 & 16 & 6 & 13 & 2 & 20 & 3 \\
\hline Avg. & 1704 & & 2773 & & 3212 & & 736 & & 2442 & & 505 & \\
\hline Stdev. & 665 & & 1558 & & 1714 & & 698 & & 2895 & & 438 & \\
\hline
\end{tabular}


Th Sorption to the Clayey Sediment as a Function of $\mathrm{pH}$ and SR-NOM Concentrations

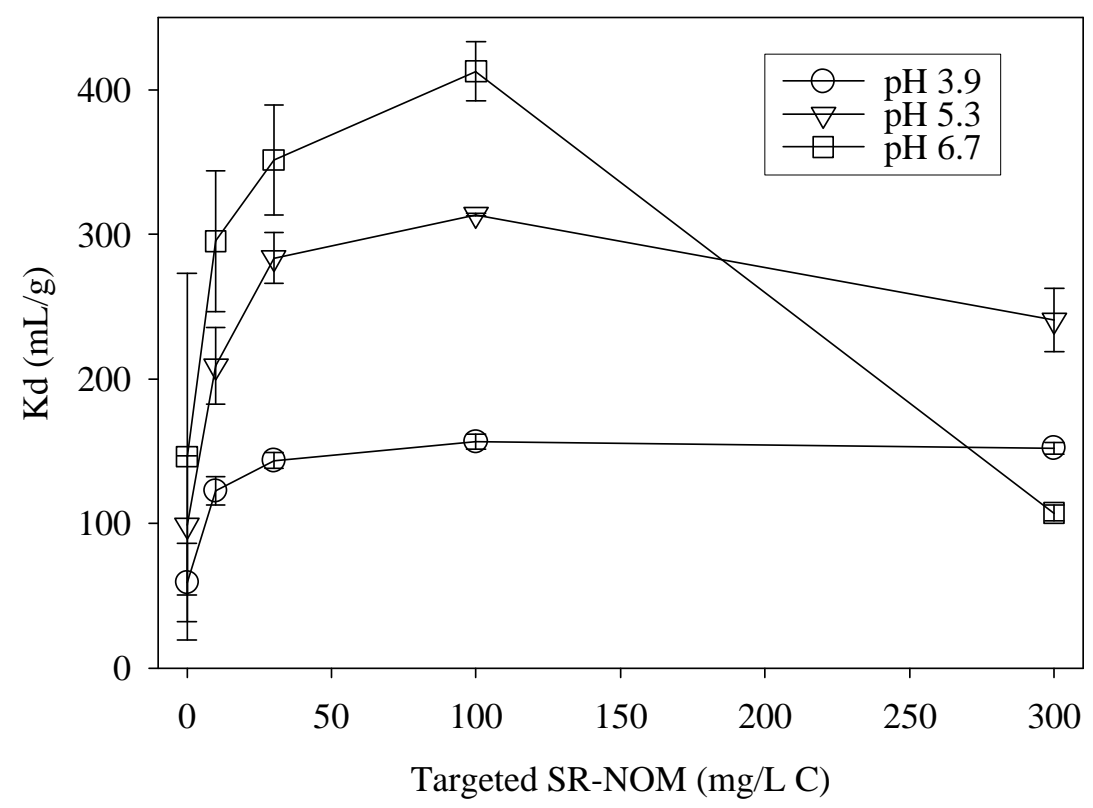

Th Sorption to the Sandy Sediment as a Function of $\mathrm{pH}$ and SR-NOM Concentrations

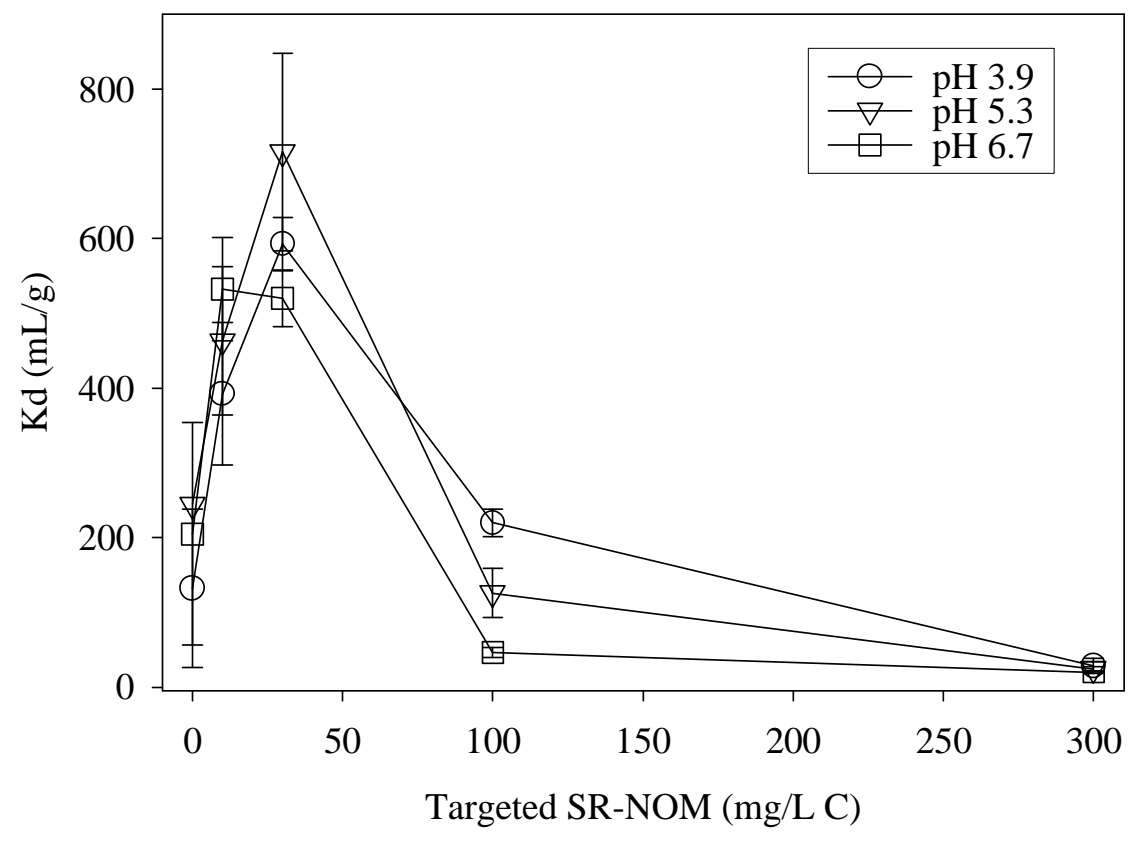

Figure 16. Th $\mathrm{K}_{\mathrm{d}}$ values as a function of $\mathrm{pH}$ and SR-NOM concentrations in clayey (top) and sandy (bottom) sediments. 
Table 11. Th $\mathrm{K}_{\mathrm{d}}$ values $(\mathrm{mL} / \mathrm{g})$.

\begin{tabular}{|c|c|c|c|c|c|c|c|c|c|c|c|c|}
\hline \multirow{3}{*}{$\begin{array}{c}\text { Target } \\
\text { SR-NOM } \\
(\mathrm{mg} / \mathrm{L} \mathrm{C})\end{array}$} & \multicolumn{6}{|c|}{ Clayey Sediment } & \multicolumn{6}{|c|}{ Sandy Sediment } \\
\hline & \multicolumn{2}{|c|}{ pH 3.9} & \multicolumn{2}{|c|}{$\mathrm{pH} 5.3$} & \multicolumn{2}{|c|}{$\mathrm{pH} 6.7$} & \multicolumn{2}{|c|}{$\mathrm{pH} 3.9$} & \multicolumn{2}{|c|}{$\mathrm{pH} 5.3$} & \multicolumn{2}{|c|}{$\mathrm{pH} 6.7$} \\
\hline & Avg. & Stdev. & Avg. & Stdev. & Avg. & Stdev. & Avg. & Stdev. & Avg. & Stdev. & Avg. & Stdev. \\
\hline 0 & 59 & 27 & 99 & 48 & 146 & 127 & 132 & 106 & 245 & 0 & 205 & 149 \\
\hline 10 & 122 & 10 & 209 & 27 & 295 & 49 & 392 & 95 & 463 & 99 & 532 & 69 \\
\hline 30 & 144 & 5 & 284 & 17 & 351 & 38 & 593 & 36 & 716 & 132 & 520 & 38 \\
\hline 100 & 157 & 5 & 314 & 1 & 413 & 21 & 220 & 19 & 126 & 33 & 47 & 7 \\
\hline 300 & 152 & 4 & 241 & 22 & 107 & 6 & 29 & 10 & 24 & 3 & 20 & 2 \\
\hline Avg & 127 & & 229 & & 263 & & 273 & & 315 & & 265 & \\
\hline Stdev & 40 & & 83 & & 132 & & 223 & & 277 & & 249 & \\
\hline
\end{tabular}


WSRC-RP-2004-00593

\subsection{CONCLUSIONS}

\subsection{Recommended Conservative CDP-Impacted $K_{d}$ Values}

The approach used to estimate Recommended Conservative (with respect to the Groundwater pathway; low values) CDP-Impacted $\mathrm{K}_{\mathrm{d}}$ Values is as follows.

1. A $K_{d}$ vs. CDP concentration table was created based on the sandy sediment sorption data. The data from the sandy sediment was selected instead of those from the clayey sediment because the latter were typically 2 to 3 times more than the former. The $\mathrm{pH} 5.3 \mathrm{~K}_{\mathrm{d}}$ data was selected as the basis for the look-up table for the $0,10,20$, and $100 \mathrm{mg} / \mathrm{L} \mathrm{C} \mathrm{K}_{\mathrm{d}}$ values because this $\mathrm{pH}$ is closest to the anticipated background $\mathrm{pH}$ value at the E-Area subsurface environment, pH 5.5 (Kaplan 2004). pH $3.9 \mathrm{~K}_{\mathrm{d}}$ data were used for the $222 \mathrm{mg} / \mathrm{L}$ C condition because elevated DOC levels commonly cause sediment $\mathrm{pH}$ to decrease. For example Serkiz (2000) used the same sandy sediment employed in this study and observed that at $1 \mathrm{mg} / \mathrm{L} \mathrm{C}$ from SR-NOM that the $\mathrm{pH}$ was 5.5 ; at $30 \mathrm{mg} / \mathrm{L} \mathrm{C}$, the $\mathrm{pH}$ was 5.0 ; and at $1000 \mathrm{mg} / \mathrm{L} \mathrm{C}$, the $\mathrm{pH}$ was 4.5 .

2. Using the $\mathrm{K}_{\mathrm{d}}$ data table created in Step 1, CDP Correction Factors were created. These Correction Factors are the ratio of the $K_{d}$ measured at a given DOC system divided by the $K_{d}$ when DOC $=0 \mathrm{mg} / \mathrm{L} \mathrm{C}$. For example, the CDP Correction Factor for $\mathrm{Sr}$ in porewater containing $95 \mathrm{mg} / \mathrm{L} \mathrm{C}$ is: $\mathrm{Sr}-\mathrm{Kd}_{95} \mathrm{ppm} \mathrm{C} / \mathrm{Sr}-\mathrm{Kd}_{0 \mathrm{ppm} \mathrm{C}}$.

3. CDP Correction Factors were then adjusted in a manner so as to assume that DOC did not enhance radionuclide sorption to sediments. DOC was assumed to have either no effect or it decreased radionuclide sorption. To capture these conservative assumptions, all Correction Factors established in Step 2, that were $>1$ were reassigned a value of 1 . All CDP Correction Factors $\leq 1$ were not adjusted. This was assumed because the length of time that the CDPs would be present in a subsurface system before natural degradation occurred (such as by microbial degradation) is not known.

4. The most recent recommended radionuclide soil $K_{d}$ values for the LLW-PA were then multiplied by the CDP Correction Factors derived in Step 3 to yield the recommended Conservative CDP-Impacted $\mathrm{K}_{\mathrm{d}}$ Values.

5. Finally, the Conservative CDP-Impacted $\mathrm{K}_{\mathrm{d}}$ Values were compared to previous values (Serkiz 2000).

As discussed for Step 1 above, measured $\mathrm{K}_{\mathrm{d}}$ values as a function of DOC concentration for the sandy sediment at $\mathrm{pH} 5.3$ are presented in Table 12. It is important to keep in mind that the DOC concentrations shown in Table 12 are those that were originally included in the spike concentrations (i.e., total DOC added to the system), and not solution concentrations at the end of the equilibrium period with the sediment. Equilibrium DOC values will be used to model organic carbon sorption, but are not as easy to display. Also presented in Table 12 are the CDP Correction Factors, as discussed in Step 2 above. The trends in this data are consistent:

- $\mathrm{K}_{\mathrm{d}}$ values of monovalent and divalent cations gradually increased as DOC concentrations increased, whereas 
WSRC-RP-2004-00593

- $\mathrm{K}_{\mathrm{d}}$ values of trivalent and tetravalent cations increased in the presence of low DOC additions, and decreased at elevated DOC additions. In the highest DOC treatments, the tri- and tetravalent $K_{d}$ values were less than those measured in treatment that did not receive any DOC.

Table 13 presents the most recently used soil $\mathrm{K}_{\mathrm{d}}$ values for the radionuclides of interest to the LLWPA. The CDP Correction Factors adjusted to assume that the presence of CDP does not enhance radionuclide sorption are presented in Table 14, as described for Steps 3 and 4 on page 45.

Finally, a comparison of past recommended $K_{d}$ values in Serkiz (2000) with those from this study are presented in Table 15. Serkiz (2000) estimated the $K_{d}$ values of multivalent radionuclides based on trends observed from CDP laboratory sorption experiments with $\mathrm{U}$ and Eu. Furthermore, he assumed that monovalent cationic radionuclides were influenced indirectly by CDPs' influence on $\mathrm{pH}$, not by direct organic matter/cation complexation. This assumption is based on the well established observation that monovalent cations form weak complexes to DOC and that increases in DOC result in decreases in sediment $\mathrm{pH}$. Specifically, monovalent cation $\mathrm{K}_{\mathrm{d}}$ values were assigned based on trends observed with $\mathrm{Cs}^{+}$sorption to SRS sediments as a function of $\mathrm{pH}$ (Johnson 1995). This indirect approach was adopted in the absence of more direct data.

As identified in Table 15 through the use of gray shading, the Recommended CDP-Corrected $\mathrm{K}_{\mathrm{d}}$ Values from this report were equal to or greater than those proposed by Serkiz (2000). In the case of most tri- and tetra-valent cations, the differences between the two sets of $K_{d}$ values were often greater than an order of magnitude. The main reasons for these differences can in part be attributed to the differences in assumptions in developing these two data sets and the need for greater conservatism by Serkiz (2000) in the absence of appropriate data.

\subsection{Utilization of Recommended CDP-Impacted $K_{d}$ Values in Future PA Modeling}

Incorporation of recommended CDP-Impacted $\mathrm{K}_{\mathrm{d}}$ Values into future PA modeling will be the subject of a follow-up project. The general approach will be to first run an organic carbon sorption model in the transport code to estimate spatial distributions of DOC (a measure of CDP) in the aqueous phase. This sorption model will likely not be linear, i.e., it will not be well described by a single $K_{d}$ value, because of the wide range of organic carbon concentrations expected in the system. Instead, a more robust model, applicable over a wide range of DOC concentrations will need to be invoked, such as a Freundlich or a model in which surface electrostatic properties are taken into consideration, such as one of the many surface complexation models. Once the dissolved organic carbon or sorbed organic carbon concentrations are established, then the $\mathrm{K}_{\mathrm{d}}$ values recommended in Table 15 will be incorporated in a radionuclide simulation. The final recommended CDP-impacted $\mathrm{K}_{\mathrm{d}}$ values may be organized as a function of $\mathrm{pH}$ and DOC concentrations, instead of only by DOC as presented in Table 15 . 
Table 12. CDP Correction Factors based on $\mathrm{K}_{\mathrm{d}}$ values measured in the $\mathrm{pH} 3.9$ or 5.3 sandy sediment system.

\begin{tabular}{|c|c|c|c|c|c|c|c|c|c|c|}
\hline & \multirow[b]{2}{*}{$\begin{array}{l}\text { Val- } \\
\text { ance }\end{array}$} & \multirow[b]{2}{*}{$\begin{array}{c}0^{(\mathrm{a})} \\
(\mathrm{mg} / \mathrm{L} \mathrm{C})\end{array}$} & \multicolumn{4}{|c|}{$\mathrm{K}_{\mathrm{d}}(\mathrm{mL} / \mathrm{g})$} & \multicolumn{4}{|c|}{ CDP Correction Factors } \\
\hline & & & $\begin{array}{c}10 \\
(\mathrm{mg} / \mathrm{L} \mathrm{C})\end{array}$ & $\begin{array}{c}20 \\
(\mathrm{mg} / \mathrm{L} \mathrm{C})\end{array}$ & $\begin{array}{c}95 \\
(\mathrm{mg} / \mathrm{L} \mathrm{C})\end{array}$ & $\begin{array}{c}222^{(\mathrm{b})} \\
(\mathrm{mg} / \mathrm{L} \mathrm{C})\end{array}$ & $\mathrm{K}_{\mathrm{d}}(10) / \mathrm{K}_{\mathrm{d}}(0)$ & $\mathrm{K}_{\mathrm{d}}(20) / \mathrm{K}_{\mathrm{d}}(0)$ & $\mathrm{K}_{\mathrm{d}}(95) / \mathrm{K}_{\mathrm{d}}(0)$ & $\mathrm{K}_{\mathrm{d}}(222) / \mathrm{K}_{\mathrm{d}}(0)$ \\
\hline $\mathrm{Cs}$ & +1 & 11.4 & 13 & 13 & 18.9 & 17 & 1.14 & 1.14 & 1.66 & 1.49 \\
\hline $\mathrm{Ni}$ & +2 & 6.8 & 7.7 & 12.4 & 9.6 & 6 & 1.13 & 1.82 & 1.41 & 0.88 \\
\hline $\mathrm{Sr}$ & +2 & 4.5 & 5.5 & 10.7 & 8.5 & 2 & 1.22 & 2.38 & 1.89 & 0.44 \\
\hline $\mathrm{Ce}$ & +3 & 1220 & 3840 & 1210 & 69 & 21 & 3.15 & 0.99 & 0.057 & 0.02 \\
\hline $\mathrm{Eu}$ & +3 & 1170 & 3100 & 641 & 49 & 15 & 2.65 & 0.55 & 0.042 & 0.01 \\
\hline Ce\& & & & & & & & & & & \\
\hline $\mathrm{Eu}$ & +3 & & & & & & $2.900^{(\mathrm{c})}$ & 0.770 & 0.049 & 0.015 \\
\hline Th & +4 & 245 & 463 & 716 & 126 & 29 & 1.89 & 2.92 & 0.514 & 0.12 \\
\hline $\mathrm{Zr}$ & +4 & 990 & 5120 & 6010 & 75 & 16 & 5.17 & 6.07 & 0.076 & 0.02 \\
\hline
\end{tabular}

(a) DOC concentration represent those in the aqueous phase prior to coming into contact with sediment, i.e., the leachate DOC concentrations rather than the final concentrations after the system obtains steady state with the sediment.

(b) $\mathrm{pH} 3.9 \mathrm{~K}_{\mathrm{d}}$ data was used for the $222 \mathrm{mg} / \mathrm{L} \mathrm{C}$ condition because elevated DOC levels commonly cause sediment pH to decrease. For example Johnson (1995) used the same sandy sediment as used in this study and observed that at $1 \mathrm{mg} / \mathrm{L} \mathrm{C}$ from $\mathrm{SR}-\mathrm{NOM}$ that the $\mathrm{pH}$ was 5.5 ; $30 \mathrm{mg} / \mathrm{L} \mathrm{C}$, the $\mathrm{pH}$ was 5.0 , at $1000 \mathrm{mg} / \mathrm{L} \mathrm{C}$, the $\mathrm{pH}$ was 4.5 .

(c) Ce \& Eu average CDP Correction Factors. 
Table 13. Present soil Kd values for radionuclides of interest to the LLW-PA.

\begin{tabular}{|c|c|c|c|c|}
\hline Radionuclide & $\begin{array}{c}\text { Assumed } \\
\text { Valance }\end{array}$ & Analogue & Present Soil $\mathrm{K}_{\mathrm{d}}$ Values & Ref. $^{(a)}$ \\
\hline Ac & 3 & $\mathrm{Ce} \& \mathrm{Eu}$ & 450 & 1 \\
\hline $\mathrm{Am}$ & 3 & Ce \& Eu & 1900 & 1 \\
\hline $\mathrm{C}^{(\mathrm{a})}$ & -2 & None & 2 & 1 \\
\hline $\mathrm{Cf}$ & 3 & $\mathrm{Ce} \& \mathrm{Eu}$ & 510 & 1 \\
\hline $\mathrm{Cm}$ & 3 & Ce \& Eu & 4000 & 1 \\
\hline Cs & 1 & Cs & 18 & 2 \\
\hline $\mathrm{Eu}$ & 3 & $\mathrm{Eu}$ & 7300 & 2 \\
\hline $\mathrm{H}^{(\mathrm{a})}$ & 1 & None & 0 & 1 \\
\hline I & -1 & None & 0.6 & 1 \\
\hline $\mathrm{Nb}$ & -1 & None & 160 & 1 \\
\hline $\mathrm{Ni}$ & 2 & $\mathrm{Ni}$ & 400 & 1 \\
\hline $\mathrm{Np}$ & 1 & Cs & 5 & 1 \\
\hline $\mathrm{Pa}$ & 4 & Th & 550 & 1 \\
\hline $\mathrm{Pb}$ & 2 & $\mathrm{Ni}$ & 270 & 1 \\
\hline $\mathrm{Pd}$ & 2 & $\mathrm{Ni}$ & 55 & 1 \\
\hline Po & 2 & $\mathrm{Ni}$ & 150 & 1 \\
\hline $\mathrm{Pu}$ & 4 & Th & 370 & 3 \\
\hline $\mathrm{Ra}$ & 2 & $\mathrm{Sr}$ & 500 & 1 \\
\hline $\mathrm{Rb}$ & 1 & Cs & 55 & 1 \\
\hline $\mathrm{Se}$ & -1 & None & 36 & 3 \\
\hline $\mathrm{Sn}$ & 2 & $\mathrm{Ni}$ & 130 & 1 \\
\hline $\mathrm{Sr}$ & 2 & $\mathrm{Sr}$ & 10 & 1 \\
\hline $\mathrm{Tc}$ & -1 & None & 0.36 & 1 \\
\hline Th & 4 & Th & 3200 & 1 \\
\hline $\mathrm{U}$ & 2 & $\mathrm{Sr}$ & 800 & 2 \\
\hline $\mathrm{Zr}$ & 4 & $\mathrm{Zr}$ & 600 & 1 \\
\hline
\end{tabular}

(a) References: 1 = McDowell-Boyer et al. 2000; 2 = Serkiz 2000; 3 = Kaplan 2004 
Table 14. CDP Correction Factors assuming no enhanced sorption due to presence of CDP and CDP-Corrected Kd values.

\begin{tabular}{|c|c|c|c|c|c|c|c|c|c|}
\hline \multirow[t]{2}{*}{$\begin{array}{l}\text { Radio- } \\
\text { nuclide }\end{array}$} & \multirow{2}{*}{$\begin{array}{l}\text { Present Soil } \\
\mathrm{K}_{\mathrm{d}} \mathrm{s}^{(\mathrm{a})} \\
(\mathrm{mL} / \mathrm{g})\end{array}$} & \multicolumn{4}{|c|}{$\begin{array}{l}\text { CDP Correction Factors Assuming No Enhanced Sorption } \\
\text { in the Presence of DOC }\end{array}$} & \multicolumn{4}{|c|}{ CDP Corrected Kd (mL/g) } \\
\hline & & $\begin{array}{c}10 \\
\mathrm{mg} / \mathrm{L} \mathrm{C}\end{array}$ & $\begin{array}{c}20 \\
\mathrm{mg} / \mathrm{L} \mathrm{C}\end{array}$ & $\begin{array}{l}95 \\
\mathrm{mg} / \mathrm{L} \mathrm{C}\end{array}$ & $\begin{array}{l}222 \\
\mathrm{mg} \mathrm{LCC}\end{array}$ & $\begin{array}{c}10 \\
\mathrm{mg} / \mathrm{L} \mathrm{C}\end{array}$ & $\begin{array}{c}20 \\
\mathrm{mg} / \mathrm{L} \mathrm{C}\end{array}$ & $\begin{array}{l}95 \\
\mathrm{mg} / \mathrm{L} \mathrm{C}\end{array}$ & $\begin{array}{l}222 \\
\mathrm{mg} / \mathrm{L} \mathrm{C}\end{array}$ \\
\hline Ac & 450 & 1.00 & 0.770 & 0.049 & 0.015 & 450 & 347 & 22 & 7 \\
\hline Am & 1900 & 1.00 & 0.770 & 0.049 & 0.015 & 1900 & 1464 & 94 & 29 \\
\hline $\mathrm{C}^{(\mathrm{b})}$ & 2 & & & & & & & & \\
\hline $\mathrm{Cf}$ & 510 & 1.00 & 0.770 & 0.049 & 0.015 & 510 & 393 & 25 & 8 \\
\hline $\mathrm{Cm}$ & 4000 & 1.00 & 0.770 & 0.049 & 0.015 & 4000 & 3081 & 197 & 60 \\
\hline Cs & 18 & 1.00 & 1.00 & 1.00 & 1.00 & 18 & 18 & 18 & 18 \\
\hline $\mathrm{Eu}$ & 7300 & 1.00 & 0.55 & 0.04 & 0.01 & 7300 & 4006 & 306 & 94 \\
\hline $\mathrm{H}^{(\mathrm{b})}$ & 0 & & & & & & & & \\
\hline $\mathrm{I}^{(\mathrm{b})}$ & 0.6 & & & & & & & & \\
\hline $\mathrm{Nb}$ & 160 & & & & & & & & \\
\hline $\mathrm{Ni}$ & 400 & 1.00 & 1.00 & 1.00 & 0.88 & 400 & 400 & 400 & 353 \\
\hline $\mathrm{Np}$ & 5 & 1.00 & 1.00 & 1.00 & 1.00 & 5 & 5 & 5 & 5 \\
\hline $\mathrm{Pa}$ & 550 & 1.00 & 1.00 & 0.51 & 0.12 & 550 & 550 & 283 & 65 \\
\hline $\mathrm{Pb}$ & 270 & 1.00 & 1.00 & 1.00 & 0.88 & 270 & 270 & 270 & 238 \\
\hline $\mathrm{Pd}$ & 55 & 1.00 & 1.00 & 1.00 & 0.88 & 55 & 55 & 55 & 49 \\
\hline Po & 150 & 1.00 & 1.00 & 1.00 & 0.88 & 150 & 150 & 150 & 132 \\
\hline $\mathrm{Pu}$ & 370 & 1.00 & 1.00 & 0.51 & 0.12 & 370 & 370 & 190 & 44 \\
\hline $\mathrm{Ra}$ & 500 & 1.00 & 1.00 & 1.00 & 0.44 & 500 & 500 & 500 & 222 \\
\hline $\mathrm{Rb}$ & 55 & 1.00 & 1.00 & 1.00 & 1.00 & 55 & 55 & 55 & 55 \\
\hline $\mathrm{Se}$ & 36 & & & & & & & & \\
\hline $\mathrm{Sn}$ & 130 & 1.00 & 1.00 & 1.00 & 0.88 & 130 & 130 & 130 & 115 \\
\hline $\mathrm{Sr}$ & 10 & 1.00 & 1.00 & 1.00 & 0.44 & 10 & 10 & 10 & 4 \\
\hline $\mathrm{Tc}$ & 0.36 & & & & & & & & \\
\hline Th & 3200 & 1.00 & 1.00 & 0.51 & 0.12 & 3200 & 3200 & 1646 & 379 \\
\hline $\mathrm{U}$ & 800 & 1.00 & 1.00 & 1.00 & 0.44 & 800 & 800 & 800 & 356 \\
\hline $\mathrm{Zr}$ & 600 & 1.00 & 1.00 & 0.08 & 0.02 & 600 & 600 & 45 & 10 \\
\hline
\end{tabular}

(a) References for most recent Soil Kd values are presented in Table 13.

(b) No analogues were included in this study for C, H, I, Se, and Tc. 
Table 15. Comparison of Recommended CDP-Corrected $\mathrm{K}_{\mathrm{d}}$ Values from this study and those proposed by Serkiz (2000); larger $\mathrm{K}_{\mathrm{d}}$ values based on comparison of both sets of data are shaded.

\begin{tabular}{|c|c|c|c|c|c|c|c|c|c|c|}
\hline \multirow[b]{2}{*}{$\begin{array}{l}\text { Radio- } \\
\text { nuclide }\end{array}$} & \multicolumn{5}{|c|}{ Recommended CDP-Corrected $\mathrm{K}_{\mathrm{d}}$ Values (mL/g) } & \multicolumn{5}{|c|}{ Serkiz (2000) SDP-Corrected $\mathrm{K}_{\mathrm{d}}$ Values $(\mathrm{mL} / \mathrm{g}$ ) } \\
\hline & $\begin{array}{c}<1 \\
\mathrm{mg} / \mathrm{L} \mathrm{C}\end{array}$ & $\begin{array}{l}1 \text { to } 10 \\
\mathrm{mg} / \mathrm{L} \mathrm{C}\end{array}$ & $\begin{array}{l}10 \text { to } 20 \\
\mathrm{mg} / \mathrm{L} \mathrm{C}\end{array}$ & $\begin{array}{c}20 \text { to } 100 \\
\mathrm{mg} / \mathrm{L} \mathrm{C}\end{array}$ & $\begin{array}{c}>225 \\
\text { mg L C }\end{array}$ & $\begin{array}{c}<1 \\
\mathrm{mg} / \mathrm{L} \mathrm{C}\end{array}$ & $\begin{array}{l}1 \text { to } 10 \\
\mathrm{mg} / \mathrm{L} \mathrm{C}\end{array}$ & $\begin{array}{l}10 \text { to } 30 \\
\mathrm{mg} / \mathrm{L} \mathrm{C}\end{array}$ & $\begin{array}{c}30 \text { to } 100 \\
\mathrm{mg} / \mathrm{L} \mathrm{C}\end{array}$ & $\begin{array}{c}100 \text { to } 1000 \\
\mathrm{mg} / \mathrm{L} \mathrm{C}\end{array}$ \\
\hline Ac & 450 & 450 & 347 & 22 & 7 & 450 & 80 & 13 & 4 & 2 \\
\hline Am & 1900 & 1900 & 1464 & 94 & 29 & 1900 & 338 & 55 & 18 & 10 \\
\hline $\mathrm{C}^{(\mathrm{b})}$ & 2 & 2 & 2 & 2 & 2 & 2 & 2 & 2 & 2 & 2 \\
\hline $\mathrm{Cf}$ & 510 & 510 & 393 & 25 & 8 & 510 & 91 & 15 & 5 & 3 \\
\hline $\mathrm{Cm}$ & 4000 & 4000 & 3081 & 197 & 60 & 4000 & 712 & 115 & 38 & 22 \\
\hline Cs & 18 & 18 & 18 & 18 & 18 & 18 & 12 & 5 & 5 & 5 \\
\hline $\mathrm{Eu}$ & 7300 & 7300 & 4006 & 306 & 94 & 7300 & 1300 & 210 & 70 & 40 \\
\hline $\mathrm{H}^{(\mathrm{b})}$ & 0 & 0 & 0 & 0 & 0 & 0 & 0 & 0 & 0 & 0 \\
\hline$I^{(b)}$ & 0.6 & 0.6 & 0.6 & 0.6 & 0.6 & 0.6 & 0.6 & 0.6 & 0.6 & 0.6 \\
\hline $\mathrm{Nb}$ & 160 & 160 & 160 & 160 & 160 & 160 & 160 & 160 & 160 & 160 \\
\hline $\mathrm{Ni}$ & 400 & 400 & 400 & 400 & 353 & 400 & 163 & 8 & 3.8 & 2.2 \\
\hline $\mathrm{Np}$ & 5 & 5 & 5 & 5 & 5 & 5 & 3 & 1 & 1 & 1 \\
\hline $\mathrm{Pa}$ & 550 & 550 & 550 & 283 & 65 & 550 & 3 & 1.4 & 1.4 & 1.4 \\
\hline $\mathrm{Pb}$ & 270 & 270 & 270 & 270 & 238 & 270 & 110 & 5 & 3 & 1 \\
\hline $\mathrm{Pd}$ & 55 & 55 & 55 & 55 & 49 & 55 & 22 & 1.1 & 0.5 & 0.3 \\
\hline $\mathrm{Po}^{(\mathrm{b})}$ & 150 & 150 & 150 & 150 & 132 & 150 & 150 & 150 & 150 & 150 \\
\hline $\mathrm{Pu}$ & $370^{(\mathrm{d})}$ & 370 & 370 & 190 & 44 & 100 & 18 & 3 & 1 & 1 \\
\hline $\mathrm{Ra}$ & 500 & 500 & 500 & 500 & 222 & 500 & 203 & 10 & 4.8 & 2.7 \\
\hline $\mathrm{Rb}^{(\mathrm{b})}$ & 55 & 55 & 55 & 55 & 55 & 55 & 3 & 1 & 1 & 1 \\
\hline $\mathrm{Se}$ & $36^{(\mathrm{d})}$ & 36 & 36 & 36 & 36 & 5 & 5 & 5 & 5 & 5 \\
\hline $\mathrm{Sn}$ & 130 & 130 & 130 & 130 & 115 & 130 & 53 & 2.6 & 1.3 & 0.7 \\
\hline $\mathrm{Sr}$ & 10 & 10 & 10 & 10 & 4 & 10 & 4 & 0.2 & 0.1 & 0.1 \\
\hline $\mathrm{Tc}^{(\mathrm{b})}$ & 0.36 & 0.36 & 0.36 & 0.36 & 0.36 & 0.36 & 0.36 & 0.36 & 0.36 & 0.36 \\
\hline Th & 3200 & 3200 & 3200 & 1646 & 379 & 3200 & 570 & 92 & 31 & 18 \\
\hline $\mathrm{U}^{(\mathrm{c})}$ & 800 & 325 & 16 & 8 & 4 & 800 & 325 & 16 & 8 & 4 \\
\hline $\mathrm{Zr}$ & 600 & 600 & 600 & 45 & 10 & 600 & 107 & 17 & 6 & 3 \\
\hline
\end{tabular}

(a) Column two contains the Most Recent Soil $\mathrm{K}_{\mathrm{d}}$ values. Column seven contains the most recent soil $\mathrm{K}_{\mathrm{d}}$ values in the year 2000 .

(b) Anion $\mathrm{K}_{\mathrm{d}}$ values recommended in this study and in Serkiz (2000), were assumed not to be influenced by the presence of CDP.

${ }^{\text {(c) }} \mathrm{U} \mathrm{K}_{\mathrm{d}}$ values recommended in this study are adopted from Serkiz 2000, since the later were based on actual laboratory studies with U and SR-NOM.

(d) $\mathrm{Pu}$ and Se soil $\mathrm{K}_{\mathrm{d}}$ values were increased during the interim between issuing Serkiz (2000) and this report. 
WSRC-RP-2004-00593

\subsection{REFERENCES}

Allard, B., Moulin, V., Ballo, L., Tran, M.T., Stammose, D. (1989). Americium Adsorption on Alumina in the Presence of Humic Materials. Geoderma. 44, 181-187.

Bovard, P., Grauby, A., Saas, A. (1970). Chelating Effect of Organic Matter and its Influence on the Migration of Fission Products. In Proceedings of Symposium: Isotopes and Radiation in Soil Organic Matter Studies, pp. 471-495, STI/PUB-190, NSA 24:5659-5668, International Atomic Energy Agency (IAEA), 1968, CONF 680725, Vienna, Austria.

Choppin G.R. (1989). Soluble Rare Earth and Actinide Species in Seawater. Mar. Chem. 28: 1926.

Fairhurst A.J., Warwick P., Richardson S. (1995). The Effect of pH on Europium-Mineral Interaction in the Presence of Humic Acid. Radiochim. Acta. 69: 103-111.

Gustaffsson, J. P. Visual MINTEQA2. http://www.lwr.kth.se/english/oursoftware/Vminteq/ (Version 2.15; March 6, 2003).

Johnson, W. H. (1995). Sorption Models for U, Cs, and Cd on Upper Atlantic Coastal Plain Soils. Ph.D. Thesis. Georgia Institute of Technology, Atlanta, GA.

Kaplan, D. I. (2001). Discovery of New Plutonium Chemistry and Its Potential Effect on LLW Disposal at SRS. WSRC-RP-2000-00980. Westinghouse Savannah River Company. Aiken, SC.

Perdue, E.M. and Gjessing, E.T. (1990). Dahlem Workshop Reports: Organic Acids in Aquatic Ecosystems. Wiley \& Sons, New York.

Pourbaix, M. (1972). Atlas of Electrochemical Equilibria in Aqueous Solutions. National Association of Corrosion Engineers (NACE) International, Houston, TX

Serkiz S.M., (1991). Factors Affecting the Binding of Protons and Metal Ions to Naturally Occurring Dissolved Organic Matter. Doctoral Thesis, Georgia Institute of Technology, Atlanta, GA.

Serkiz S. M., Knaub D., and Uhal H., (1998). Phase I Nuclide Partition Laboratory Study Influence of Cellulose Degradation Products On the Transport of Nuclides from SRS Shallow Land Burial Facilities. WSRC-TC-98-00460. Westinghouse Savannah River Company. Aiken, SC.

Serkiz S. M. and Myers J.L., (1996). Additional Information for E-area Vault Performance Assessment, Appendix I "Suspect Soil Performance Analysis" - Results of Modeling the Effects of Organic Matter on the Mobility of Radionuclides as it Relates to the Disposal of Wood Products in E-Area Slit Trenches. WSRC-TR-98-00049. Westinghouse Savannah River Company. Aiken, SC.

Serkiz, S. M., (2000). Recommended Partition Coefficient $\left(\mathrm{K}_{\mathrm{d}}\right)$ Values for Nuclide Partitioning in the Presence of Cellulose Degradation Products. WSRC-TR-2000-00262. Westinghouse Savannah River Company, Aiken, SC.

Serne, R.J., Conca, J.L., LeGora, V.L., Cantrell, K.J., Lindenmeier, C.W., Campbell, J.A., Amonette, J.E. and Wood, M.I. (1993). Solid-Waste Leach Characteristics and Contaminant-Sediment Interactions, Volume 1: Batch Leach and Adsorption Tests and Sediment Characterization. Report No. PNL-8889 Vol. 1. PNNL, Richland, WA.

Stumm W. and Morgan, J.J. (1981). Aquatic Chemistry. Wiley \& Sons, New York. Thurman, E.M. (1985). Organic Geochemistry of Natural Waters. Kluwer Academic, Hingham, MA. 
WSRC-RP-2004-00593

This page was purposely left blank. 
WSRC-RP-2004-00593

8.0 APPENDIX A: DETAILED DESCRIPTION OF MATERIALS AND METHODS 
WSRC-RP-2004-00593

\title{
Detailed Work Instructions for Influence of DOC on Constituent of Concern Sorption to SRS Sediments
}

\author{
Dan Kaplan \& Steve Serkiz \\ $5 / 24 / 04$
}

Objective: The overall objective of this study is to create input geochemistry values for PA calculations related to constituents of concern (COC) sorption to E-Area sediment in the presence of cellulose degradation products (CDP). The specific objectives are to:

1. create a soil titration,

2. determine how $\mathrm{pH}$ varies as a function of SR-NOM (FA; an analog for CDP) concentrations,

3. determine how SR-NOM sorbs to E-Area sediment as a function of $\mathrm{pH}$, and

4. determine sorption envelopes (sorption vs. $\mathrm{pH}$ ) of COCs as a function of SR-NOM concentrations.

General Approach: The general approach is to incrementally add complexity to the same set of tubes. The first system will include a pH adjusted soil + water system (Figure 1). This will generate sediment titration curves (Objective 1). SR-NOM will then be added to the $\mathrm{pH}$-adjusted sediments, the system will be permitted to come to equilibrium and then $\mathrm{pH}$ and $\mathrm{FA}$ concentrations will be measured. This will provide SR-NOM sorption isotherms as a function of $3 \mathrm{pH}$ levels (Objective 3) and the relationship between FA vs. $\mathrm{pH}$ (Objective 2). Finally, COCs will be added to the sediment + water + FA system. After 1 week, COC concentrations will be measured. This will provide a series of COC vs. FA and COC vs. $\mathrm{pH}$ Kd values. To lower costs, there will be a down selection of $\mathrm{pH}$ levels evaluated: starting at $11 \mathrm{pH}$ levels in the "sediment + water system" and then $3 \mathrm{pH}$ levels for the "sediment + water + FA system" and the "sediment + water + FA + COC system". Five FA concentrations were used 0, 10, 30, 100, and $300 \mathrm{mg} \mathrm{L}^{-1} \mathrm{C}$.

Materials:

1. 20050 - $\mathrm{mL}$ centrifuge tubes

2. BG1 sandy sediment

3. subsurface clayey sediment

4. 2.0-L $0.02 \mathrm{M} \mathrm{NaCl}$

5. $0.1-\mathrm{L} 0.005 \mathrm{M} \mathrm{HCl}$

6. $0.1-\mathrm{L} 0.005 \mathrm{M} \mathrm{NaOH}$

7. $0.1-\mathrm{L} 0.05 \mathrm{M} \mathrm{HCl}$

8. $0.1-\mathrm{L} 0.05 \mathrm{M} \mathrm{NaOH}$

9. 75-mL 10,000 mg/L SR-NOM Stock: dissolve 0.75g IHSS SR-NOM (FA; Suwannee River SR-NOM) in $75 \mathrm{~mL}$ water. Mix well. Store in refrigerator and in light-proof or amber glass container.

10. 70-mL $1000 \mathrm{mg} / \mathrm{L}$ SR-NOM Stock: Add $7 \mathrm{~mL}$ of 10,000 mg/L FA Stock solution to a 25 $\mathrm{mL}$ volumetric flask. Bring up to volume with DI water. Mix well. Store in refrigerator and in light-proof or amber glass container.

11. ICP-MS standards stock solution (Dan will acquire) 
WSRC-RP-2004-00593

12. 100 24-mL glass vials: Borosilicate glass, with PTFE-lined screw cap.

13. $0.5 \% \mathrm{HNO}_{3}$ : Add $5 \mathrm{~mL}$ of $\mathrm{HNO}_{3}$ to $995 \mathrm{~mL}$ water.

14. 100 acid washed scintillation vials

15. 100 water-washed $0.45-\mu \mathrm{m}$ filters

Methods:

Scoping Sediment-Water Experiment:

1. Label tubes as shown in Table 1 and record tare weights.

2. Add $5 \mathrm{~g}$ of appropriate sediment to treatment tubes. Record "tare + sediment" weight in Table 1.

3. Add acid, base, ionic strength salt and distilled water as shown in Table 1. Record final weight in Table 1.

4. Place tubes on an air tight box and leave on platform shaker for $\sim 1$ week.

5. Measure $\mathrm{pH}$ and enter into Table 1.

6. Select $3 \mathrm{pH}$ treatments for the clayey sediment and another $4 \mathrm{pH}$ treatments for the sandy sediment to provide a good titration curves. These tubes will constitute the 0-ppm FA treatment in the Sediment + Water + FA study.

Sediment-Water-FA Experiment:

[For the Sand, tubes \# 4, 8, \& 9 were selected. For the Clay, tubes \# 3, 10, \& 11 were selected.]

Preparation of Additional Sets of $\mathrm{pH}$-adjusted Sediments Samples

7. Prepare 8 additional sets of tubes as shown in Table 2: 2 sets for 10-ppm DOC, 2 sets for 30-ppm DOC, 2 sets for 100-ppm DOC, and 2 sets for 300-ppm DOC.

8. Follow steps $1-4$, except use the labeling presented in Table 2 and record data in Table 2. Let samples equilibrate on a shaker for the same duration as used in Step 4. Note: You do not need to measure $\mathrm{pH}$ at the end of the equilibration period as was done for Step 5.

9. Remove 3-mL from each tube described in Table 2. We're doing this to ensure we have enough volume in tube for subsequent acid, base, FA, and COC solution additions.

Preparation of No-Sediment Control Samples

10. Label tubes as shown in Table 3. Record "Tare Wt." in Table 3. Add 40-mL of $0.02 \mathrm{M}$ $\mathrm{NaCl}$.

Adding FA

11. Add 0,1 , or $3 \mathrm{~mL}$ of appropriate FA stock solution to each tube as shown in Tables $2 \&$ 3.

12. Put samples in light-proof box and place box in refrigerator for overnight.

13. Take samples out of refrigerator and let tubes come to near room temperature. $\mathrm{pH}$ adjust solutions by adding $0.01 \mathrm{M} \mathrm{NaOH}, 0.01 \mathrm{M} \mathrm{HCl}, 0.1 \mathrm{M} \mathrm{NaOH} 0.1 \mathrm{M} \mathrm{HCl}$, and/or $1.0 \mathrm{M}$ $\mathrm{NaOH}(\mathrm{NaOH}$ solutions will be needed more than $\mathrm{HCl}$ solutions) to the targeted $\mathrm{pH}$ levels listed in Tables $2 \& 3$. We want to add $<\sim 2 \mathrm{~mL}$ of acid or base. Please ask Carl, Dave or Adrian to help you because we need to complete all the $\mathrm{pH}$ adjustments in 1 or 2 days. 
WSRC-RP-2004-00593

14. Return samples to the light-proof box and refrigerator.

15. Shake samples at the start and end of each work shift. Assign someone to shake tubes on Friday.

16. After one week, take tubes out of refrigerator and let tubes come to near room temperature. $\mathrm{pH}$ adjust tubes again. (Again, request help from Carl, Dave or Adrian. We need to complete this step in 1 or 2 days.)

17. Measure weight of each tube and contents and record "Wt after adj pH of FA soln wt (g)" in Tables $2 \& 3$. Show me these weights and we'll decide what weight to target for the next step, which is to bring all the tubes up to the same weight.

18. Record in Tables $2 \& 3$ the amount of water needed to bring each tube up to the same volume. Add water to tubes.

19. Put tubes back in light-proof box and the box in a refrigerator.

Sediment-Water-DOC-COC Experiment:

20. Add $0.25-\mathrm{mL}$ of $\mathrm{Ni}, \mathrm{Sr}, \mathrm{K}, \mathrm{Cs}, \mathrm{Eu}, \mathrm{Ce}$, Th, and Zr of $100 \mathrm{ppm}$ ICP-MS standards solution to each tube.

21. Add $0.75 \mathrm{~mL}$ of Th $10 \mathrm{ppm}$ ICP-MS standards solution to each tube.

22. Put tubes back in light-proof box and the box in a refrigerator. Shake box vigorously 2 times a day for 1 week.

23. After one week, take tubes out of refrigerator and let tubes come to near room temperature. Measure $\mathrm{pH}$ and record in Tables $2 \& 3$.

24. Let sediment settle to bottom of tube or if necessary, centrifuge (also it is OK to centrifuge some but not all samples).

25. Pass $>28 \mathrm{~mL}$ of each sample through washed $0.45-\mu \mathrm{m}$ filter (see instruction in Materials section on how to wash filters; Steve will provide). Collect filtrate in acid washed $50-\mathrm{mL}$ centrifuge tubes.

26. Add $0.150 \mathrm{~mL}$ of concentrated Ultra Pure $\mathrm{HNO}_{3}$ to each filtered aqueous sample to preserve the aqueous samples. (Assuming $30-\mathrm{mL}$ of sample solution, this is a $0.5 \%$ $\mathrm{HNO}_{3}$ addition.)

27. Each sample will then be pipetted into 3 containers (2 24-mL glass vials for duplicate C analyses and 1 acid washed scintillation vial for ICP-MS)

- $10.0 \mathrm{~mL}$ into a $24 \mathrm{~mL}$ glass vial (labeled e.g., 900-I, 901-I, 902-I, 903-I...).

These are replicate 1 for DOC measurements.

- 10.0 mL into a 24 mL glass vial (labeled e.g., 900-II, 901-II, 902-II, 903-II...).

These are replicate 2 for DOC measurements.

- The remainder of sample, $>8 \mathrm{~mL}$, into the acid washed scintillation vials (labeled identically to samples, e.g., 900, 901, 902, 903, 904... These samples will be used to measure ICP-MS at UGa and will be used to measure absorbance on the spectrophotometer.

28. Add $10.0 \mathrm{~mL}$ of $0.5 \% \mathrm{HNO}_{3}\left(995 \mathrm{~mL}\right.$ water $\left.+5 \mathrm{~mL} \mathrm{HNO}_{3}\right)$ to each $24 \mathrm{~mL}$ vial.

29. Store all samples in dark and in refrigerator.

30. The samples in the acid washed scintillation vials will be used to measure absorbance on the spectrophotometer prior to shipping to UGa. Anna will help us with this step.

31. Submit samples to UGa for ICP-MS analysis and to Steve for DOC analysis. 
Order-of-Addition Controls: (These Controls are design to determine whether the order in which we add the FA and COC has an effect on how much metal sorption we measure. There are actually two sets of controls, the first set of controls are described in steps $32-44$, and the second set of controls are described in steps 45 - 56.)

32. First set of Order-of-Addition Controls: Label 4 50-mL centrifuge tubes as shown in the top 4 rows in Table 4. Record "tare wt".

33. Add $5 \mathrm{~g}$ surface clayey sediment to each tube.

34. Add $40-\mathrm{mL}$ of $0.02 \mathrm{M} \mathrm{NaCl}$. $\mathrm{pH}$-adjust to the $\mathrm{pH}$ shown in Table 4 using $\mathrm{NaOH}$ or $\mathrm{HCl}$. Put in refrigerator for week. Agitate twice a day.

35. Add COCs as done in steps 20 and $21(0.25 \mathrm{~mL}$ of mixed spike and $0.75 \mathrm{~mL}$ of $\mathrm{Th}$ spike). Put in refrigerator for $\sim$ two days. Agitate twice a day.

36. Add $0.4 \mathrm{~mL}$ of $10,000 \mathrm{mg} / \mathrm{L} \mathrm{SR-NOM}$ Stock to each tube.

37. $\mathrm{pH}$-adjust using $\mathrm{NaOH}$ or $\mathrm{HCl}$.

38. Weigh and record "tare+ sed+COC+FA wt".

39. See me and we'll decide how much water to add to each tube to make similar total volumes.

40. Add appropriate amount of water (Table 4).

41. Put tubes in light-proof box and box put in refrigerator. Shake sample twice a day for one week.

42. Pass $\sim 10 \mathrm{~mL}$ of each sample through washed $0.45-\mu \mathrm{m}$ filter and store in labeled acid wash scintillation vial.

43. Add $0.05 \mathrm{~mL}(50-\mu \mathrm{L})$ of concentrated Ultra Pure $\mathrm{HNO}_{3}$ to each filtered aqueous sample to preserve the aqueous samples (this is a $0.5 \%-\mathrm{HNO}_{3}$ addition).

44. Send to UGa for ICP-MS.

45. Second set of Order of Addition Controls: Label 4 50-mL centrifuge tubes as shown in the bottom 4 rows in Table 4 . Record "tare wt". Add 40-mL of $0.02 \mathrm{M} \mathrm{NaCl}$. pH-adjust using $\mathrm{NaOH}$ or $\mathrm{HCl}$. Put in refrigerator for week. Agitate twice a day.

46. Add $1.25 \mathrm{~mL}$ of mixed COC solution $+3.75 \mathrm{~mL}$ of Th spike solution $+2.0 \mathrm{~mL}$ of 10,000 $\mathrm{mg} / \mathrm{L}$ SR-NOM Stock $+2.0 \mathrm{~mL}$ of $1,000 \mathrm{mg} / \mathrm{L}$ SR-NOM Stock to a small vial (such as a scintillation vial). Mix on platform shaker for 30 minutes.

47. Add $1.8 \mathrm{~mL}$ of above mixture described in Step 46 to each tube.

48. $\mathrm{pH}$-adjust using $\mathrm{NaOH}$ or $\mathrm{HCl}$.

49. Put in refrigerator for week. Agitate twice a day.

50. Add $5 \mathrm{~g}$ surface clayey sediment to each tube.

51. $\mathrm{pH}$-adjust using $\mathrm{NaOH}$ or $\mathrm{HCl}$.

52. Record "tare+FA+COC+sed wt".

53. See me and we'll decide how much water to add to each tube to make similar total volumes.

54. Add appropriate amount of water (see Table 4).

55. Put tubes in light-proof box and box put in refrigerator. Shake sample twice a day for one week.

56. Follow steps $42-44$.

Safety Topics to Discuss: Non-rad. Weak acids and weak bases. ICP-MS stock solution. Centrifuge. 
Waste: Depending on the final list and concentration of COCs, it may be possible to dispose of all waste as non-hazardous. $\mathrm{Cl}$ will not be an issue. Concentrated stock solutions of COCs (ICPMS Standards Solution) will not be thrown out.

Hazards Analysis Checklist: It is located in WSRC-NB-2003-00251 on page 11. 
WSRC-RP-2004-00593

Table 1. Sample ID and amount of acid base, ionic strength salt and distilled water needed for each sample.

\begin{tabular}{|c|c|c|c|c|c|c|c|c|c|}
\hline $\begin{array}{c}\text { Sample ID } \\
\text { (pH\#-FA- } \\
\text { Rep-Sed) }\end{array}$ & $\begin{array}{c}\text { pH tube } \\
\#\end{array}$ & $\begin{array}{c}\text { Sed- } \\
\text { iment }\end{array}$ & $\begin{array}{c}\mathrm{mL} \\
0.005 \mathrm{M} \\
\mathrm{HCl}\end{array}$ & $\begin{array}{c}\mathrm{mL} \\
0.005 \mathrm{M} \\
\mathrm{NaOH}\end{array}$ & $\begin{array}{l}\text { mL 0.02 } \\
\text { M NaCl }\end{array}$ & $\begin{array}{r}\mathrm{mL} \\
\mathrm{H}_{2} \mathrm{O}\end{array}$ & $\begin{array}{c}\text { pH } \\
\text { after 1 } \\
\text { wk }\end{array}$ & $\begin{array}{c}\text { Tare wt } \\
\text { (g) }\end{array}$ & $\begin{array}{c}\text { Tare + Sed. } \\
\text { Wt. (g) }\end{array}$ \\
\hline 1-0-1-C & 1 & Clay & 25 & 0 & 18.8 & 6.2 & 3.13 & 11.741 & 16.745 \\
\hline $1-0-2-\mathrm{C}$ & 1 & Clay & 25 & 0 & 18.8 & 6.2 & 3.12 & 11.828 & 16.828 \\
\hline $2-0-1-\mathrm{C}$ & 2 & Clay & 15 & 0 & 21.2 & 13.8 & 3.50 & 11.715 & 16.719 \\
\hline $2-0-2-\mathrm{C}$ & 2 & Clay & 15 & 0 & 21.2 & 13.8 & 3.49 & 11.755 & 16.759 \\
\hline $3-0-1-\mathrm{C}$ & 3 & Clay & 4 & 0 & 24 & 22 & 4.18 & 11.770 & 16.770 \\
\hline $3-0-2-\mathrm{C}$ & 3 & Clay & 4 & 0 & 24 & 22 & 4.16 & 11.738 & 16.737 \\
\hline $4-0-1-\mathrm{C}$ & 4 & Clay & 2 & 0 & 24.5 & 23.5 & 4.36 & 11.714 & 16.716 \\
\hline $4-0-2-\mathrm{C}$ & 4 & Clay & 2 & 0 & 24.5 & 23.5 & 4.36 & 11.777 & 16.778 \\
\hline 5-0-1-C & 5 & Clay & 0.5 & 0 & 24.8 & 24.7 & 4.49 & 11.744 & 16.746 \\
\hline $5-0-2-\mathrm{C}$ & 5 & Clay & 0.5 & 0 & 24.8 & 24.7 & 4.48 & 11.794 & 16.792 \\
\hline 6-0-1-C & 6 & Clay & 0 & 0 & 25 & 25 & 4.53 & 11.728 & 16.728 \\
\hline 6-0-2-C & 6 & Clay & 0 & 0 & 25 & 25 & 4.53 & 11.821 & 16.821 \\
\hline 7-0-1-C & 7 & Clay & 0 & 0.5 & 24.8 & 24.7 & 4.59 & 11.847 & 16.846 \\
\hline $7-0-2-\mathrm{C}$ & 7 & Clay & 0 & 0.5 & 24.8 & 24.7 & 4.59 & 11.735 & 16.737 \\
\hline $8-0-1-\mathrm{C}$ & 8 & Clay & 0 & 2 & 24.5 & 23.5 & 4.75 & 11.780 & 16.778 \\
\hline $8-0-2-\mathrm{C}$ & 8 & Clay & 0 & 2 & 24.5 & 23.5 & 4.75 & 11.804 & 16.804 \\
\hline $9-0-1-\mathrm{C}$ & 9 & Clay & 0 & 4 & 24 & 22 & 4.93 & 11.738 & 16.739 \\
\hline 9-0-2-C & 9 & Clay & 0 & 4 & 24 & 22 & 4.94 & 11.776 & 16.777 \\
\hline $10-0-1-C$ & 10 & Clay & 0 & 15 & 21.2 & 13.8 & 6.08 & 11.721 & 16.721 \\
\hline $10-0-2-C$ & 10 & Clay & 0 & 15 & 21.2 & 13.8 & 6.06 & 11.744 & 16.746 \\
\hline $11-0-1-C$ & 11 & Clay & 0 & 25 & 18.8 & 6.2 & 8.72 & 11.730 & 16.734 \\
\hline $11-0-2-C$ & 11 & Clay & 0 & 25 & 18.8 & 6.2 & 8.74 & 11.715 & 16.720 \\
\hline $1-0-1-S$ & 1 & Sand & 25 & 0 & 18.8 & 6.2 & 2.79 & 11.709 & 16.712 \\
\hline $1-0-2-S$ & 1 & Sand & 25 & 0 & 18.8 & 6.2 & 2.78 & 11.755 & 16.756 \\
\hline $2-0-1-S$ & 2 & Sand & 15 & 0 & 21.2 & 13.8 & 3.02 & 11.702 & 16.706 \\
\hline $2-0-2-S$ & 2 & Sand & 15 & 0 & 21.2 & 13.8 & 3.03 & 11.736 & 16.739 \\
\hline 3-0-1-S & 3 & Sand & 4 & 0 & 24 & 22 & 3.74 & 11.703 & 16.705 \\
\hline $3-0-2-S$ & 3 & Sand & 4 & 0 & 24 & 22 & 3.76 & 11.711 & 16.714 \\
\hline 4-0-1-S & 4 & Sand & 2 & 0 & 24.5 & 23.5 & 4.11 & 11.824 & 16.825 \\
\hline $4-0-2-S$ & 4 & Sand & 2 & 0 & 24.5 & 23.5 & 4.11 & 11.737 & 16.738 \\
\hline $5-0-1-S$ & 5 & Sand & 0.5 & 0 & 24.8 & 24.7 & 4.53 & 11.721 & 16.721 \\
\hline $5-0-2-S$ & 5 & Sand & 0.5 & 0 & 24.8 & 24.7 & 4.54 & 11.701 & 16.701 \\
\hline $6-0-1-S$ & 6 & Sand & 0 & 0 & 25 & 25 & 4.71 & 11.842 & 16.844 \\
\hline $6-0-2-S$ & 6 & Sand & 0 & 0 & 25 & 25 & 4.73 & 11.703 & 16.704 \\
\hline $7-0-1-S$ & 7 & Sand & 0 & 0.5 & 24.8 & 24.7 & 4.96 & 11.726 & 16.726 \\
\hline $7-0-2-S$ & 7 & Sand & 0 & 0.5 & 24.8 & 24.7 & 4.95 & 11.705 & 16.706 \\
\hline 8-0-1-S & 8 & Sand & 0 & 2 & 24.5 & 23.5 & 5.53 & 11.764 & 16.767 \\
\hline $8-0-2-\mathrm{S}$ & 8 & Sand & 0 & 2 & 24.5 & 23.5 & 5.51 & 11.719 & 16.722 \\
\hline 9-0-1-S & 9 & Sand & 0 & 4 & 24 & 22 & 7.24 & 11.698 & 16.698 \\
\hline 9-0-2-S & 9 & Sand & 0 & 4 & 24 & 22 & 7.37 & 11.728 & 16.729 \\
\hline $10-0-1-S$ & 10 & Sand & 0 & 15 & 21.2 & 13.8 & 10.54 & 11.698 & 16.699 \\
\hline $10-0-2-S$ & 10 & Sand & 0 & 15 & 21.2 & 13.8 & 10.54 & 11.819 & 16.823 \\
\hline $11-0-1-S$ & 11 & Sand & 0 & 25 & 18.8 & 6.2 & 10.91 & 11.727 & 16.729 \\
\hline $11-0-2-S$ & 11 & Sand & 0 & 25 & 18.8 & 6.2 & 10.91 & 11.754 & 16.754 \\
\hline
\end{tabular}


Table 2. Addition of SR-NOM to $\mathrm{pH}$ adjusted tubes containing sediment.

\begin{tabular}{|c|c|c|c|c|c|c|c|c|c|c|c|c|c|c|}
\hline $\begin{array}{l}\text { Sample ID } \\
\text { (pH \#-FA- } \\
\text { Rep-Sed) }\end{array}$ & $\begin{array}{c}\text { Lab } \\
\text { ID }\end{array}$ & Sed. & $\begin{array}{c}\text { Target } \\
\text { pH } \\
( \pm 0.15)\end{array}$ & $\begin{array}{c}\text { SR- } \\
\text { NOM } \\
(p p m C)\end{array}$ & $\begin{array}{c}\mathbf{0 . 0 0 5} \\
\text { M } \\
\text { HCl } \\
(\mathbf{m L})\end{array}$ & $\begin{array}{c}0.005 \\
\mathrm{M} \\
\mathrm{NaOH} \\
(\mathrm{mL})\end{array}$ & $\begin{array}{c}0.02 \mathrm{M} \\
\mathrm{NaCl}\end{array}$ & $\begin{array}{c}\mathrm{H}_{2} \mathrm{O} \\
(\mathrm{mL})\end{array}$ & $\begin{array}{c}\text { Tare } \\
\text { wt (g) }\end{array}$ & $\begin{array}{c}\text { Tare + } \\
\text { Sed. wt. } \\
\text { (g) }\end{array}$ & $\begin{array}{c}\text { FA added } \\
\text { (mL-Stock } \\
\text { ppm FA) }\end{array}$ & $\begin{array}{c}\text { Wt after adj } \\
\text { pH of FA } \\
\text { soln wt (g) }\end{array}$ & $\begin{array}{c}\text { Amt } \\
\text { water } \\
\text { added } \\
(\mathrm{g})\end{array}$ & $\begin{array}{c}\text { Final } \\
\text { pH } \\
(\mathbf{p H})\end{array}$ \\
\hline Proc. Step & & & & & 8 & 8 & 8 & 8 & 8 & 8 & 11 & 17 & 18 & 23 \\
\hline $3-0-1-\mathrm{C}$ & 901 & Clay & 4.0 & 0 & 4 & 0 & 24 & 22 & 11.770 & 16.770 & 0 & $*$ & & \\
\hline $3-0-2-C$ & 902 & & & 0 & & & & & 11.738 & 16.737 & 0 & $*$ & & \\
\hline $3-10-1-C$ & 903 & & & 10 & & & & & & & $1-1,000$ & $*$ & & \\
\hline $3-10-2-C$ & 904 & & & 10 & & & & & & & $1-1,000$ & & & \\
\hline $3-30-1-\mathrm{C}$ & 905 & & & 30 & & & & & & & $3-1,000$ & & & \\
\hline $3-30-2-C$ & 906 & & & 30 & & & & & & & $3-1,000$ & & & \\
\hline $3-100-1-\mathrm{C}$ & 907 & & & 100 & & & & & & & $1-10,000$ & & & \\
\hline $3-100-2-C$ & 908 & & & 100 & & & & & & & $1-10,000$ & & & \\
\hline 3-300-1-C & 909 & & & 300 & & & & & & & $3-10,000$ & & & \\
\hline $3-300-2-\mathrm{C}$ & 910 & & & 300 & & & & & & & $3-10,000$ & & & \\
\hline $10-0-1-\mathrm{C}$ & 911 & & 6.1 & 0 & 0 & 15 & 21.2 & 13.8 & 11.721 & 16.721 & 0 & & & \\
\hline $10-0-2-C$ & 912 & & & 0 & & & & & 11.744 & 16.746 & 0 & & & \\
\hline 10-10-1-C & 913 & & & 10 & & & & & & & $1-1,000$ & & & \\
\hline 10-10-2-C & 914 & & & 10 & & & & & & & $1-1,000$ & & & \\
\hline $10-30-1-\mathrm{C}$ & 915 & & & 30 & & & & & & & $3-1,000$ & & & \\
\hline $10-30-2-\mathrm{C}$ & 916 & & & 30 & & & & & & & $3-1,000$ & & & \\
\hline $10-100-1-C$ & 917 & & & 100 & & & & & & & $1-10,000$ & & & \\
\hline $10-100-2-\mathrm{C}$ & 918 & & & 100 & & & & & & & $1-10,000$ & & & \\
\hline $10-300-1-C$ & 919 & & & 300 & & & & & & & $3-10,000$ & & & \\
\hline $10-300-2-\mathrm{C}$ & 920 & & & 300 & & & & & & & $3-10,000$ & & & \\
\hline $11-0-1-\mathrm{C}$ & 921 & & 8.7 & 0 & 0 & 25 & 18.8 & 6.2 & 11.730 & 16.734 & 0 & & & \\
\hline $11-0-2-C$ & 922 & & & 0 & & & & & 11.715 & 16.720 & 0 & & & \\
\hline 11-10-1-C & 923 & & & 10 & & & & & & & $1-1,000$ & & & \\
\hline 11-10-2-C & 924 & & & 10 & & & & & & & $1-1,000$ & & & \\
\hline 11-30-1-C & 925 & & & 30 & & & & & & & $3-1,000$ & & & \\
\hline $11-30-2-\mathrm{C}$ & 926 & & & 30 & & & & & & & $3-1,000$ & & & \\
\hline $11-100-1-\mathrm{C}$ & 927 & & & 100 & & & & & & & $1-10,000$ & & & \\
\hline 11-100-2-C & 928 & & & 100 & & & & & & & $1-10,000$ & & & \\
\hline $11-300-1-\mathrm{C}$ & 929 & & & 300 & & & & & & & $3-10,000$ & & & \\
\hline $11-300-2-\mathrm{C}$ & 930 & & & 300 & & & & & & & $3-10,000$ & & & \\
\hline & & & & & & & & & & & & & & \\
\hline
\end{tabular}


Table 2 (continuation). Addition of SR-NOM to $\mathrm{pH}$ adjusted tubes containing sediment.

\begin{tabular}{|c|c|c|c|c|c|c|c|c|c|c|c|c|c|c|}
\hline $\begin{array}{l}\text { Sample ID } \\
\text { (pH \#-FA- } \\
\text { Rep-Sed) }\end{array}$ & $\begin{array}{c}\text { Lab } \\
\text { ID }\end{array}$ & Sed. & $\begin{array}{c}\text { Target } \\
\text { pH } \\
( \pm 0.15)\end{array}$ & $\begin{array}{c}\text { SR- } \\
\text { NOM } \\
(\text { ppmC) }\end{array}$ & $\begin{array}{c}\mathbf{0 . 0 0 5} \\
\mathbf{M} \\
\text { HCl } \\
(\mathbf{m L}) \\
\end{array}$ & $\begin{array}{c}\mathbf{0 . 0 0 5} \\
\mathrm{M} \\
\mathrm{NaOH} \\
(\mathrm{mL}) \\
\end{array}$ & $\begin{array}{c}0.02 \mathrm{M} \\
\mathrm{NaCl}\end{array}$ & $\begin{array}{c}\mathrm{H}_{2} \mathrm{O} \\
(\mathrm{mL})\end{array}$ & $\begin{array}{c}\text { Tare } \\
\text { wt (g) }\end{array}$ & $\begin{array}{l}\text { Tare + } \\
\text { Sed. wt. } \\
\text { (g) }\end{array}$ & $\begin{array}{c}\text { FA added } \\
\text { (mL-Stock } \\
\text { ppm FA) }\end{array}$ & $\begin{array}{c}\text { Wt after adj } \\
\text { pH of FA } \\
\text { soln wt (g) }\end{array}$ & $\begin{array}{c}\text { Amt } \\
\text { water } \\
\text { added } \\
(\mathrm{g})\end{array}$ & $\begin{array}{c}\text { Final } \\
\text { pH } \\
(\mathbf{p H})\end{array}$ \\
\hline Proc. Step & & & & & 8 & 8 & 8 & 8 & 8 & 8 & 11 & 17 & 18 & 23 \\
\hline $4-0-1-S$ & 931 & Sand & 4.1 & 0 & 2 & 0 & 24.5 & 23.5 & 11.824 & 16.825 & 0 & & & \\
\hline $4-0-2-S$ & 932 & & & 0 & & & & & 11.737 & 16.738 & 0 & & & \\
\hline $4-10-1-S$ & 933 & & & 10 & & & & & & & $1-1,000$ & & & \\
\hline $4-10-2-S$ & 934 & & & 10 & & & & & & & $1-1,000$ & & & \\
\hline 4-30-1-S & 935 & & & 30 & & & & & & & $3-1,000$ & & & \\
\hline $4-30-2-S$ & 936 & & & 30 & & & & & & & $3-1,000$ & & & \\
\hline $4-100-1-S$ & 937 & & & 100 & & & & & & & $1-10,000$ & & & \\
\hline 4-100-2-S & 938 & & & 100 & & & & & & & $1-10,000$ & & & \\
\hline 4-300-1-S & 939 & & & 300 & & & & & & & $3-10,000$ & & & \\
\hline $4-300-2-S$ & 940 & & & 300 & & & & & & & $3-10,000$ & & & \\
\hline $8-0-1-S$ & 941 & & 5.5 & 0 & 0 & 2 & 24.5 & 23.5 & 11.764 & 16.767 & 0 & & & \\
\hline $8-0-2-S$ & 942 & & & 0 & & & & & 11.719 & 16.722 & 0 & & & \\
\hline 8-10-1-S & 943 & & & 10 & & & & & & & $1-1,000$ & & & \\
\hline 8-10-2-S & 944 & & & 10 & & & & & & & $1-1,000$ & & & \\
\hline $8-30-1-S$ & 945 & & & 30 & & & & & & & $3-1,000$ & & & \\
\hline $8-30-2-S$ & 946 & & & 30 & & & & & & & $3-1,000$ & & & \\
\hline 8-100-1-S & 947 & & & 100 & & & & & & & $1-10,000$ & & & \\
\hline $8-100-2-S$ & 948 & & & 100 & & & & & & & $1-10,000$ & & & \\
\hline $8-300-1-S$ & 949 & & & 300 & & & & & & & $3-10,000$ & & & \\
\hline $8-300-2-\mathrm{S}$ & 950 & & & 300 & & & & & & & $3-10,000$ & & & \\
\hline 9-0-1-S & 951 & & 7.2 & 0 & 0 & 4 & 24 & 22 & 11.698 & 16.698 & 0 & & & \\
\hline $9-0-2-S$ & 952 & & & 0 & & & & & 11.728 & 16.729 & 0 & & & \\
\hline $9-10-1-S$ & 953 & & & 10 & & & & & & & $1-1,000$ & & & \\
\hline 9-10-2-S & 954 & & & 10 & & & & & & & $1-1,000$ & & & \\
\hline $9-30-1-S$ & 955 & & & 30 & & & & & & & $3-1,000$ & & & \\
\hline $9-30-2-S$ & 956 & & & 30 & & & & & & & $3-1,000$ & & & \\
\hline $9-100-1-S$ & 957 & & & 100 & & & & & & & $1-10,000$ & & & \\
\hline 9-100-2-S & 958 & & & 100 & & & & & & & $1-10,000$ & & & \\
\hline $9-300-1-S$ & 959 & & & 300 & & & & & & & $3-10,000$ & & & \\
\hline 9-300-2-S & 960 & & & 300 & & & & & & & $3-10,000$ & & & \\
\hline & & & & & & & & & & & & & & \\
\hline
\end{tabular}


Table 3. Preparation of No-Sediment Control Samples.

\begin{tabular}{|c|c|c|c|c|c|c|c|c|}
\hline $\begin{array}{l}\text { Sample ID } \\
\text { (pH \#-FA- } \\
\text { Rep-Sed) }\end{array}$ & Lab ID & $\begin{array}{c}\text { Targeted } \\
\text { pH } \\
( \pm 0.15) \\
\end{array}$ & $\begin{array}{c}\text { SR-NOM } \\
(\text { ppm C) }\end{array}$ & Tare Wt (g) & $\begin{array}{c}\text { FA added } \\
\text { (mL/Stock ppm) }\end{array}$ & $\begin{array}{l}\text { Wt after adj pH } \\
\text { of FA soln wt (g) }\end{array}$ & $\begin{array}{l}\text { Amt water } \\
\text { added (g) }\end{array}$ & $\begin{array}{l}\text { Final pH } \\
\quad(\mathbf{p H})\end{array}$ \\
\hline Proc. Step & & & & 10 & 11 & 17 & 18 & 22 \\
\hline $4-0-1-\mathrm{N}$ & 961 & 4.1 & 0 & & 0 & & & \\
\hline $4-0-1-\mathrm{N}$ & 962 & & 0 & & 0 & & & \\
\hline $4-10-1-\mathrm{N}$ & 963 & & 10 & & $1-1,000$ & & & \\
\hline $4-10-1-\mathrm{N}$ & 964 & & 10 & & $1-1,000$ & & & \\
\hline $4-30-1-\mathrm{N}$ & 965 & & 30 & & $3-1,000$ & & & \\
\hline $4-30-1-\mathrm{N}$ & 966 & & 30 & & $3-1,000$ & & & \\
\hline $4-100-1-\mathrm{N}$ & 967 & & 100 & & $1-10,000$ & & & \\
\hline $4-100-1-\mathrm{N}$ & 968 & & 100 & & $1-10,000$ & & & \\
\hline $4-300-1-\mathrm{N}$ & 969 & & 300 & & $3-10,000$ & & & \\
\hline $4-300-1-\mathrm{N}$ & 970 & & 300 & & $3-10,000$ & & & \\
\hline $8-0-1-\mathrm{N}$ & 971 & 8.0 & 0 & & 0 & & & \\
\hline $8-0-2-\mathrm{N}$ & 972 & & 0 & & 0 & & & \\
\hline $8-10-1-\mathrm{N}$ & 973 & & 10 & & $1-1,000$ & & & \\
\hline $8-10-1-\mathrm{N}$ & 974 & & 10 & & $1-1,000$ & & & \\
\hline $8-30-1-\mathrm{N}$ & 975 & & 30 & & $3-1,000$ & & & \\
\hline $8-30-1-\mathrm{N}$ & 976 & & 30 & & $3-1,000$ & & & \\
\hline $8-100-1-\mathrm{N}$ & 977 & & 100 & & $1-10,000$ & & & \\
\hline $8-100-1-\mathrm{N}$ & 978 & & 100 & & $1-10,000$ & & & \\
\hline $8-300-1-\mathrm{N}$ & 979 & & 300 & & $3-10,000$ & & & \\
\hline $8-300-1-\mathrm{N}$ & 980 & & 300 & & $3-10,000$ & & & \\
\hline
\end{tabular}


Table 4. Preparation of Order-of-Addition Controls (Clayey Sediment \& 100 ppm C Only)

\begin{tabular}{|c|c|c|c|c|c|}
\hline $\begin{array}{c}\text { Sample ID } \\
\text { (pH-FA-Rep-Sed) }\end{array}$ & Lab ID & $\begin{array}{c}\text { Target } \\
\text { pH } \\
( \pm 0.15)\end{array}$ & Tare wt. (g) & $\begin{array}{c}\text { Tare+Sed+COC+FA } \\
\text { wt. }(g)\end{array}$ & $\begin{array}{c}\text { Make up Water wt. } \\
\text { (g) }\end{array}$ \\
\hline Proc. Step & & & 32 & 38 & 40 \\
\hline 4-100-1-COC/FA & 981 & 4.0 & & & \\
\hline 4-100-2-COC/FA & 982 & 4.0 & & & \\
\hline 8-100-1-COC/FA & 983 & 8.0 & & & \\
\hline 8-100-2-COC/FA & 984 & 8.0 & & & \\
\hline & & & & & \\
\hline Proc. Step & & & 45 & 52 & 54 \\
\hline 4-100-1-COC+FA & 985 & 4.0 & & & \\
\hline 4-100-2-COC+FA & 986 & 4.0 & & & \\
\hline 8-100-1-COC+FA & 987 & 8.0 & & & \\
\hline 8-100-2-COC+FA & 988 & 8.0 & & & \\
\hline
\end{tabular}


Figure 1. Original conceptualization of Experimen

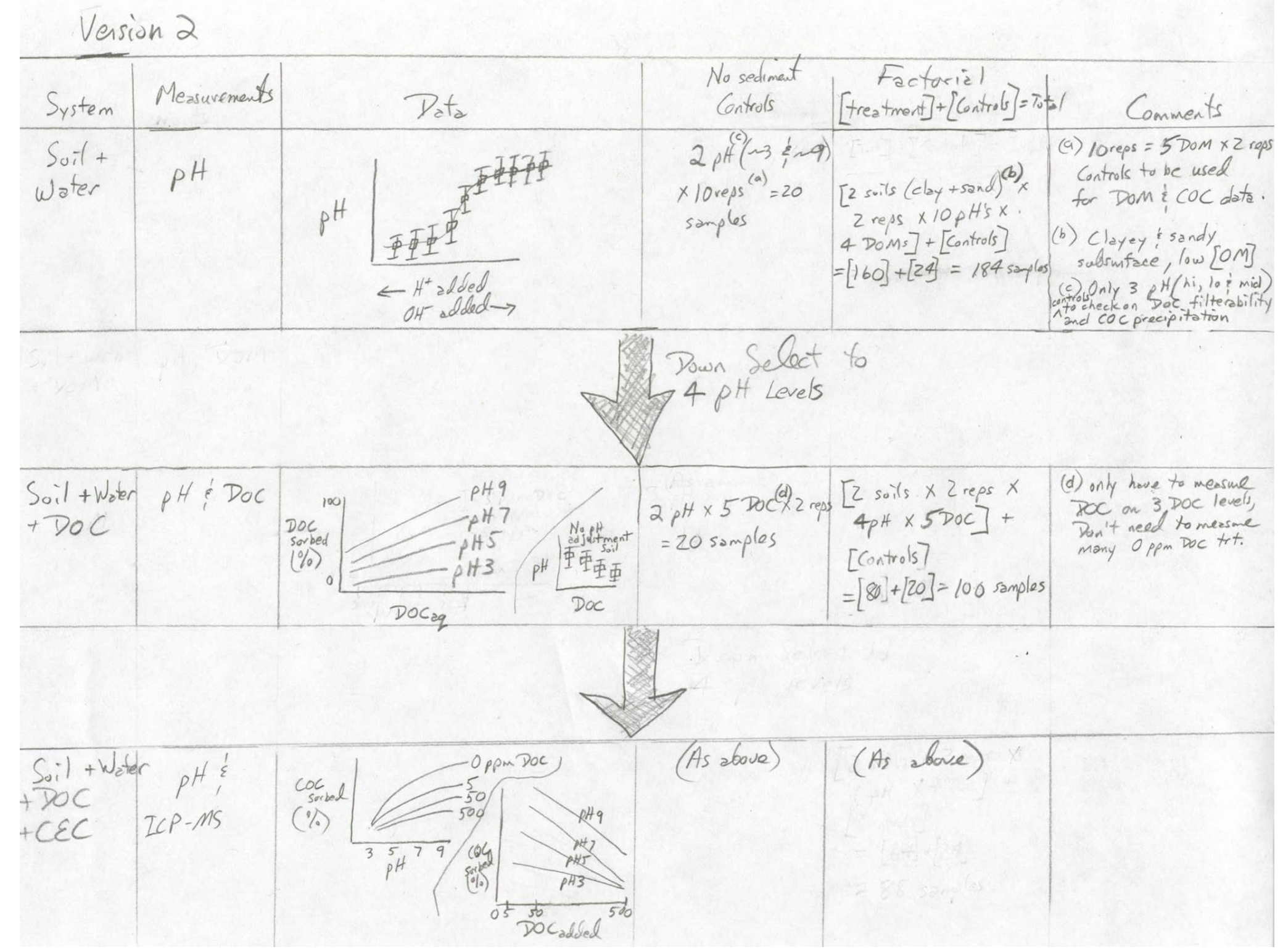


WSRC-RP-2004-00593

9.0 APPENDIX B: ADDITIONAL DATA 
WSRC-RP-2004-00593

Table A 1. Point of Zero Salt Effect for Sandy Sediment Raw Data.

\begin{tabular}{lrr}
\hline $\mathrm{g}(0.005=$ & $0.925 \mathrm{M}$ & Ionic strengths of background solutions; Corrected by Davies Equation. \\
$\mathrm{g}(0.01)=$ & $0.89 \mathrm{M}$ & \\
$\mathrm{g}(0.05)=$ & $0.807 \mathrm{M}$ &
\end{tabular}

\begin{tabular}{|c|c|c|c|c|c|c|c|}
\hline \multirow[t]{2}{*}{ Sample } & \multirow{2}{*}{$\begin{array}{l}\text { Soil } \\
\text { Weight (g) }\end{array}$} & \multirow{2}{*}{$\begin{array}{l}\text { Blank } \\
\mathrm{pH}\end{array}$} & \multirow{2}{*}{\multicolumn{2}{|c|}{$\begin{array}{l}2 \text { week } \\
\mathrm{pH}\end{array}$}} & \multicolumn{3}{|c|}{2 week } \\
\hline & & & & & DH & $\mathrm{DOH}$ & DH-DOH \\
\hline $1-005-s$ & 2.5547 & 2.77 & 3.74 & $*$ & 0.001516 & $-4.90657 \mathrm{E}-11$ & $6.41647 \mathrm{E}-05$ \\
\hline $2-005-s$ & 2.5357 & 2.93 & 4.26 & * & 0.00112 & $-1.73459 \mathrm{E}-10$ & $4.77482 \mathrm{E}-05$ \\
\hline $3-005-s$ & 2.5416 & 3.22 & 4.5 & $*$ & 0.000571 & $-2.99632 \mathrm{E}-10$ & $2.42851 \mathrm{E}-05$ \\
\hline 4-005-s & 2.5232 & 3.53 & 4.69 & $*$ & 0.000275 & $-4.55894 \mathrm{E}-10$ & $1.17699 \mathrm{E}-05$ \\
\hline 5-005-s & 2.5592 & 3.84 & 4.9 & $*$ & 0.000132 & $-7.25145 \mathrm{E}-10$ & $5.57418 \mathrm{E}-06$ \\
\hline 6-005-s & 2.5041 & 4.43 & 5.49 & & 3.39E-05 & $-2.82114 \mathrm{E}-09$ & $1.46443 \mathrm{E}-06$ \\
\hline 7-005-s & 2.5198 & 5.59 & 5.77 & & $8.72 \mathrm{E}-07$ & -1.99799E-09 & $3.75041 \mathrm{E}-08$ \\
\hline 8-005-s & 2.5334 & 9.28 & 6.25 & & $-5.6 \mathrm{E}-07$ & $1.90368 \mathrm{E}-05$ & $-8.36335 \mathrm{E}-07$ \\
\hline 9-005-s & 2.5202 & 10.16 & 7.15 & & $-7.1 \mathrm{E}-08$ & 0.000144403 & $-6.19743 \mathrm{E}-06$ \\
\hline $10-005-\mathrm{s}$ & 2.5487 & 10.59 & 7.48 & & $-3.3 \mathrm{E}-08$ & 0.000388743 & $-1.64907 \mathrm{E}-05$ \\
\hline $11-005-\mathrm{s}$ & 2.5201 & 10.94 & 8.49 & $*$ & $-3.2 \mathrm{E}-09$ & 0.000867873 & $-3.72305 \mathrm{E}-05$ \\
\hline $12-005-\mathrm{s}$ & 2.5531 & 11.25 & 9.21 & $*$ & $-6.1 \mathrm{E}-10$ & 0.001762061 & $-7.46125 \mathrm{E}-05$ \\
\hline $13-005-\mathrm{s}$ & 2.5452 & 11.49 & 9.95 & $*$ & $-1.1 \mathrm{E}-10$ & 0.00300117 & -0.000127476 \\
\hline $1-01-\mathrm{s}$ & 2.5655 & 2.78 & 3.68 & $*$ & 0.001451 & $-4.18374 \mathrm{E}-11$ & $6.11295 \mathrm{E}-05$ \\
\hline $2-01-s$ & 2.5551 & 3.01 & 4.41 & $*$ & 0.000938 & $-2.46807 \mathrm{E}-10$ & $3.97015 \mathrm{E}-05$ \\
\hline $3-01-s$ & 2.551 & 3.27 & 4.48 & $*$ & 0.000504 & $-2.83374 \mathrm{E}-10$ & $2.13554 \mathrm{E}-05$ \\
\hline 4-01-s & 2.5579 & 3.61 & 4.79 & $*$ & 0.000229 & $-5.75857 \mathrm{E}-10$ & $9.68926 \mathrm{E}-06$ \\
\hline $5-01-\mathrm{s}$ & 2.523 & 3.86 & 4.91 & & 0.000126 & $-7.40387 \mathrm{E}-10$ & 5.38769E-06 \\
\hline 6-01-s & 2.5114 & 4.47 & 5.55 & & $3.11 \mathrm{E}-05$ & $-3.25301 \mathrm{E}-09$ & $1.33744 \mathrm{E}-06$ \\
\hline 7-01-s & 2.5561 & 5.75 & 5.93 & & $6.03 \mathrm{E}-07$ & $-2.88797 \mathrm{E}-09$ & $2.56417 \mathrm{E}-08$ \\
\hline $8-01-s$ & 2.5421 & 9.95 & 6.51 & & $-3.1 \mathrm{E}-07$ & 8.90927E-05 & $-3.80199 \mathrm{E}-06$ \\
\hline 9-01-s & 2.6239 & 10.26 & 6.91 & & $-1.2 \mathrm{E}-07$ & 0.000181889 & $-7.49912 \mathrm{E}-06$ \\
\hline 10-01-s & 2.5394 & 10.6 & 7.59 & & $-2.6 \mathrm{E}-08$ & 0.000397718 & $-1.69329 \mathrm{E}-05$ \\
\hline 11-01-s & 2.5288 & 10.96 & 8.71 & $*$ & $-1.9 \mathrm{E}-09$ & 0.000906882 & $-3.877 \mathrm{E}-05$ \\
\hline $12-01-\mathrm{s}$ & 2.543 & 11.26 & 9.28 & $*$ & $-5.2 \mathrm{E}-10$ & 0.001800646 & $-7.65492 \mathrm{E}-05$ \\
\hline 13-01-s & 2.5205 & 11.5 & 9.93 & $*$ & $-1.1 \mathrm{E}-10$ & 0.003077164 & -0.000131984 \\
\hline $1-05-\mathrm{s}$ & 2.5127 & 2.73 & 4.01 & & 0.001764 & $-9.6959 \mathrm{E}-11$ & 7.59112E-05 \\
\hline $2-05-s$ & 2.5573 & 2.96 & 4.4 & & 0.001057 & $-2.42069 \mathrm{E}-10$ & 4.46699E-05 \\
\hline $3-05-s$ & 2.5151 & 3.24 & 4.63 & & 0.000552 & $-4.09202 \mathrm{E}-10$ & 2.37269E-05 \\
\hline $4-05-s$ & 2.502 & 3.55 & 4.83 & & 0.000267 & $-6.40602 \mathrm{E}-10$ & $1.15388 \mathrm{E}-05$ \\
\hline $5-05-s$ & 2.511 & 3.87 & 5.08 & & 0.000127 & $-1.12813 \mathrm{E}-09$ & $5.44974 \mathrm{E}-06$ \\
\hline $6-05-s$ & 2.5063 & 4.54 & 5.63 & & $2.65 \mathrm{E}-05$ & $-3.91906 \mathrm{E}-09$ & 1.14307E-06 \\
\hline $7-05-s$ & 2.5643 & 6.01 & 5.87 & & $-3.7 \mathrm{E}-07$ & 2.81983E-09 & $-1.57904 \mathrm{E}-08$ \\
\hline $8-05-s$ & 2.512 & 9.32 & 6.2 & & $-6.3 E-07$ & 2.08771E-05 & $-9.25615 \mathrm{E}-07$ \\
\hline $9-05-\mathrm{s}$ & 2.5136 & 10.14 & 6.84 & & $-1.4 \mathrm{E}-07$ & 0.000137969 & $-5.94017 \mathrm{E}-06$ \\
\hline $10-05-\mathrm{s}$ & 2.5244 & 10.5 & 7.57 & & $-2.7 \mathrm{E}-08$ & 0.000315856 & $-1.35278 \mathrm{E}-05$ \\
\hline $11-05-\mathrm{s}$ & 2.5132 & 10.88 & 8.07 & & $-8.5 \mathrm{E}-09$ & 0.000757403 & $-3.25809 \mathrm{E}-05$ \\
\hline $12-05-\mathrm{s}$ & 2.519 & 11.16 & 8.55 & *light & $-2.8 \mathrm{E}-09$ & 0.001441892 & $-6.18819 \mathrm{E}-05$ \\
\hline $13-05-\mathrm{s}$ & 2.5205 & 11.44 & 11.06 & *light & $-5.1 \mathrm{E}-12$ & 0.001606075 & $-6.8887 \mathrm{E}-05$ \\
\hline
\end{tabular}

*= The solution was cloudy even after centrifugation and sitting still for three weeks. 
Table A 2. Point-of-Zero-Salt Effect of Clayey Sediment (Lysimeter Sediment).

\begin{tabular}{|c|c|c|c|c|c|c|c|c|c|}
\hline \multirow[b]{3}{*}{ Tube } & \multicolumn{4}{|c|}{ Point of Zero Charge pH Testing --Blank } & \multicolumn{5}{|c|}{ Point of Zero Charge pH Testing - Lycimeter } \\
\hline & \multicolumn{2}{|c|}{ Concentration } & \multirow[b]{2}{*}{$.05 \mathrm{M}$} & \multicolumn{4}{|c|}{ Concentration } & & \\
\hline & $.005 \mathrm{M}$ & $.01 \mathrm{M}$ & & Tube & $.005 \mathrm{M}$ & $.01 \mathrm{M}$ & $.05 \mathrm{M}$ & & \\
\hline 1 & 2.73 & 2.78 & 2.8 & 1 & 3.36 & 3.44 & 3.42 & & \\
\hline 2 & 2.98 & 2.96 & 2.98 & 2 & 3.98 & 3.67 & 3.91 & $\begin{array}{l}\text { Labbook ID: } \\
\text { ESE209, p3 }\end{array}$ & \\
\hline 3 & 3.25 & 3.25 & 3.17 & 3 & 4.6 & 4.57 & 4.73 & & \\
\hline 4 & 3.59 & 3.62 & 3.78 & 4 & 5.03 & 5.16 & 5.21 & & \\
\hline 5 & 3.68 & 3.85 & 3.71 & 5 & 5.05 & 5.32 & 5.08 & & \\
\hline 6 & 4 & 4.02 & 4.13 & 6 & 5.37 & 5.72 & 5.36 & & \\
\hline 7 & 5.04 & 5.56 & 5.71 & 7 & 5.58 & 5.86 & 5.69 & & \\
\hline 8 & 7.27 & 9.66 & 8.49 & 8 & 6.06 & 6.27 & 6 & & \\
\hline 9 & 8.26 & 10.08 & 10.27 & 9 & 6.08 & 6.33 & 6.45 & & \\
\hline 10 & 10.69 & 10.6 & 10.19 & 10 & 6.5 & 6.73 & 6.42 & & \\
\hline 11 & 11.1 & 11.19 & 11.04 & 11 & 6.99 & 7.39 & 7.03 & & \\
\hline 12 & 11.53 & 11.55 & 11.52 & 12 & 9.55 & 9.56 & 9.1 & & \\
\hline \multirow[t]{2}{*}{13} & 11.84 & 11.8 & 11.6 & 13 & 10.88 & 10.83 & 10.51 & & \\
\hline & \multicolumn{3}{|c|}{ DH } & \multicolumn{3}{|c|}{ DOH } & \multicolumn{3}{|c|}{ DH-DOH } \\
\hline Tube & $0.005 \mathrm{M}$ & $0.01 M$ & $0.05 \mathrm{M}$ & $0.005 \mathrm{M}$ & $0.01 \mathrm{M}$ & $0.05 \mathrm{M}$ & $0.005 \mathrm{M}$ & $0.01 \mathrm{M}$ & $0.05 \mathrm{M}$ \\
\hline 1 & 0.001425571 & 0.001296509 & 0.001204704 & $-1.75384 \mathrm{E}-11$ & $-2.15167 \mathrm{E}-11$ & $-1.99931 \mathrm{E}-11$ & 0.001425571 & 0.001296509 & 0.001204704 \\
\hline 2 & 0.000942416 & 0.000882682 & 0.000924102 & $-8.59493 \mathrm{E}-11$ & $-3.76534 \mathrm{E}-11$ & $-7.17331 \mathrm{E}-11$ & 0.000942416 & 0.000882682 & 0.000924102 \\
\hline 3 & 0.000537222 & 0.000535426 & 0.000657462 & $-3.80324 \mathrm{E}-10$ & $-3.53752 \mathrm{E}-10$ & $-5.22241 \mathrm{E}-10$ & 0.000537223 & 0.000535426 & 0.000657463 \\
\hline 4 & 0.000247707 & 0.000232965 & 0.000159793 & $-1.03261 \mathrm{E}-09$ & $-1.40375 \mathrm{E}-09$ & $-1.56155 \mathrm{E}-09$ & 0.000247708 & 0.000232966 & 0.000159794 \\
\hline 5 & 0.000200017 & 0.000136467 & 0.000186667 & $-1.07416 \mathrm{E}-09$ & $-2.0185 \mathrm{E}-09$ & $-1.15098 \mathrm{E}-09$ & 0.000200018 & 0.000136469 & 0.000186668 \\
\hline 6 & $9.57342 \mathrm{E}-05$ & 9.35938E-05 & $6.97659 \mathrm{E}-05$ & $-2.24423 \mathrm{E}-09$ & $-5.14336 \mathrm{E}-09$ & -2.15597E-09 & $9.57364 \mathrm{E}-05$ & 9.35989E-05 & $6.9768 \mathrm{E}-05$ \\
\hline 7 & $6.48984 \mathrm{E}-06$ & $1.37384 \mathrm{E}-06$ & $-9.18933 \mathrm{E}-08$ & $-2.70542 \mathrm{E}-09$ & $-3.61358 \mathrm{E}-09$ & $2.30826 \mathrm{E}-10$ & $6.49255 \mathrm{E}-06$ & $1.37746 \mathrm{E}-06$ & $-9.2124 \mathrm{E}-08$ \\
\hline 8 & $-8.1726 \mathrm{E}-07$ & $-5.36813 \mathrm{E}-07$ & $-9.96764 \mathrm{E}-07$ & $1.74727 \mathrm{E}-07$ & $4.56902 \mathrm{E}-05$ & 3.0803E-06 & $-9.9198 \mathrm{E}-07$ & $-4.6227 \mathrm{E}-05$ & $-4.0776 \mathrm{E}-06$ \\
\hline 9 & $-8.2626 \mathrm{E}-07$ & $-4.67652 \mathrm{E}-07$ & $-3.5476 \mathrm{E}-07$ & $1.80768 \mathrm{E}-06$ & 0.000120205 & 0.000186181 & $-2.6339 \mathrm{E}-06$ & -0.000120673 & -0.00018653 \\
\hline 10 & $-3.1620 \mathrm{E}-07$ & $-1.86184 \mathrm{E}-07$ & $-3.80125 \mathrm{E}-07$ & 0.000489747 & 0.000398053 & 0.000154855 & -0.00049006 & -0.00039824 & -0.00015523 \\
\hline 11 & $-1.023 \mathrm{E}-07$ & $-4.07316 \mathrm{E}-08$ & $-9.33163 \mathrm{E}-08$ & 0.001258828 & 0.001548571 & 0.001096371 & -0.00125893 & -0.001548612 & -0.00109646 \\
\hline 12 & $-2.7888 \mathrm{E}-10$ & $-2.72604 \mathrm{E}-10$ & $-7.91308 \mathrm{E}-10$ & 0.00335296 & 0.003511826 & 0.003298722 & -0.00335296 & -0.003511826 & -0.00329872 \\
\hline 13 & $-1.1737 \mathrm{E}-11$ & $-1.32062 \mathrm{E}-11$ & $-2.83911 \mathrm{E}-11$ & 0.006159732 & 0.00563349 & 0.003657478 & -0.00615973 & -0.00563349 & -0.00365747 \\
\hline
\end{tabular}


WSRC-RP-2004-00593

\begin{tabular}{|c|c|c|c|c|c|c|c|}
\hline \multirow[b]{2}{*}{ Tube } & \multicolumn{3}{|c|}{ Soil Weights (g) } & \multicolumn{4}{|c|}{ DH-DOH } \\
\hline & $0.005 \mathrm{M}$ & $0.01 M$ & $0.05 M$ & Tube & $0.005 \mathrm{M}$ & $0.01 M$ & $0.05 M$ \\
\hline 1 & 0.525 & 0.542 & 0.523 & 1 & 0.000293554 & 0.000268773 & 0.000285 \\
\hline 2 & 0.509 & 0.521 & 0.513 & 2 & 0.000200163 & 0.00019036 & 0.000223 \\
\hline 3 & 0.503 & 0.516 & 0.52 & 3 & 0.000115464 & 0.00011659 & 0.000157 \\
\hline 4 & 0.519 & 0.519 & 0.52 & 4 & $5.15978 \mathrm{E}-05$ & 5.04354E-05 & $3.81 \mathrm{E}-05$ \\
\hline 5 & 0.506 & 0.513 & 0.509 & 5 & 4.27344E-05 & $2.98902 \mathrm{E}-05$ & 4.54E-05 \\
\hline 6 & 0.529 & 0.527 & 0.505 & 6 & $1.9565 \mathrm{E}-05$ & 1.99559E-05 & $1.71 \mathrm{E}-05$ \\
\hline 7 & 0.52 & 0.52 & 0.51 & 7 & $1.3498 \mathrm{E}-06$ & $2.97636 \mathrm{E}-07$ & $-2.24 \mathrm{E}-08$ \\
\hline 8 & 0.521 & 0.514 & 0.506 & 8 & $-2.05839 \mathrm{E}-07$ & $-1.01051 \mathrm{E}-05$ & $-9.98 \mathrm{E}-07$ \\
\hline 9 & 0.524 & 0.511 & 0.515 & 9 & $-5.43418 \mathrm{E}-07$ & $-2.65337 \mathrm{E}-05$ & $-4.49 \mathrm{E}-05$ \\
\hline 10 & 0.52 & 0.493 & 0.512 & 10 & -0.000101884 & $-9.07627 \mathrm{E}-05$ & $-3.76 \mathrm{E}-05$ \\
\hline 11 & 0.517 & 0.51 & 0.508 & 11 & -0.000263251 & -0.000341179 & -0.000267 \\
\hline 12 & 0.506 & 0.512 & 0.51 & 12 & -0.000716368 & -0.000770678 & -0.000801 \\
\hline 13 & 0.518 & 0.509 & 0.513 & 13 & -0.001285554 & -0.001243569 & -0.000883 \\
\hline
\end{tabular}


Table A 3. ICP-MS results from solutions at the end of the equilibration period.

\begin{tabular}{|c|c|c|c|c|c|c|c|c|c|c|c|c|c|}
\hline $\begin{array}{l}\text { Lab } \\
\text { ID }\end{array}$ & $\begin{array}{c}\text { Lab } \\
\text { Description }\end{array}$ & $\begin{array}{c}\text { Target } \\
\text { pH }\end{array}$ & $\begin{array}{c}\text { Target } \\
\text { FA } \\
(\mathrm{ppmC})\end{array}$ & K(ppb) & $\mathbf{N i}(\mathbf{p p b})$ & $\operatorname{Sr}(\mathbf{p p b})$ & Zr(ppb) & $\mathbf{R h}(\mathbf{p p b})$ & Cs(ppb) & $\mathrm{Ce}(\mathbf{p p b})$ & Eu(ppb) & Th(ppb) & Final pH \\
\hline 901 & 3-0-1-Clay & 4 & 0 & 5635 & 528.2 & 533.7 & 15.7 & 0.463 & 205.5 & 136.0 & 118.0 & 29.8 & 3.76 \\
\hline 902 & 3-0-2-Clay & & 0 & 2934 & 485.2 & 507.2 & 8.9 & 0.457 & 180.4 & 107.9 & 95.9 & 17.1 & 3.94 \\
\hline 903 & 3-10-1- Clay & & 10 & 5037 & 511.8 & 527.7 & 7.0 & 0.457 & 194.4 & 142.3 & 125.0 & 12.0 & 3.66 \\
\hline 904 & 3-10-2-Clay & & 10 & 2264 & 521.6 & 537.7 & 6.4 & 0.459 & 177.4 & 133.6 & 119.9 & 10.5 & 3.80 \\
\hline 905 & 3-30-1- Clay & & 30 & 3115 & 538.4 & 536.5 & 6.5 & 0.459 & 175.5 & 117.6 & 105.6 & 9.7 & 3.83 \\
\hline 906 & 3-30-2 Clay & & 30 & 3007 & 537.5 & 538.1 & 6.5 & 0.461 & 189.5 & 133.5 & 119.0 & 9.3 & 3.77 \\
\hline 907 & 3-100-1- Clay & & 100 & 2917 & 515.8 & 534.9 & 7.6 & 0.457 & 168.9 & 109.7 & 95.2 & 9.0 & 3.79 \\
\hline 908 & 3-100-2-Clay & & 100 & 2720 & 518.2 & 542.6 & 8.1 & 0.464 & 197.0 & 121.9 & 105.0 & 8.6 & 3.81 \\
\hline 909 & 3-300-1-Clay & & 300 & 7175 & 386.3 & 427.4 & 19.9 & 0.457 & 98.9 & 64.3 & 66.3 & 9.5 & 3.76 \\
\hline 910 & 3-300-2- Clay & & 300 & 4489 & 465.7 & 502.0 & 22.5 & 0.464 & 175.5 & 95.4 & 92.8 & 9.2 & 3.68 \\
\hline 911 & 10-0-1- Clay & 6.1 & 0 & 4749 & 159.9 & 190.6 & 9.4 & 0.000 & 85.5 & 0.5 & 0.5 & 19.4 & 5.10 \\
\hline 912 & 10-0-2- Clay & & 0 & 2979 & 164.3 & 190.7 & 6.3 & 0.000 & 79.5 & 1.1 & 0.9 & 10.2 & 5.12 \\
\hline 913 & 10-10-1- Clay & & 10 & 1941 & 69.5 & 77.0 & 4.1 & 0.000 & 46.6 & 0.2 & 0.2 & 7.3 & 5.48 \\
\hline 914 & 10-10-2- Clay & & 10 & 1781 & 113.4 & 136.0 & 3.6 & 0.000 & 62.4 & 0.2 & 0.2 & 6.1 & 5.29 \\
\hline 915 & 10-30-1- Clay & & 30 & 2572 & 73.0 & 89.9 & 3.3 & 0.000 & 53.7 & 0.2 & 0.2 & 5.2 & 5.44 \\
\hline 916 & 10-30-2- Clay & & 30 & 2437 & 122.8 & 131.4 & 3.8 & 0.000 & 60.8 & 0.3 & 0.2 & 4.8 & 5.23 \\
\hline 917 & 10-100-1- Clay & & 100 & 3933 & 95.4 & 107.4 & 4.3 & 0.000 & 62.5 & 0.9 & 0.5 & 4.5 & 5.32 \\
\hline 918 & 10-100-2- Clay & & 100 & 2399 & 167.6 & 187.5 & 4.8 & 0.000 & 79.6 & 1.5 & 2.0 & 4.5 & 5.00 \\
\hline 919 & 10-300-1- Clay & & 300 & 3060 & 62.3 & 63.9 & 37.8 & 0.000 & 44.0 & 22.9 & 29.1 & 6.2 & 5.57 \\
\hline 920 & 10-300-2- Clay & & 300 & 2707 & 57.8 & 54.8 & 27.4 & 0.000 & 2.1 & 11.2 & 17.5 & 5.5 & 5.20 \\
\hline 921 & 11-0-1-CLAY & 8.7 & 0 & 6167 & 0.8 & 40.8 & 55.9 & 0.012 & 47.8 & 0.4 & 0.5 & 21.7 & 8.25 \\
\hline 922 & 11-0-2-CLAY & & 0 & 3176 & 22.1 & 60.3 & 3.9 & 0.012 & 46.6 & 0.2 & 0.3 & 5.9 & 6.21 \\
\hline 923 & 11-10-1-CLAY & & 10 & 3474 & 7.7 & 55.3 & 4.7 & 0.007 & 46.8 & 0.2 & 0.3 & 5.4 & 6.62 \\
\hline 924 & 11-10-2-CLAY & & 10 & 3263 & 31.9 & 85.3 & 2.5 & 0.008 & 56.8 & 0.2 & 0.2 & 4.3 & 5.72 \\
\hline 925 & 11-30-1-CLAY & & 30 & 2251 & 6.8 & 51.7 & 4.7 & 0.007 & 43.8 & 0.2 & 0.3 & 4.4 & 6.73 \\
\hline 926 & 11-30-2-CLAY & & 30 & 1366 & 7.5 & 40.5 & 4.0 & 0.005 & 24.9 & 0.2 & 0.3 & 3.8 & 6.59 \\
\hline 927 & 11-100-1-CLAY & & 100 & 2303 & 28.6 & 70.6 & 3.8 & 0.006 & 45.7 & 0.6 & 1.2 & 3.6 & 5.81 \\
\hline 928 & 11-100-2-CLAY & & 100 & 2876 & 19.0 & 56.9 & 3.7 & 0.005 & 44.9 & 0.8 & 1.3 & 3.4 & 6.15 \\
\hline 929 & 11-300-1-CLAY & & 300 & 3191 & 55.9 & 48.4 & 54.7 & 0.006 & 21.3 & 52.8 & 42.0 & 12.8 & 7.15 \\
\hline 930 & 11-300-2-CLAY & & 300 & 1560 & 48.8 & 40.7 & 63.4 & 0.005 & 20.8 & 44.6 & 41.3 & 12.0 & 6.27 \\
\hline
\end{tabular}


WSRC-RP-2004-00593

\begin{tabular}{|c|c|c|c|c|c|c|c|c|c|c|c|c|c|}
\hline 931 & 4-0-1-SAND & 4.1 & 0 & 2847 & 567.7 & 530.4 & 49.2 & 0.000 & 324.4 & 101.2 & 108.7 & 21.5 & 3.80 \\
\hline 932 & 4-0-2-SAND & & 0 & 1103 & 550.0 & 511.6 & 17.0 & 0.000 & 328.2 & 85.2 & 91.4 & 6.7 & 4.01 \\
\hline 933 & 4-10-1-SAND & & 10 & 1626 & 535.9 & 509.2 & 12.8 & 0.000 & 319.5 & 78.9 & 83.8 & 4.4 & 4.04 \\
\hline 934 & 4-10-2-SAND & & 10 & 1331 & 520.9 & 506.7 & 10.4 & 0.000 & 320.8 & 63.9 & 68.5 & 3.1 & 4.17 \\
\hline 935 & 4-30-1-SAND & & 30 & 1168 & 516.4 & 516.4 & 9.6 & 0.000 & 329.8 & 65.0 & 70.9 & 2.5 & 3.89 \\
\hline 936 & 4-30-2-SAND & & 30 & 1056 & 497.0 & 482.1 & 8.7 & 0.000 & 307.6 & 37.6 & 42.8 & 2.3 & 4.15 \\
\hline 937 & 4-100-1-SAND & & 100 & 1071 & 463.2 & 415.9 & 78.1 & 0.000 & 270.5 & 51.2 & 79.7 & 6.0 & 4.04 \\
\hline 938 & 4-100-2-SAND & & 100 & 1753 & 469.8 & 435.7 & 84.1 & 0.000 & 292.5 & 57.7 & 85.9 & 6.8 & 3.99 \\
\hline 939 & 4-300-1-SAND & & 300 & 1368 & 382.8 & 365.5 & 472.7 & 0.000 & 198.6 & 163.3 & 218.6 & 31.6 & 3.98 \\
\hline 940 & 4-300-2-SAND & & 300 & 1421 & 392.8 & 410.6 & 642.9 & 0.000 & 216.9 & 191.7 & 222.3 & 44.6 & 3.99 \\
\hline 941 & 8-0-1-SAND & 5.5 & 0 & 4849 & 390.1 & 343.3 & 19.9 & 0.106 & 288.3 & 11.3 & 16.0 & 18.2 & 5.49 \\
\hline 942 & 8-0-2-SAND & & 0 & 1217 & 344.2 & 305.5 & 12.0 & 0.102 & 228.2 & 2.8 & 2.9 & 5.7 & 5.41 \\
\hline 943 & 8-10-1-SAND & & 10 & 912.3 & 328.0 & 286.3 & 5.2 & 0.099 & 220.5 & 0.8 & 1.1 & 3.6 & 5.40 \\
\hline 944 & 8-10-2-SAND & & 10 & 960.5 & 374.5 & 336.6 & 2.0 & 0.100 & 257.4 & 5.7 & 6.3 & 2.7 & 5.33 \\
\hline 945 & 8-30-1-SAND & & 30 & 1196 & 294.6 & 267.3 & 3.3 & 0.101 & 213.0 & 5.0 & 9.4 & 2.3 & 5.31 \\
\hline 946 & 8-30-2-SAND & & 30 & 874.9 & 266.1 & 236.3 & 2.0 & 0.099 & 204.4 & 4.2 & 8.4 & 1.8 & 5.37 \\
\hline 947 & 8-100-1-SAND & & 100 & 1391 & 438.9 & 424.5 & 203.5 & 0.108 & 318.5 & 87.1 & 101.0 & 9.2 & 5.23 \\
\hline 948 & 8-100-2-SAND & & 100 & 1391 & 248.4 & 199.9 & 151.3 & 0.096 & 136.6 & 59.0 & 90.1 & 12.9 & 5.17 \\
\hline 949 & 8-300-1-SAND & & 300 & 1356 & 268.7 & 152.7 & 584.2 & 0.097 & 82.7 & 204.3 & 239.2 & 38.7 & 5.24 \\
\hline 950 & 8-300-2-SAND & & 300 & 1372 & 319.6 & 197.4 & 665.7 & 0.096 & 154.0 & 236.0 & 272.8 & 44.1 & 5.22 \\
\hline 951 & 9-0-1-SAND & 7.2 & 0 & 2968 & 45.8 & 93.0 & 135.4 & 0.000 & 183.6 & 0.8 & 13.7 & 13.3 & 6.56 \\
\hline 952 & 9-0-2-SAND & & 0 & 1615 & 37.0 & 89.3 & 25.1 & 0.000 & 168.7 & 0.2 & 0.1 & 4.6 & 6.70 \\
\hline 953 & 9-10-1-SAND & & 10 & 1594 & 23.3 & 76.2 & 19.3 & 0.000 & 156.0 & 0.2 & 0.3 & 3.2 & 6.83 \\
\hline 954 & 9-10-2-SAND & & 10 & 1714 & 23.6 & 76.3 & 14.3 & 0.000 & 164.2 & 0.2 & 0.3 & 2.5 & 6.85 \\
\hline 955 & 9-30-1-SAND & & 30 & 1494 & 45.0 & 80.4 & 14.6 & 0.000 & 173.2 & 7.6 & 10.2 & 2.6 & 6.59 \\
\hline 956 & 9-30-2-SAND & & 30 & 2302 & 31.1 & 77.3 & 18.7 & 0.000 & 167.7 & 10.4 & 12.3 & 3.1 & 6.83 \\
\hline 957 & 9-100-1-SAND & & 100 & 1524 & 148.5 & 94.6 & 156.8 & 0.000 & 142.2 & 111.2 & 124.4 & 23.5 & 6.52 \\
\hline 958 & 9-100-2-SAND & & 100 & 1725 & 161.4 & 108.7 & 177.4 & 0.000 & 146.3 & 123.1 & 135.8 & 27.6 & 6.61 \\
\hline 959 & 9-300-1-SAND & & 300 & 1499 & 331.2 & 164.2 & 481.4 & 0.000 & 145.2 & 277.1 & 291.5 & 48.2 & 6.59 \\
\hline 960 & 9-300-2-SAND & & 300 & 1788 & 334.3 & 170.8 & 539.1 & 0.000 & 140.0 & 274.6 & 291.7 & 52.0 & 6.55 \\
\hline \multicolumn{14}{|c|}{ NO-SEDIMENT CONTROLS } \\
\hline 961 & 4-0-1-NOSOLID & 4.1 & 0 & 10630 & 567.9 & 450.0 & 1502.0 & 0.000 & 533.7 & 534.3 & 550.3 & 168.7 & 4.06 \\
\hline 962 & 4-0-1-NOSOLID & & 0 & 4293 & 542.7 & 455.7 & 932.2 & 0.000 & 523.1 & 439.8 & 526.0 & 124.9 & 4.29 \\
\hline 963 & 4-10-1-NOSOLID & & 10 & 6588 & 550.4 & 459.7 & 1270.0 & 0.000 & 503.2 & 481.5 & 489.3 & 132.2 & 4.20 \\
\hline 964 & 4-10-1-NOSOLID & & 10 & 3097 & 566.7 & 464.3 & 1311.0 & 0.000 & 507.2 & 422.4 & 434.0 & 111.2 & 4.00 \\
\hline 965 & 4-30-1-NOSOLID & & 30 & 2810 & 628.8 & 498.6 & 1465.0 & 0.000 & 519.6 & 504.9 & 513.4 & 138.0 & 3.95 \\
\hline
\end{tabular}


WSRC-RP-2004-00593

\begin{tabular}{|c|c|c|c|c|c|c|c|c|c|c|c|c|c|}
\hline 966 & 4-30-1-NOSOLID & & 30 & 2960 & 608.1 & 482.5 & 1521.0 & 0.000 & 506.8 & 494.4 & 502.6 & 140.0 & 3.96 \\
\hline 967 & 4-100-1-NOSOLID & & 100 & 22260 & 603.7 & 482.6 & 1431.0 & 0.000 & 512.2 & 517.2 & 520.8 & 132.6 & 4.13 \\
\hline 968 & 4-100-1-NOSOLID & & 100 & 3514 & 596.0 & 473.0 & 1608.0 & 0.000 & 518.4 & 534.5 & 538.1 & 151.3 & 4.08 \\
\hline 969 & 4-300-1-NOSOLID & & 300 & 3730 & 594.5 & 480.3 & 1199.0 & 0.000 & 504.9 & 545.8 & 542.3 & 109.1 & 4.00 \\
\hline 970 & 4-300-1-NOSOLID & & 300 & 4115 & 634.0 & 482.7 & 1135.0 & 0.000 & 511.2 & 541.7 & 536.9 & 106.5 & 3.99 \\
\hline 971 & 8-0-1-NOSOLID & 8 & 0 & 2809 & 423.2 & 416.2 & 671.1 & 0.239 & 424.8 & 0.6 & 39.0 & 15.1 & 7.67 \\
\hline 972 & 8-0-2-NOSOLID & & 0 & 1400 & 471.0 & 431.7 & 623.2 & 0.248 & 428.8 & 0.4 & 0.4 & 4.3 & 7.58 \\
\hline 973 & 8-10-1-NOSOLID & & 10 & 1450 & 497.3 & 422.4 & 1396.0 & 0.241 & 479.2 & 463.4 & 447.2 & 130.0 & 7.39 \\
\hline 974 & 8-10-1-NOSOLID & & 10 & 2230 & 483.8 & 428.0 & 1515.0 & 0.246 & 483.8 & 504.3 & 486.2 & 144.1 & 7.45 \\
\hline 975 & 8-30-1-NOSOLID & & 30 & 2113 & 459.2 & 404.3 & 1536.0 & 0.242 & 470.1 & 504.0 & 502.8 & 129.5 & 7.39 \\
\hline 976 & 8-30-1-NOSOLID & & 30 & 1473 & 488.5 & 421.2 & 1725.0 & 0.242 & 497.2 & 499.4 & 503.7 & 131.2 & 7.16 \\
\hline 977 & 8-100-1-NOSOLID & & 100 & 1879 & 508.6 & 440.6 & 1265.0 & 0.247 & 473.7 & 535.0 & 532.0 & 109.6 & 7.39 \\
\hline 978 & 8-100-1-NOSOLID & & 100 & 1833 & 590.2 & 470.8 & 1584.0 & 0.245 & 513.9 & 578.2 & 576.9 & 113.1 & 7.26 \\
\hline 979 & 8-300-1-NOSOLID & & 300 & 1989 & 522.8 & 447.2 & 808.4 & 0.245 & 454.1 & 510.8 & 496.9 & 48.8 & 7.20 \\
\hline 980 & 8-300-1-NOSOLID & & 300 & 1620 & 503.4 & 434.7 & 749.1 & 0.246 & 428.1 & 484.5 & 475.0 & 49.9 & 7.25 \\
\hline
\end{tabular}


Table A 4. Titration curve data for the sandy and red-clay sediments.

\begin{tabular}{cc|cc}
\hline Clay $\mathrm{pH}$ & $\begin{array}{c}\text { meq added to Clay } \\
(\mathrm{meq} / \mathrm{g}) * *\end{array}$ & Sand $\mathrm{pH}$ & $\begin{array}{c}\text { meq added to } \\
\text { Sand }(\mathrm{meq} / \mathrm{g}) * *\end{array}$ \\
\hline 3.125 & -0.02499 & 2.785 & -0.02499 \\
3.495 & -0.014988 & 3.025 & -0.0149895 \\
4.17 & -0.0040004 & 3.75 & -0.003998 \\
4.36 & -0.0019994 & 4.11 & -0.0019996 \\
4.485 & -0.0005 & 4.535 & -0.0005 \\
4.53 & 0 & 4.72 & 0 \\
4.59 & 0.0005 & 4.955 & 0.0005 \\
4.75 & 0.0020004 & 5.52 & 0.0019988 \\
4.935 & 0.0039992 & 7.305 & 0.0039996 \\
6.07 & 0.014997 & 10.54 & 0.0149925 \\
8.73 & 0.0249775 & 10.91 & 0.024995 \\
\hline
\end{tabular}

** Negative values are for acid additions, positive values are for base additions.

Average of 2 replicates. 